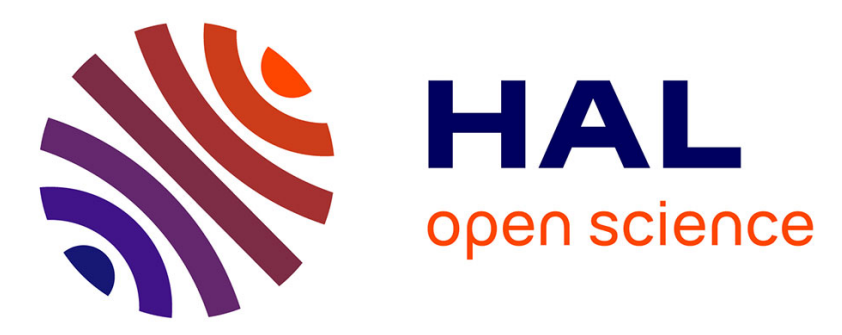

\title{
Caractérisation technique et culturelle de la céramique du site lacustre de Conjux 3 (lac du Bourget, Savoie) Le Néolithique final des avant-pays savoyards en question
} Pierre-Jérôme Rey, André Marguet

\section{- To cite this version:}

Pierre-Jérôme Rey, André Marguet. Caractérisation technique et culturelle de la céramique du site lacustre de Conjux 3 (lac du Bourget, Savoie) Le Néolithique final des avant-pays savoyards en question. Bulletin de la Société préhistorique française, 2016, 113 (1), pp. 57-94. hal-02499576

\author{
HAL Id: hal-02499576 \\ https://hal.science/hal-02499576
}

Submitted on 5 Mar 2020

HAL is a multi-disciplinary open access archive for the deposit and dissemination of scientific research documents, whether they are published or not. The documents may come from teaching and research institutions in France or abroad, or from public or private research centers.
L'archive ouverte pluridisciplinaire HAL, est destinée au dépôt et à la diffusion de documents scientifiques de niveau recherche, publiés ou non, émanant des établissements d'enseignement et de recherche français ou étrangers, des laboratoires publics ou privés. 


\title{
Caractérisation technique et culturelle de la céramique du site lacustre de Conjux 3 (lac du Bourget, Savoie)
}

\section{Le Néolithique final des avant-pays savoyards en question}

\author{
Pierre-Jérôme REY et André MARGueT
}

Résumé : Un sondage dans le lac du Bourget, sur le site immergé de Conjux 3 (lieudit « la Chatière » sur la commune de Conjux, Savoie), a révélé en 1985 une stratigraphie du Néolithique final comportant trois niveaux superposés, bien calés par une série de dates ${ }^{14} \mathrm{C}$ et dendrochronologiques (niveau 1, 2sup et $2 \mathrm{inf}$ ). Une modélisation bayésienne permet de proposer un positionnement chronologique assez précis de la succession des occupations : entre -2580 et -2455 av. n. è. pour le niveau 1, entre -2750 et -2570 pour le niveau 2 sup, entre -2905 et -2660 pour le niveau 2 inf. Vingtneuf kilos de fragments céramiques ont permis d'individualiser soixante-treize unités d'appariement et de restituer une quarantaine de formes incomplètes. Le corpus est largement dominé par les jarres cylindriques, ovoïdes ou en tonneau, en pâtes grossières et comprend également quelques petits récipients. Les éléments plastiques sont constitués de languettes horizontales et de cordons lisses horizontaux, uniques ou multiples.

L'étude technique des récipients montre l'usage presque systématique d'inclusions cristallines. Le montage des panses et des cols est majoritairement réalisé au colombin étiré à plans de joint obliques alternés. Une proportion importante des surfaces externes est traitée par brunissage ou par la réalisation de polis sans traces. La cuisson partiellement oxydante domine. Les résidus carbonisés sont nombreux et attestent de la fonction culinaire de la plupart des grandes jarres. Les comparaisons morphologiques soulignent des connexions septentrionales dans les deux niveaux inférieurs. L'ensemble 2inf constitue un intermédiaire entre le Lüscherz et les groupes inornés de moyenne vallée du Rhône. Des influences caussenardes issues du groupe des Treilles sont également perceptibles. L'ensemble 2 sup traduit un impact limité de la première phase de l'Auvernier-Cordé. Enfin, le mobilier céramique du niveau 1 présente des affinités avec le mobilier du niveau supérieur des Baigneurs à Charavines (Isère) et reflète le développement d'un groupe local dans une ambiance un peu plus méridionale. Ces propositions sont parfaitement compatibles avec les intervalles chronologiques issus de la modélisation bayésienne.

Ces ensembles sont comparés à de petits lots de vestiges inédits issus des lacs du Bourget et d'Annecy. Sur le Bourget, une nette distinction s'observe entre les récipients provenant des gisements du nord du lac, caractérisés par l'emploi majoritaire d'inclusions de roches cristallines, et les vases des Bourres (Tresserve, Savoie) au sud du lac, où domine l'emploi d'inclusions carbonatées, fréquemment constituées de calcite pilée. Sur le lac d'Annecy, l'ajout de calcite apparaît de manière prépondérante sur trois sites. Présente assez précocement dès le $\mathrm{xxx}^{\mathrm{e}}$ siècle à Angon (Talloires, Haute-Savoie), cette pratique d'origine méridionale semble s'étendre assez largement dans le second tiers du III ${ }^{\mathrm{e}}$ millénaire, entre le cours du Rhône et les vallées internes des Alpes.

La séquence de Conjux 3 décrit l'affaiblissement progressif des influences septentrionales dans la première moitié du III millénaire, au nord du Bourget. Aux fortes interactions qui existent pendant le Lüscherz récent succèdent des liens plus limités durant la phase ancienne de l'Auvernier-Cordé, puis une déconnexion assez claire, moins affirmée cependant dans les paramètres techniques. La montée en puissance des influences méridionales et italiennes, perceptible à l'échelle régionale, constitue vraisemblablement l'une des causes de cette évolution.

L'apparente réticence à l'acquisition des décors, qu'ils soient d'origine méridionale, jurassienne ou septentrionale, et l'emploi d'inclusions cristallines constituent des caractères partagés entre Conjux 3 et les Baigneurs (Charavines, Isère). D'autres convergences stylistiques existent entre les récipients de ces deux sites, mais l'absence d'étude technique des céramiques de Charavines ne permet pas une parfaite appréciation des liens qu'ils entretiennent.

L'importance des influences septentrionales dans les productions céramiques des faciès inornés de moyenne vallée du Rhône reste actuellement très discutée. Sans permettre de conclure, les ensembles de Conjux 3 apportent un nouveau jalon géographique pour la compréhension des relations avec le plateau Suisse dans le premier tiers du III ${ }^{e}$ millénaire et soulignent une filiation septentrionale pour l'usage des inclusions cristallines, bien représenté à Charavines.

Mots clefs : Alpes occidentales, lac du Bourget, Néolithique final, habitat palafittique, dendrochronologie, céramique, technologie céramique, inclusions et dégraissants, façonnage, brunissage, Lüscherz, Auvernier-Cordé, Charavines. 
Abstract: Final Neolithic ceramic assemblages are still rare in the northern French Alps. Since the excavation of Les Baigneurs (Charavines, Isère) in the 1970s, the only important sites to complete the documentation are those of Parc La Grange (Geneva, Switzerland) and Les Balmes (Sollières-Sardières, Savoie). Although inclusions are sometimes described, none of these sets have been studied with regard to modelling and finishing techniques. This article presents unpublished sets from a stratified pile-dwelling site, which was studied from both technical and stylistic points of view. These data are compared with smaller ceramic sets, also unpublished, from other pile dwellings in Savoy. A wider contextualization allows the studied site to be replaced within the cultural dynamics of the second half of the Final Neolithic. In 1985, a test pit in Lake Bourget, on the submerged pile dwelling Conjux 3 (La Chatière, Conjux, Savoie), revealed a stratigraphy going back to the Final Neolithic, and comprising three superposed levels defined by a series of radiocarbon and dendrochronological dates (levels 1, 2sup and 2inf). A Bayesian model based on the seven most reliable dates leads to the following chronological steps: -2905 to -2660 cal. BC (level 2inf), -2750 to -2570 cal. BC (level 2 sup), and -2580 to -2455 cal. BC (level 1). Nearly $29 \mathrm{~kg}$ of ceramic fragments were found in these layers. The large number of assemblies has identified 73 stratigraphically related units, with 40 incomplete bowls. Coarse-ware jars - cylindrical, ovoid or barrel-shaped - mainly prevail in the corpus. Their lip is generally rounded and is, in a few cases, decorated with tool impressions. Frequent plastic ornaments are protruding horizontal strips and smooth cords, which may be single or multiple.

Technical study of the pottery shows a quasi-systematic use of crystalline inclusions, mainly composed of crushed granitic stone in level 2 and crystalline sand in level 1, practices that seem clearly related to traditions found on the Swiss Plateau. The body and neck are mainly built by coiling, using stretched coils with oblique alternating joins, as in the contemporary pottery of the Jura groups. The exterior surface of many bowls is treated by burnishing or by polishing which has left no traces. Partially oxidizing firing dominates, even though some vessels that may have been made by firing in a reducing atmosphere-mainly small bowls with fine walls - occur in level 2inf and, less frequently, in the other levels. Finally, burnt residues are numerous and attest to the culinary use of most of the large pots.

Morphological comparisons show northern influences from the Swiss Plateau in the two lower levels. Influences from the Treilles group (Causses region) can also be detected, while relations with Jura groups (Clairvaux and Chalain) seem more tenuous. The assemblage from level $2 \mathrm{inf}$ is thus transitory between the Lüscherz group and the groups without ornamentation from the middle Rhone Valley. Level 2sup points to a limited impact of the first Auvernier-Corded Ware phase, while a vessel with a reduced opening recalls some Italian influence. Pottery from level 1 no longer participates in the evolution of the Auvernier-Corded Ware, but rather shows links with ceramics from the upper levels of Charavines, and points to the development of a local group in a more southern tradition. These hypotheses are quite compatible with the chronological steps indicated by the Bayesian model.

The series from Conjux 3 are compared with small unpublished ceramic sets from the pile-dwelling settlements of the Bourget and Annecy lakes. Around Lake Bourget, the settlements of Sous-le-Four and Mémars 1 (Brison-Saint-Innocent, Savoie) and Les Bourres (Tresserve, Savoie) delivered bowls and dates similar to those of Conjux. Technically, a clear division can be observed between sets from the north of the lake, characterized by dominant crystalline inclusions, and Les Bourres, on the southern shore, with carbonated inclusions mainly composed of crushed calcite. Other indications towards stronger southern influences can be seen in the morphology of the ceramics from the southern shore of Lake Bourget. The use of crushed calcite, already known around the 30th century at Angon (Talloires, Haute-Savoie), is dated to between the 26th century and the first half of the 24th century at Les Bourres (Tresserve, Savoie). This practice, of southern origin, seems to cover a fairly wide area between the Rhone and the inner Alpine valleys in the course of the second third of the third millennium.

The Final Neolithic phase at Conjux 3 points to the gradual fading of northern influences during the first half of the third millennium, to the north of Lake Bourget. The strong relations with the recent Lüscherz were followed by more limited northern relations during the early phase of Auvernier-Corded Ware, then by a quite clear break (although less visible in the technical aspects). The rise of influences from Southern France and Italy is probably one of the causes of this evolution, as can be seen in the levels at La Chauve-Souris (Donzère, Drôme) and the two successive assemblages from Les Baigneurs, Charavines.

The apparent reluctance to call on ornaments, whether of southern, Jura, or northern origin, and the use of crystalline inclusions are characteristics shared by Conjux 3 and Les Baigneurs, Charavines. Other stylistic similarities can be observed in pottery from these two sites, but the present state of studies of the collections does not allow an exact definition of their relations.

The importance of northern influences in the pottery from Charavines and other cultural groups with non-decorated ceramics from the middle Rhone Valley (Les Bruyères, Allan, Drôme) is still subject to discussion. Even if they do not allow this question to be brought to a close, the assemblages from Conjux 3 provide a welcome geographical marker to help in understanding relations with the Swiss Plateau during the first third of the third millennium, and emphasize a northern filiation concerning the use of crystalline inclusions frequently found at Charavines.

Keywords: Western Alps, Lake Bourget, Final Neolithic, pile dwellings, dendrochronology, ceramics, ceramic technology, inclusions, shaping, burnishing, Lüscherz, Auvernier-Corded Ware, Charavines.

$\mathrm{E}$ N 1985, un sondage subaquatique de surface restreinte a livré une importante série céramique de la fin du Néolithique, sur le site de Conjux 3 (lieudit « la Chatière », commune de Conjux, Savoie).
La stratigraphie générale montre trois couches organiques séparées de fins horizons crayeux. Le mobilier céramique, abondant mais très fragmenté, a fait l'objet d'une présentation préliminaire à Neuchâtel, en octobre 
2005 (Marguet et Rey, 2007). La poursuite du travail de remontage en 2009-2010 a permis de compléter les premiers collages par plus de deux cents nouveaux remontages. Mené en parallèle, le réexamen des données de terrain a précisé l'insertion stratigraphique des récipients. Constituée au total d'une quarantaine de formes, la série de Conjux 3 est donc aujourd'hui bien mieux caractérisée. De nouvelles datations sur résidus carbonisés et sur charbons de bois fournissent un calage chronologique solide aux trois ensembles identifiés. L'état de conservation des tessons, globalement bon, est favorable à une approche des techniques de façonnage et de finition qui profite du référentiel établi sur les séries jurassiennes de Chalain et de Clairvaux (Martineau, 2000, 2004 et 2005; Martineau et Maigrot, 2010). Les mobiliers céramiques de Conjux 3 sont confrontés aux éléments en grande partie inédits, issus de quatre gisements des lacs du Bourget et d'Annecy, occupés dans une fourchette chronologique sensiblement comparable : les Bourres (Tresserve, Savoie); Sous-le-Four et Mémars 1 (Brison-Saint-Innocent, Savoie); Angon (Talloires, Haute-Savoie). Sur ces bases mieux assurées, la discussion aborde les relations entre Conjux 3 et le contexte régional durant le second quart du III ${ }^{\mathrm{e}}$ millénaire av. n. è.

\section{PRÉSENTATION DU SITE ET DU CONTEXTE RÉGIONAL}

\section{Localisation et historique des recherches}

Tout à fait au nord de la rive occidentale du lac, accroché aux dernières pentes boisées du mont Landard, le petit village de Conjux marque le début d'une vaste zone naturelle, la baie de Conjux-Portout qui jouxte la partie aval du marais tourbeux de Chautagne. Par le canal de Savières, ce secteur s'ouvre sur le haut Rhône (fig. 1). Cette baie abrite la plateforme littorale la plus étendue du lac (70 ha, $600 \mathrm{~m}$ d'extension ouest-est). Une dizaine de gisements sous-lacustres pré- et protohistoriques y sont actuellement recensés (fig. 2; Marguet, 2004). Dans la partie centrale de la baie, le site Bronze final de Conjux-Port 1 (Conjux, Savoie), connu dès la fin du XIX ${ }^{\mathrm{e}}$ siècle par les " pêches aux antiquités lacustres », est longtemps resté le seul emplacement palafittique recensé dans ce secteur (Rabut, 1864, p. 95). Il a ensuite été visité régulièrement, de 1953-1954 à 1979, par R. Laurent et le Groupe de recherches archéologiques lacustres Savoie-Dauphiné (GRALSD), puis par R. Castel et le Centre d'archéologie lacustre d'Aix en Savoie (CALAS), les pionniers de la plongée archéologique régionale. Dans la partie la plus méridionale de la baie, la plateforme est large de $200 \mathrm{~m}$ et le rivage est aujourd'hui partiellement consacré à la plage municipale. Les pilotis n'y sont pas visibles à cause des limons sableux rapportés et de la végétation immergée assez dense qui occupent tout le secteur. Les gisements du lieudit « la Chatière » : Conjux 2 (Bronze final) et Conjux 3 (Néolithique final), ont été identifiés par carottages et sommairement abordés lors d'un petit sondage du CALAS, mené par R. Castel en 1975 (Castel, 2004, p. 85-101) ${ }^{(1)}$. Ils ont été ensuite ponctuellement étudiés par le Centre national de recherches archéologiques subaquatiques (CNRAS) en 1984-1985, dans le cadre d'une recherche sur le paléoenvironnement holocène des Alpes du Nord et de leur piémont (Marguet et al., 1995). Dans un sondage de $3,4 \mathrm{~m}^{2}$ (huit unités triangulaires de $1 \mathrm{~m}$ de côté) positionné sur la beine à environ $120 \mathrm{~m}$ du rivage et réalisé en deux temps, en janvier-mars 1984 puis en mars-avril 1985 (fig. 3), une importante séquence stratigraphique a été observée sous 4 à $5 \mathrm{~m}$ d'eau (lac à la cote NGF 231,50 m). Enfin, lors des prospections du Département des recherches archéologiques subaquatiques et sous-marines (DRASSM) en 1999, de nouveaux carottages ont permis la délimitation des emprises archéologiques des gisements de Conjux 2 et 3, sauf du côté du rivage où les tubes ne sont pas parvenus à traverser les sables superficiels compactés. La description des sédiments prélevés montre que les niveaux anthropiques néolithiques sont encore préservés sur au moins une cinquantaine de mètres de large.

\section{Stratigraphie}

Par souci de cohérence avec les publications précédentes, nous reprenons ici la numérotation partielle des couches, qui ne concerne que les niveaux d'occupation du Néolithique. Sous $55 \mathrm{~cm}$ de sédiments limono-sableux superficiels, un mince niveau de réduction contenant des vestiges de l'âge du Bronze final (altitude 228,33 m) a été décapé sur une vingtaine de mètres carrés lors de la première phase des travaux. On rencontre ensuite $90 \mathrm{~cm}$ de limons crayeux gris qui recouvrent les dépôts du Néolithique final, épais également de $90 \mathrm{~cm}$ (fig. 4). Ceux-ci se subdivisent en trois couches organiques d'épaisseur inégale, séparées de fins horizons de craie lacustre. En stratigraphie, on observe, de haut en bas, les ensembles sédimentaires sommairement décrits ci-après. À la base des limons crayeux gris, de fins lits végétaux marquent la transition avec la couche d'occupation supérieure (altitude 227,41 m), un niveau très organique constitué de débris végétaux bien lités avec feuilles et brindilles, d'environ $30 \mathrm{~cm}$ d'épaisseur (niv. 1). La partie supérieure de cette couche comporte de nombreux galets et quartzites disposés horizontalement, dont l'interprétation n'est pas évidente (épandage ou horizon de condensation?). La base de cette couche est marquée par un petit niveau de craie lacustre granuleuse à coquillages (épaisseur 3 à $5 \mathrm{~cm}$ ) qui pourrait signifier une brève remontée du niveau des eaux; à sa surface, un bois horizontal a été rencontré, sans que l'on puisse vérifier qu'il s'agissait ou non d'un bois flotté (M15 sur la coupe). La couche d'occupation médiane (niv. 2sup), un peu moins organique, est également constituée de débris végétaux lités, épaisse d'environ $35 \mathrm{~cm}$. Sa surface présente aussi un horizon de cailloux mais de plus petit calibre. On trouve ensuite un autre petit niveau de craie granuleuse blanche à coquillages (épaisseur 3 à $5 \mathrm{~cm}$ ), qui traduit lui aussi un haut niveau des eaux, puis une couche nettement moins 


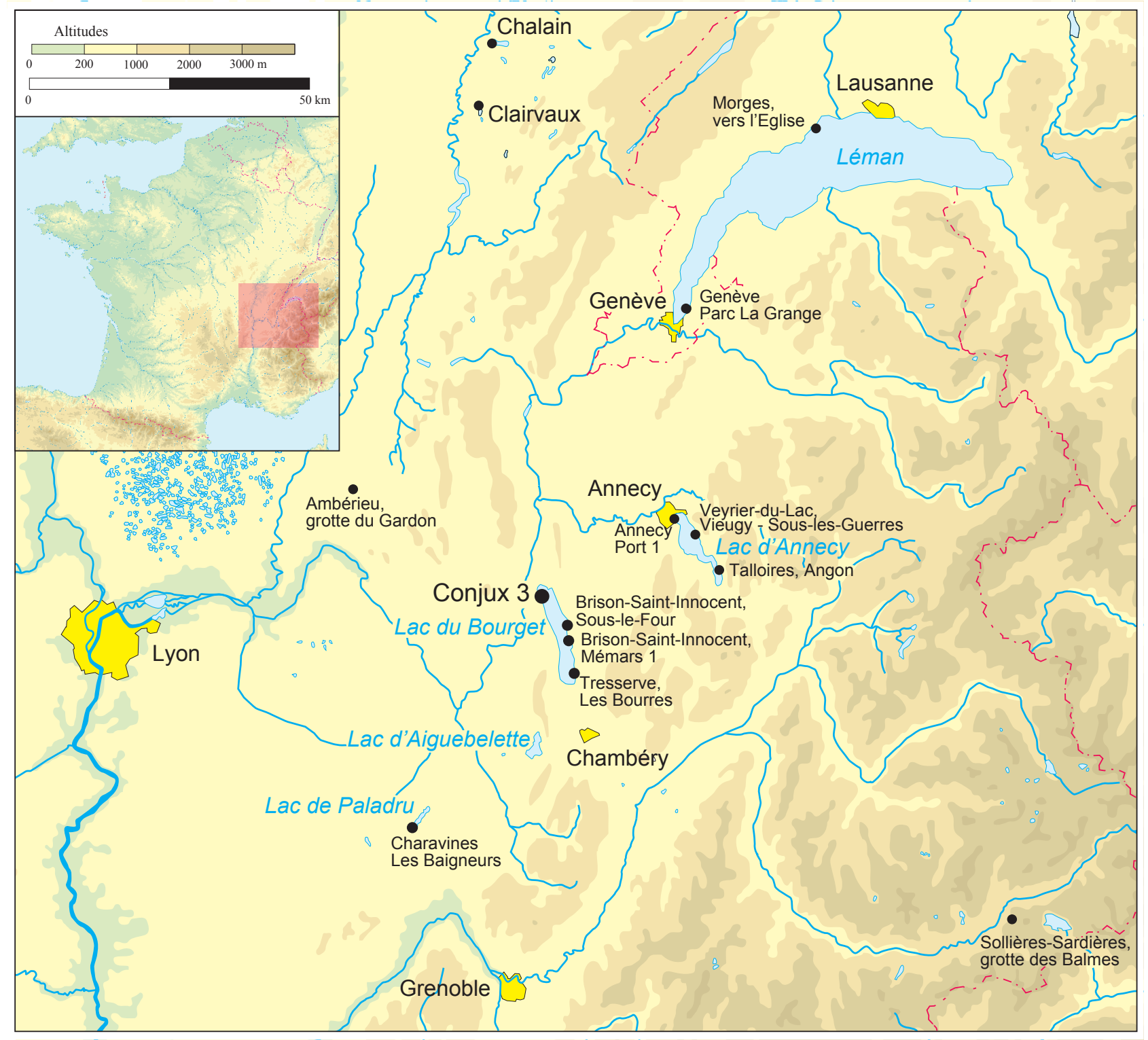

Fig. 1 - Situation géographique de Conjux 3 et des principaux sites régionaux de comparaison. Localisé dans le Jura savoisien au nordouest des Alpes françaises, le lac du Bourget est généralement classé parmi les lacs subalpins en raison de la situation géographique de son bassin versant (DAO A. Marguet).

Fig. 1 - Geographical situation of Conjux 3 and main comparable regional sites. Although located in the Savoy Jura, northwest of the French Alps, Lake Bourget is usually classified among subalpine lakes because of the location of its watershed (CAD A. Marguet).

organique (niv. 2inf). Celle-ci est constituée de limons organiques bruns (épaisseur 10 à $15 \mathrm{~cm}$ ), qui suggèrent une action lacustre plus importante que dans l'horizon supérieur. À la base de cette couche, une transition de craie brune annonce le sommet de limons crayeux lacustres blancs sur lesquels les décapages ont été arrêtés (altitude NGF 226,51 m). Un mince horizon organique plus profond (niv. 3), identifié par carottage (cote NGF 226,02 m), a été daté de la fin du Néolithique moyen (Gif.8146 : $4730 \pm 180$ BP, soit entre -3944 et -3018 cal. BC). Un gros tesson de céramique (voir fig. 10, $\mathrm{n}^{\circ} 24$ ), issu de ce niveau et remonté dans la carotte, confirme la proximité d'un autre village littoral.

Dans le sondage réalisé en 1985, les mobiliers ont été prélevés par lots successifs et la corrélation avec la stratigraphie générale du site a été établie, dans un premier temps, de manière simplifiée (niveaux 1 et 2 ). Ces niveaux organiques, principalement les couches 1 et la base du niveau 2, sont riches en mobiliers (tabl. 1) qui confirment la fonction d'habitat du site. Seules les céramiques sont présentées ici en détail.

En planimétrie, et compte tenu des faibles dimensions des décapages et du sondage stratigraphique, aucune organisation architecturale des pieux n'est directement perceptible.

\section{Données chronologiques}

L'ensemble des datations mobilisées dans cet article apparaît sur la figure 5 (des données complémentaires sur les échantillons datés sont rassemblées dans le 


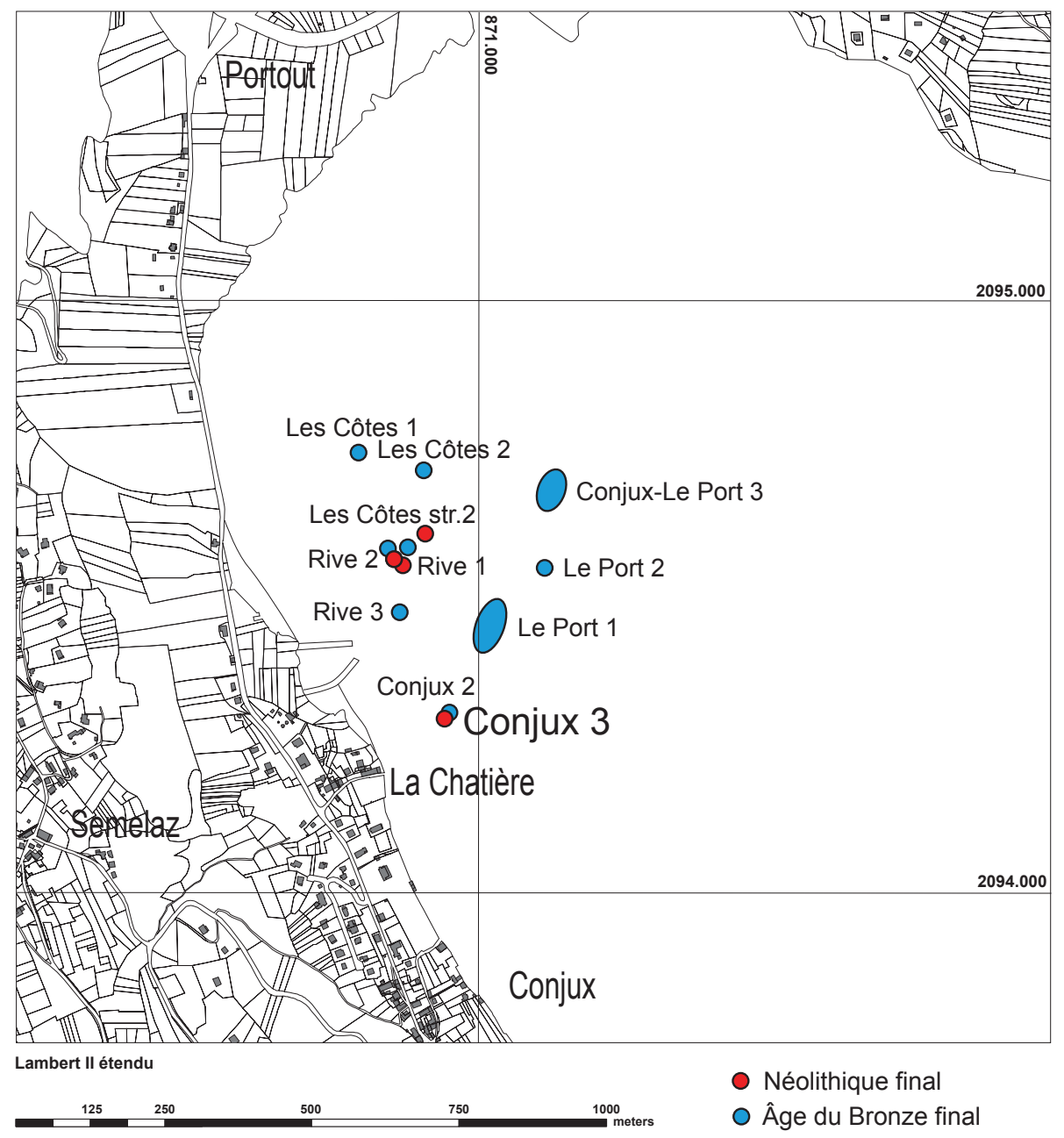

Fig. 2 - Localisation des sites palafittiques du Néolithique final (en rouge) et de l'âge du Bronze final (en bleu) actuellement recensés dans la baie de Conjux, à l'extrémité nord de la rive occidentale du lac du Bourget (DAO A. Marguet).

Fig. 2 - Location of Fnal Neolithic (red) and Final Bronze Age (blue) pile dwellings known at present in the bay of Conjux, at the northern end of the western bank of Lake Bourget (CAD A. Marguet).

tableau 2). En 1986, des débris végétaux lités, prélevés dans les niveaux organiques d'occupation, ont été calés par le ${ }^{14} \mathrm{C}$ (Gif.6770: $3760 \pm 60 \mathrm{BP}$, soit entre -2436 et -1979 cal. BC et Gif.6771 : $4250 \pm 70$ BP, soit entre -3080 et -2622 cal. BC). Ces premiers résultats suggéraient un très large intervalle d'occupation. Par ailleurs, des séquences dendrochronologiques ont pu être établies à partir des bois de chêne prélevés (LRD réf. 2 CLB et 9008CLB). Huit phases d'abattages ont été reconnues, dans la deuxième moitié du $\mathrm{Xxv}^{\mathrm{e}}$ siècle, entre -2442 et - 2427 (fig. 6). Un seul pieu fait exception : il présente une date d'abattage estimée à la fin du XXVI ${ }^{e}$ siècle $(-2525)$. Mais les bois verticaux analysés par la dendrochronologie ont été prélevés sur une très petite surface et ne reflètent pas forcément la totalité des occupations mises en évidence dans la stratigraphie. Pour tenter d'affiner la position chronologique des mobiliers archéologiques, des prélèvements de résidus carbonisés provenant de neuf vases, ainsi que des charbons de bois issus du sommet et de la base des couches, ont été soumis à la mesure d'âge par accélérateur. L'ensemble des résul- tats calibrés s'inscrit dans l'intervalle entre le $\mathrm{XXXI}^{\mathrm{e}}$ et le XXIV ${ }^{\mathrm{e}}$ siècle, à l'exception de la date Gif.6770 : $3760 \pm$ $60 \mathrm{BP}$ obtenue sur matière organique du niveau 1 , qui est vraisemblablement à écarter. L'interprétation des dates du niveau 2 est handicapée par la présence d'un palier de la courbe de calibration entre 2880 et 2570 av. n. è. environ. Mais la polarisation des résultats en deux ensembles est cohérente avec la succession de deux phases d'occupation visible en stratigraphie (niveaux 2 inf et 2 sup). La date Poz.57831 : $4305 \pm 35$ BP, soit entre -3015 et -2882 cal. BC est la seule à s'écarter légèrement des autres. Nous considérons qu'elle est probablement victime d'une pollution de l'échantillon par un produit de consolidation (paraloid). Deux autres résultats appellent un commentaire particulier. Un charbon assez petit du niveau 2 (Ly.8868-SacA.28065: $4030 \pm 30$ BP, soit entre -2623 et $-2473 \mathrm{cal}$. BC) a donné une date très récente, identique à celle obtenue sur l'échantillon du niveau 1 . Il s'agit très probablement d'un élément percolé ou d'un mélange à la fouille. Enfin, un récipient attribué au niveau 1 d'après les données de fouille (vase 87 ) a 


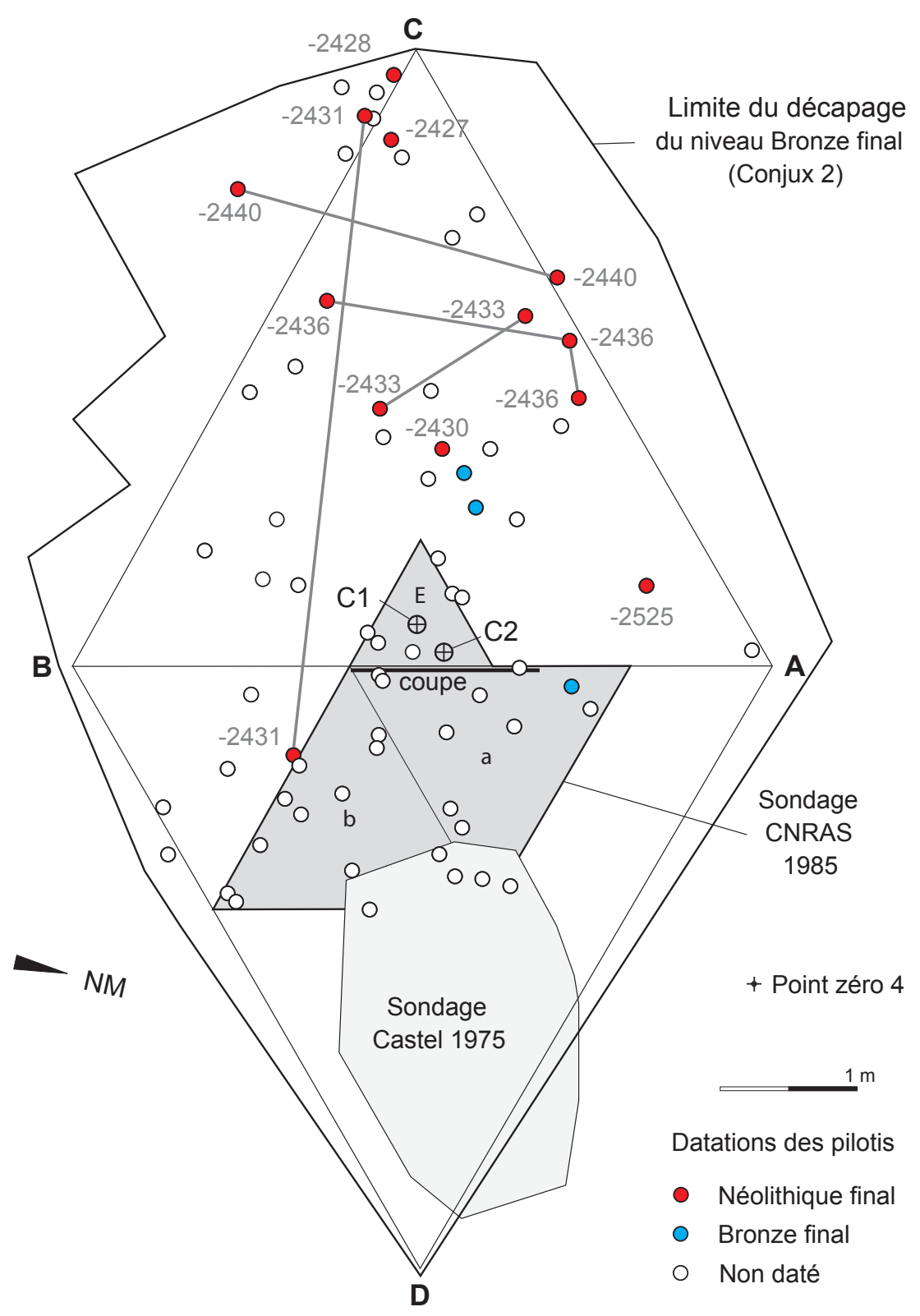

Fig. 3 - Conjux 3, lac du Bourget (Savoie, France). Plan du sondage stratigraphique de 1985 (en gris) et des triangles de $5 \mathrm{~m}$ ABC et ABD décapés en 1984. Position de la coupe (trait noir épais) et des carottes sédimentaires $\mathrm{C} 1$ et $\mathrm{C} 2$. Répartition planimétrique des pieux topographiés et des pieux datés par la dendrochronologie, les bois abattus la même année sont reliés (DAO A. Marguet).

Fig. 3 - Conjux 3, Lake Bourget (Savoie, France). Plan of the 1985 stratigraphical test pit (in grey) and the 5-metre triangles ABC and $A B D$ excavated in 1984. Position of the stratigraphic section (thick black line) and sedimentary core drillings C1 and C2. Planimetric distribution of mapped piles and piles dated by dendrochronology, wood from trees felled the same year are linked (CAD A. Marguet).

livré un résultat très précoce, qui correspond plutôt aux datations du niveau 2 sup. Un retour aux carnets de terrain révèle que le numéro de prélèvement correspond à l'extrême fin des décapages du niveau 1 , juste avant le début de la fouille du niveau 2. Comme la coupe stratigraphique montre que les deux niveaux sont par endroit en contact, nous considérons que la position des tessons de ce vase a été mal perçue à la fouille et que ce récipient doit être réattribué à l'ensemble 2 sup, en accord avec sa date ${ }^{14} \mathrm{C}$.

Dans le contexte d'un site stratifié, l'obtention d'une série de dates présentant des recouvrements importants constitue un cas de figure particulièrement propice pour effectuer une modélisation bayésienne (Perrin, 2014). Nous avons sélectionnés les huit dates les plus fiables (dont le positionnement stratigraphique des échantillons est indiscutable) disponibles pour les trois niveaux de la séquence du Néolithique final, auxquelles nous avons ajouté l'unique date plus ancienne obtenue sur le niveau 3. Produit avec la version 4.2.3 du logiciel Oxcal, le modèle présenté (fig. 7) a été contraint par le respect des informations stratigraphiques. Il permet de proposer les intervalles suivants : entre -2905 et -2660 av. n. è. pour le niveau 2 inf, entre -2750 et -2570 pour le niveau 2 sup, entre -2580 et -2455 pour le niveau 1 . 


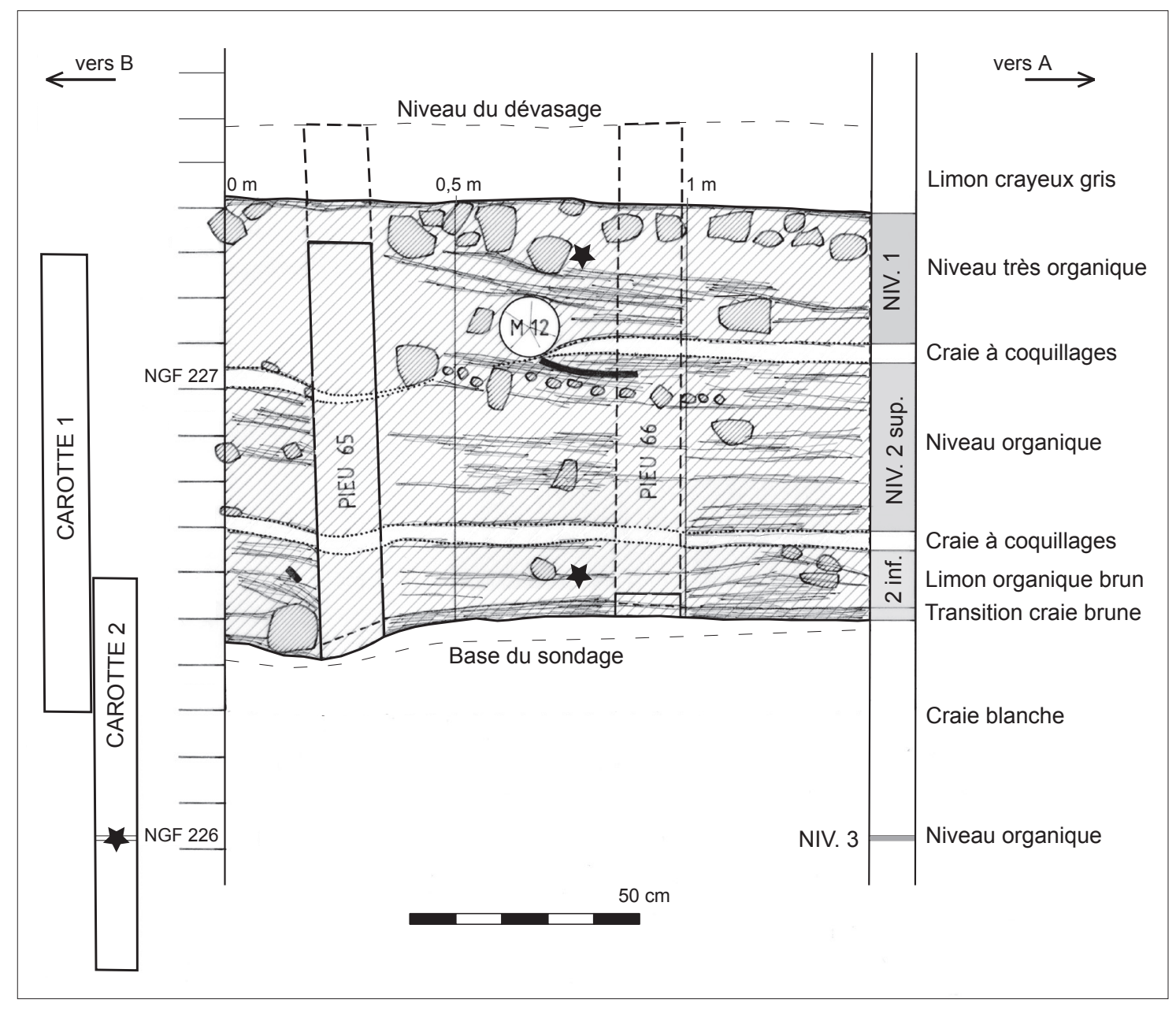

Fig. 4 - Séquence stratigraphique identifiée à Conjux 3 dans le sondage subaquatique de $3,4 \mathrm{~m}^{2}:$ des niveaux organiques de $90 \mathrm{~cm}$ d'épaisseur sont préservés sous 145 centimètres de limons-sableux. Ils se subdivisent en trois couches d'épaisseur inégale séparées de fins niveaux de craie lacustre : niveaux 1, 2sup et 2 inf. Un mince dépôt organique plus profond a été reconnu uniquement en carottage : niveau 3. Légende $:$ hachures larges $=$ couches archéologiques; hachures serrées $=$ cailloux; $M 12=$ bois couché $;$ en noir $=$ tessons céramiques; étoiles = position schématique des échantillons de matière organique datés par le ${ }^{14} \mathrm{C}$ (relevé $\mathrm{A}$. Marguet; DAO A. Marguet et P.-J. Rey).

Fig. 4 - Stratigraphical sequence identified at Conjux 3 in the underwater test pit of $3.4 \mathrm{~m}^{2}$ : organic levels 90 centimetres thick are protected by 145 centimetres of sandy silt. They are subdivided into three layers of uneven thickness, separated by thin layers of lakeside chalk: levels 1, 2 sup and 2 inf. A fine, deeper organic deposit was only identified by core drilling: level 3. Legend: wide hatching = archaeological layers; ; dense hatching = pebbles; $M 12=$ lying wood; in black = ceramic fragments; stars = schematic location of organic matter samples dated by ${ }^{14} \mathrm{C}$ (CAD A. Marguet and P.-J. Rey).

\section{Contexte chronoculturel régional}

Les lacunes de la documentation régionale imposent un large cadre de comparaison (tabl. 3). Les gisements des lacs savoyards livrent de petits ensembles de mobiliers souvent pauvres en céramiques et pas toujours bien calés chronologiquement (Marguet, 1995; cf. supra). Les sites du Combard à Trévoux dans l'Ain (Hénon, 1991) et de Chamboud à Montalieu-Vercieu en Isère (Chastel et Voruz, 1988) sont difficiles à mobiliser en raison des incertitudes qui pèsent sur l'homogénéité de leurs ensembles. Le site lacustre des Baigneurs sur le lac de Paladru (Charavines, Isère) constitue la référence majeure la plus proche et offre une abondante documentation qui ne concerne toutefois que le XXVII ${ }^{e}$ siècle et le tout début du XXVI ${ }^{\mathrm{e}}$ (Bocquet, dir., 2005). Les ensembles des deux niveaux d'occupation ont été récemment utilisés pour définir un style Charavines, issu d'influences septentrionales dont l'impact serait assez large en moyenne vallée du Rhône (Cauliez, 2011). Cette position est contestée par Joël Vital qui considère que les ensembles de Charavines témoignent plutôt d'affinités méridionales, dans le prolongement des groupes inornés de moyenne vallée du Rhône : nord Vaucluse, Bruyères, Allan (Vital, 2011). Le caractère restreint - grotte de la Balme à La Balme-lesGrottes, Isère (Bocquet et Reymond, 2007), Balme Rousse à Choranche, Isère (Vital et Bintz, 1999) - ou l'absence de publication - grotte des Sarrasins à Seyssinet-Pariset, Isère - des autres ensembles dauphinois ne permet guère d'enrichir le débat. Dans le Bugey, les céramiques des 


\begin{tabular}{|c|c|c|c|c|}
\hline & Niveau 2 & Niveau 1 & Indifférencié & Total \\
\hline Tessons de céramiques & $21,5 \mathrm{~kg}$ & $3,1 \mathrm{~kg}$ & $4,4 \mathrm{~kg}$ & $29 \mathrm{~kg}$ \\
\hline $\begin{array}{l}\text { Outils et éclats silex (lames, microdenticulés sur éclats, } \\
\text { armature losangique) }\end{array}$ & 57 & 29 & 1 & 87 \\
\hline Hache et lissoir en roche verte & 2 & & & 2 \\
\hline Autres outils lithiques & 1 polissoir & 1 meule (fgt.) & & 2 \\
\hline Flèche à oiseau en terre cuite & & 1 & & 1 \\
\hline Fusaïoles & 2 dont une en pierre & 2 en terre cuite & & 4 \\
\hline Outils en os : biseaux, poinçons, burins, lissoirs & 10 & 5 & 6 & 21 \\
\hline Ébauches de gaines en bois de cerf & 3 & & & 3 \\
\hline Restes fauniques & $4,8 \mathrm{~kg}$ & $2,06 \mathrm{~kg}$ & $0,97 \mathrm{~kg}$ & $7,83 \mathrm{~kg}$ \\
\hline Charbons de bois & $3,04 \mathrm{~kg}$ & $1,8 \mathrm{~kg}$ & $0,72 \mathrm{~kg}$ & $5,56 \mathrm{~kg}$ \\
\hline Torchis & $2,26 \mathrm{~kg}$ & $0,05 \mathrm{~kg}$ & $0,33 \mathrm{~kg}$ & $2,63 \mathrm{~kg}$ \\
\hline Pierres & $537,5 \mathrm{~kg}$ & $366,9 \mathrm{~kg}$ & $83,4 \mathrm{~kg}$ & $987,8 \mathrm{~kg}$ \\
\hline
\end{tabular}

Tabl. 1 - Tableau simplifié de répartition, en nombre ou en poids par niveau, des artéfacts prélevés dans le sondage stratigraphique. L'armature de flèche losangique en silex (Marguet 1995, fig. 25; Rey, 1999, pl. 93, n 1) est rattachée à la base du niveau 2.

Table 1 -Simplified distribution table, by number or by weight by level, artefacts collected in the stratigraphic survey. The flint lozenge arrow point (Marguet 1995, fig. 25; Rey, 1999, pl. 93, no. 1) is connected with the base of level 2.

couches 37 et 36 de la grotte du Gardon, Ambérieu-enBugey, Ain, attribuées à des influences mixtes du Jura et du plateau Suisse (Voruz et al., 2004; Boret, 2013), sont extrêmement fragmentées et représentent vraisemblablement plusieurs épisodes d'occupation entre la fin du NMB et le début du Bronze ancien. Enfin, un récipient isolé attribuable au Horgen a été recueilli sur la station lacustre de Hermance - Sous le Moulin, Chens-surLéman, Haute-Savoie (Marguet et Rey, 2007).

Plus au sud, la grotte de la Chauve-Souris, Donzère, Drôme, offre une belle stratigraphie qui couvre une large partie du Néolithique final (Vital, 2006). Deux phases livrent des ensembles céramiques importants. La plus ancienne (NF I) montre, à partir du $\mathrm{XXX}^{\mathrm{e}}$ siècle, des formes simples inornées apparentées aux productions du groupe d'Allan; la seconde (NF S), datée des XXV et XXIV ${ }^{\mathrm{e}}$ siècles, voit l'apparition de récipients segmentés de filiation Fontbouisse. Les récipients très décorés sont tout d'abord peu nombreux (surface 15AS), puis se multiplient vers 2450 2400 av. n. è. (surface 14ES et 13DS). Joël Vital accorde une validité régionale à ce retard dans la diffusion des décors complexes du Fontbouisse vers le nord (Vital, 2006).

Encore plus au sud, le schéma classique s'articule autour de la succession Ferrières-Fontbouisse en Languedoc (Gutherz et Jallot, 1995) et Couronnien-RhôneOuvèze en Provence (D'Anna, 1995). Ce canevas a été complexifié par les travaux récents de Jessie Cauliez sur la Provence qui a mis en évidence une mosaïque de styles locaux répartis en quatre phases (Cauliez, 2011), dont les ensembles céramiques de référence ne sont cependant pas encore tous publiés. En rive droite de la vallée du Rhône, le site de la Roquette (Tresques, Gard) constitue un faciès intermédiaire peu décoré, qui se place entre Ferrières et Fontbouisse (Georjon et al., 1999).

Dans le Jura et la Suisse occidentale, les sites lacustres fournissent des ensembles dont le contexte chronologique est bien mieux assuré grâce à la dendrochronologie, même si des lacunes documentaires persistent.

Sur le plateau Suisse, les contacts avec le Midi de la France, très forts au début du $\mathrm{III}^{\mathrm{e}}$ millénaire, entraînent le remplacement du Horgen par le Lüscherz dans la première moitié $\mathrm{du} \mathrm{Xxx}^{\mathrm{e}}$ siècle. La phase ancienne de cette culture est caractérisée par des récipients à fond rond, bord rentrant, lèvre amincie et décors de pastilles. Après 2790 av. n. è., le Lüscherz récent présente des céramiques à fonds ronds ou aplatis, bords droits et décors plus variés (pastilles, mamelons, languettes et cordons lisses). Vers 2700 ou un peu avant (Wolf, 1993; Giligny et Michel, 1995 ; Hafner et Suter, 1999), l'impact des influences cordées issues de Suisse centrale et plus loin de l'Allemagne du Sud, donne naissance à un faciès mixte, l'AuvernierCordé, qui évolue rapidement. Sur la base des stratigraphies de l'Avenue des Sports, Yverdon-les-Bains, Vaud, Suisse, et de la Saunerie, Auvernier, Neuchâtel, Suisse, trois phases ont été distinguées : de 2700 à 2630/2600 av. n. è., la phase Yverdon est marquée par des importations et des transferts techniques d'origine septentrionale; de 2630/2600 à 2500 av. n. è., la phase Auvernier est caractérisée par la régression des jarres et la multiplication des décors incisés; enfin, entre 2500 et 2440 av. n. è., la phase Clendy montre la hausse de la fréquence des profils en $\mathrm{S}$, la disparition des cordons, la régression des décors incisés et l'apparition de motifs de cupules impressionnées (Einstichverzirte Keramik).

Sur les lacs de Clairvaux et de Chalain, des occupations Horgen sont présentes au $\mathrm{XXXII}^{\mathrm{e}}$ siècle. Des impacts du Ferrières commencent à être perceptibles et sont attribués à un mouvement de population. Dans la seconde moitié du $\mathrm{XXXI}^{\mathrm{e}}$ siècle, le renouvellement des apports Ferrières entraîne le développement d'un style local, le groupe de Clairvaux qui évolue rapidement jusqu'à la fin du XXvIII ${ }^{\mathrm{e}}$ siècle. À partir du XXvII ${ }^{\mathrm{e}}$ siècle, 


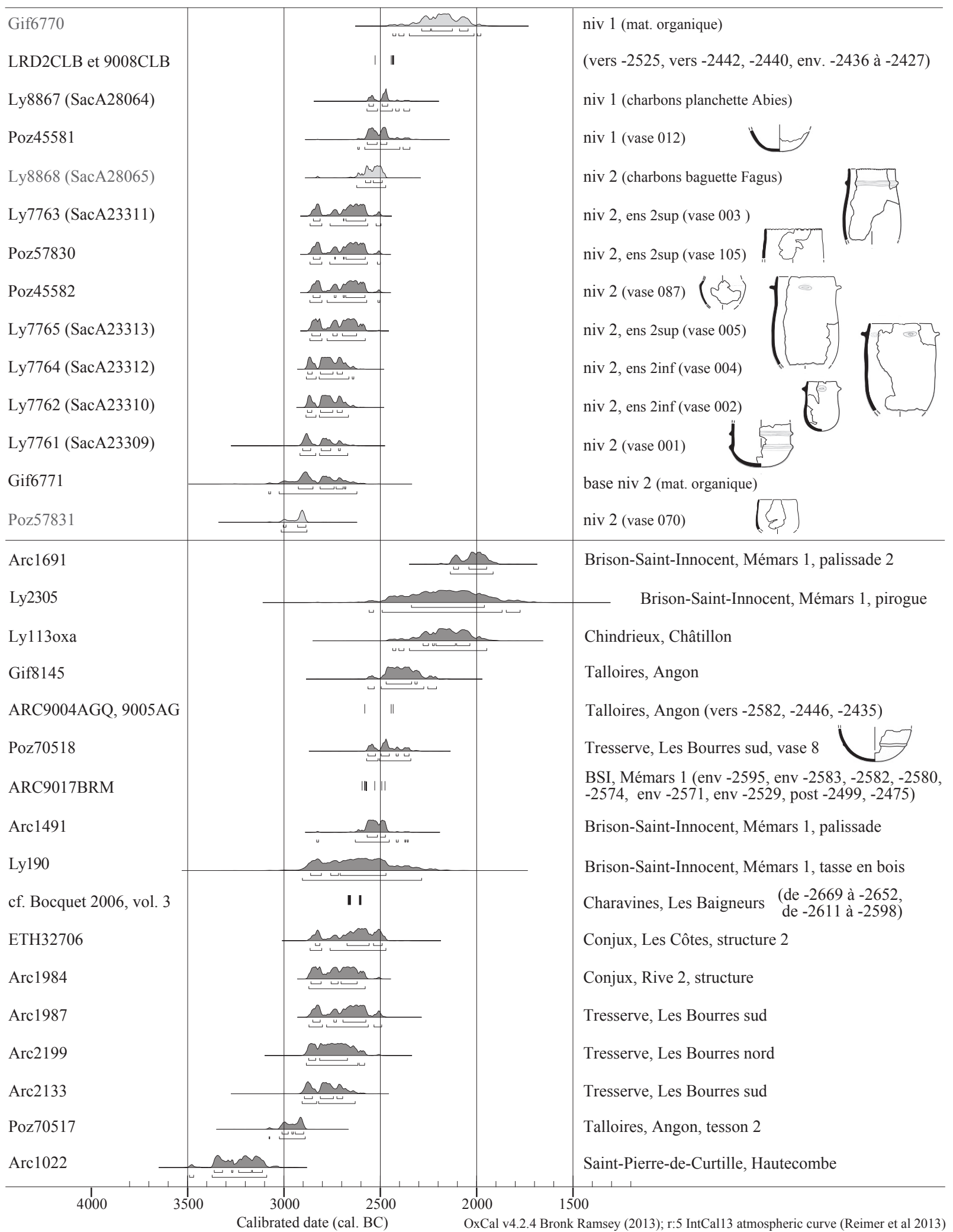

Fig. 5 - Datations ${ }^{14} \mathrm{C}$ calibrées et des séquences dendrochronologiques fournies par Conjux 3 (en haut du tableau) et par les autres sites du lac du Bourget et du lac de Paladru (en bas) entre 3400 et 2000 av. n. è. Les dates ${ }^{14} \mathrm{C}$ figurées en gris clair sont probablement à écarter. On trouvera dans le tableau 2 l'ensemble des informations disponibles sur les échantillons datés (DAO P.-J. Rey).

Fig. 5 - Calibrated ${ }^{14} \mathrm{C}$ dates and dendrochonological sequences from Conjux 3 (upper part of the table) and from other pile dwellings of Lakes Bourget and Paladru (lower part), between 3400 and $2000 \mathrm{BC} .{ }^{14}$ Cdates represented in grey are probably to be ruled out. Table 2 summarize all the information available on the dated samples (CAD P.-J. Rey). 


\begin{tabular}{|c|c|c|c|c|c|c|c|c|}
\hline Référence laboratoire & Méthode & Âge BP & \begin{tabular}{|c|} 
Âge cal. BC \\
$2 \sigma$
\end{tabular} & Commune, lieudit & Matériau & Essence & Référence de l'échantillon & $\begin{array}{l}\text { Référence du rapport, situation } \\
\text { de la séquence dendro. }\end{array}$ \\
\hline Gif.6770 & conv. & $3760 \pm 60$ & $-2436-1979$ & Conjux, Conjux 3 & mat. org. & ind. & Point $6, n^{\circ} 1$. Conj. C6/nos $35-38$, niv. sup. & Rapport du 09.07.1985 \\
\hline Ly.8867 (SacA.28064) & AMS & $3960 \pm 25$ & $-2570-2349$ & Conjux, Conjux 3 & charbons & Abies & planchette calcinée $n^{\circ} 85.210$, niv. 1 & \\
\hline Poz.45581 & AMS & $3980 \pm 40$ & $-2618-2347$ & Conjux, Conjux 3 & rés. carb. & & Conjux $3, n^{\circ} 85.127$, vase 12, niv. 1 & $\begin{array}{l}\text { Job n }{ }^{\circ} 5920 / 11, \text { rapport du } \\
24.02 .2012\end{array}$ \\
\hline Ly.8868 (SacA.28065) & AMS & $4030 \pm 30$ & $-2623-2473$ & Conjux, Conjux 3 & charbons & Fagus & baguette calcinée $n^{\circ} 85.20$, niv. 2 & \\
\hline Ly.7763 (SacA.23311) & AMS & $4095 \pm 35$ & $-2865-2497$ & Conjux, Conjux 3 & rés. carb. & & vase 3 , niv. 2 & \\
\hline Poz.57830 & AMS & $4100 \pm 35$ & $-2866-2500$ & Conjux, Conjux 3 & rés. carb. & & Conjux 3 , vase 105 , niv. 2 sup. & $\begin{array}{l}\text { Job n }{ }^{\circ} 7552 / 13, \text { rapport du } \\
13.11 .2013\end{array}$ \\
\hline Poz.45582 & AMS & $4105 \pm 35$ & $-2866-2503$ & Conjux, Conjux 3 & rés. carb. & & Conjux $3, n^{\circ} 85.146$, vase 87, niv. 2 sup. & $\begin{array}{l}\text { Job n } n^{\circ} 5920 / 11 \text {, rapport du } \\
24.02 .2012\end{array}$ \\
\hline Ly.7765 (SacA.23313) & AMS & $4120 \pm 30$ & $-2866-2579$ & Conjux, Conjux 3 & rés. carb. & & vase 5 , niv. 2 & \\
\hline Ly.7764 (SacA.23312) & AMS & $4175 \pm 30$ & $-2885-2638$ & Conjux, Conjux 3 & rés. carb. & & vase 4 , niv. 2 & \\
\hline Ly.7762 (SacA.23310) & AMS & $4180 \pm 30$ & $-2887-2666$ & Conjux, Conjux 3 & rés. carb. & & vase 2 , niv. 2 & \\
\hline Ly.7761 (SacA.23309) & AMS & $4230 \pm 45$ & $-2918-2670$ & Conjux, Conjux 3 & rés. carb. & & vase 1 , niv. 2 & \\
\hline Gif.6771 & conv. & $4250 \pm 70$ & $-3080-2622$ & Conjux, Conjux 3 & mat. org. & ind. & $\begin{array}{l}\text { Point } 6, n^{\circ} 2 \text {. Conj. C6/nos 55-56, 11g., } \\
\text { niv. inf. }\end{array}$ & Rapport du 09.07.1985 \\
\hline Poz.57831 & AMS & $4305 \pm 35$ & $-3015-2882$ & Conjux, Conjux 3 & rés. carb. & & Conjux 3 , vase 70 , niv. 2 & $\begin{array}{l}\text { Job } n^{\circ} 7552 / 13 \text {, rapport du } \\
13.11 .2013\end{array}$ \\
\hline Gif.8146 & conv. & $4730 \pm 180$ & $-3944-3018$ & Conjux, Conjux 3 & mat. org. & ind. & Conj.C2/15-16, s/s niv. 2inf. & Rapport du 20.02.1990 \\
\hline Arc.1691 & conv. & $3645 \pm 40$ & $\mid-2137-1915$ & BSI, Mémars 1 & bois & Quercus & $\begin{array}{l}\text { palissade } 2 \text {, regr. piquets } 1045+1051 \\
\text { BRM, c. } 10 \text { à } 49\end{array}$ & $\begin{array}{l}9015 \text { BRM, } 69 \text { ans, } 7 \text { éch., n. d. } \\
\text { ARC97/R722C du 09.10.1997 }\end{array}$ \\
\hline Ly.2305 & conv. & $3740 \pm 130$ & $-2559-1775$ & BSI, Mémars 1 & bois & ind. & pirogue & \\
\hline Ly.113oxa & AMS & $3745 \pm 70$ & $-2436-1948$ & Chindrieux,Châtillon & mat. org. & ind. & $\mathrm{C} 2 / \mathrm{n}^{\circ} 3,-108 \mathrm{~cm}, \mathrm{~s} / \mathrm{s}$ couche & Rapport du 04.04.1995 \\
\hline Gif.8145 & conv. & $3910 \pm 50$ & $-2565-2209$ & Talloires, Angon & mat. org. & ind. & $\mathrm{C} 2 / \mathrm{n}^{\circ} 10,-47 \mathrm{~cm}$ & Rapport du 20.02.1990 \\
\hline Poz.70518 & AMS & $3955 \pm 35$ & $-2572-2342$ & Tresserve, Les Bourres & rés. carb. & & secteur sud, vase 8 & $\begin{array}{l}\text { Job no } 7553 / 13, \text { rapport du } \\
24.04 .2015\end{array}$ \\
\hline Arc.1491 & conv. & $4000 \pm 40$ & $-2831-2356$ & BSI, Mémars 1 & bois & Quercus & $\begin{array}{l}\text { palissade } 1 \text {, piquets } n^{\circ s} 363,373,375 \\
\text { BRM, c. } 1-22\end{array}$ & $\begin{array}{l}9005 \text { BRM, } 23 \text { ans, } 15 \text { éch., n. d. } \\
\text { ARC96/R1385C/3 du 17.07.1996 }\end{array}$ \\
\hline Ly.190 & conv. & $4060 \pm 120$ & $-2905-2286$ & BSI, Mémars 1 & bois & ind. & tasse, $\mathrm{C} 1, \mathrm{HS}$ & \\
\hline ETH.32706 & AMS & $4065 \pm 55$ & $-2865-2472$ & Conjux, Les Côtes & bois & Alnus & structure 2 , piquet $\mathrm{n}^{\circ} 112$, env. $30 \mathrm{c}$. & ARC06/R3279C1 du 19.12.2006 \\
\hline Arc.1984 & conv. & $4125 \pm 40$ & $\mid-2872-2579$ & Conjux, Rive 2 & bois & Alnus & structure, piquet $\mathrm{n}^{\circ} 01 \mathrm{CON}, 25 \mathrm{c}$. & ARC99/R2339C du 28.10.1999 \\
\hline Arc.1987 & conv. & $4095 \pm 45$ & $-2871-2494$ & Tresserve, Les Bourres & bois & Quercus & secteur sud, pieu $n^{\circ} 10$ TVB, c. 1-15 & $\begin{array}{l}9002 \text { TVB, } 28 \text { ans, } 6 \text { éch., n. d. } \\
\text { ARC99/R2165C du 15.11.1999 }\end{array}$ \\
\hline Arc.2199 & conv. & $4155 \pm 50$ & $-2885-2582$ & Tresserve, Les Bourres & bois & Quercus & $\begin{array}{l}\text { secteur nord, piquets } n^{\text {os }} 15 \text { (19 c.), } 25 \\
\text { (16 c.), } 27 \text { (14 c.) TVB }\end{array}$ & ARC02/R2794C du 31.05.2002 \\
\hline Arc. 2133 & conv. & $4205 \pm 50$ & $-2907-2631$ & Tresserve, Les Bourres & bois & Quercus & secteur sud, pieu $\mathrm{n}^{\circ} 5 \mathrm{TVB}, 151 \mathrm{c}$. & ARC01/R2702C du 23.10.2001 \\
\hline Poz.70517 & AMS & $4330 \pm 35$ & $-3078-2890$ & Talloires, Angon & rés. carb. & & tesson $n^{\circ} 2$ & $\begin{array}{l}\text { Job } n^{\circ} 7553 / 13, \text { rapport du } \\
24.04 .2015\end{array}$ \\
\hline Arc.1022 & conv. & $4540 \pm 50$ & $-3491-3090$ & SPC, Hautecombe & bois & Quercus & $\begin{array}{l}\text { piquets } \mathrm{n}^{\mathrm{os}} 111 \text { (18c.), } 140 \text { (c.1-12), } 141 \\
\text { (c.1-12), } 144 \text { (c.1-16) }\end{array}$ & $\begin{array}{l}9004 \mathrm{HT}, 35 \text { ans, } 15 \text { éch., n. d. } \\
\text { ARC93/R1504C du } 30.09 .1993\end{array}$ \\
\hline
\end{tabular}

\begin{tabular}{|c|c|c|c|c|}
\hline Commune, lieudit & Référence de l'échantillon & Essence & Référence, situation de la séquence & Abattage \\
\hline Conjux, Conjux 3 & & Quercus & $\begin{array}{l}\text { 2CLB, } 115 \text { ans, } 1 \text { éch., située entre } \\
-2662 \text { et }-2548\end{array}$ & estimé en -2525 \\
\hline Conjux, Conjux 3 & & Quercus & $\begin{array}{l}\text { 9008CLB, } 48 \text { ans, } 16 \text { éch., située entre } \\
\text { env. }-2487 \text { et }-2440\end{array}$ & $\begin{array}{l}\text { estimé en }-2442 \text {, en }-2440 \text {, estimés en }-2436 \text {, } \\
-2433,-2431,-2430,-2428,-2427\end{array}$ \\
\hline Talloires, Angon & $\begin{array}{l}\mathrm{n}^{\text {os }} 42,44,46 \& \text { bois } n^{\text {os }} 577,1032,1033 \\
1034,1035\end{array}$ & Quercus & $\begin{array}{l}\text { 9004AGQ, } 99 \text { ans, } 8 \text { éch., située entre } \\
-2533 \text { et }-2435\end{array}$ & en -2446 , en $-2435 / 34$ \\
\hline Talloires, Angon & $n^{\circ} 43$ & Quercus & $\begin{array}{l}\text { 9005AG, } 167 \text { ans, } 1 \text { éch., située entre } \\
-2768 \text { et }-2602\end{array}$ & vers -2582 \\
\hline BSI, Mémars 1 & & Quercus & $\begin{array}{l}\text { 9017BRM, } 211 \text { ans, } 23 \text { éch., située entre } \\
-2686 \text { et }-2476\end{array}$ & $\begin{array}{l}\text { env. }-2595 \text {, post. }-2588 \text {, env. }-2583 \text {, en } 2582 \text {, } \\
\text { post. }-2582 \text {, en }-2580 / 79 \text {, post. }-2579 \text {, } \\
\text { en }-2574 / 73 \text {, env. }-2571 \text {, post. }-2543 \text {, } \\
\text { post. }-2540 \text {, en }-2529 \text {, post. }-2499 \text {, en }-2475\end{array}$ \\
\hline Charavines, Les Baigneurs & occup. $1:$ Abies : 375 & divers & \multirow{2}{*}{$\begin{array}{l}\text { une seule séquence : } 190 \text { ans, } 876 \text { éch. } \\
\text { dont } 88 \text { éch. pour la phase d'abandon } \\
\text { ARC03/R1183D/2 et ARC03/R2477D/11 } \\
\text { d'après Bocquet } 2005 \text {, vol. } 3\end{array}$} & occup. 1 de -2669 à $-2652 / 51$ \\
\hline Charavines, Les Baigneurs & $\begin{array}{l}\text { occup. } 2: \text { Abies : } 233 \text {, Fagus : } 161 \text {, } \\
\text { Ulmus : } 19\end{array}$ & divers & & occup. 2 de -2611 à -2598 \\
\hline
\end{tabular}

Tabl. 2 - Tableau des datations ${ }^{14} \mathrm{C}$ (en haut) et dendrochronologiques (en bas) de Conjux 3 et des autres sites du Néolithique final des lacs du Bourget, d'Annecy et de Paladru, avec nomenclature des échantillons, description des matériaux datés et commentaires des laboratoires. Abréviations : BSI = Brison-Saint-Innocent; SPC $=$ Saint-Pierre-de-Curtille; $\mathrm{c} .=$ cernes ; $\mathrm{n}$. d. = non daté.

Table 2 - Detailed table of the radiocarbon (top of the chart) and dendrochronological (bottom of the chart) dates for Conjux 3 and other Final Neolithic sites of lakes Bourget, Annecy and Paladru, with names of samples, description of dated materials and laboratories'comments. Abbreviations: BSI = Brison-Saint-Innocent; SPC $=$ Saint-Pierre-de-Curtille; $c .=$ tree rings; $n . d .=$ undated.

les influences Auvernier-Cordé prennent de l'ampleur et entraînent le développement d'un nouveau style local : le groupe de Chalain, dont l'évolution n'est pas connue après le milieu du $\mathrm{XXV}^{\mathrm{e}}$ siècle (Giligny et al. 1995; Martineau, 2000, pour le tableau chronologique le plus récent).
La région lémanique n'est documentée que par le mobilier du Parc La Grange, Genève, Suisse, attribuable au Lüscherz ancien (Pugin et Corboud, 2006) et par la petite série de Vers l'Église, Morges, Vaud, Suisse, non datée en absolu mais qui semble également se placer dans une ambiance Lüscherz (Courboud et Pugin, 1992). 


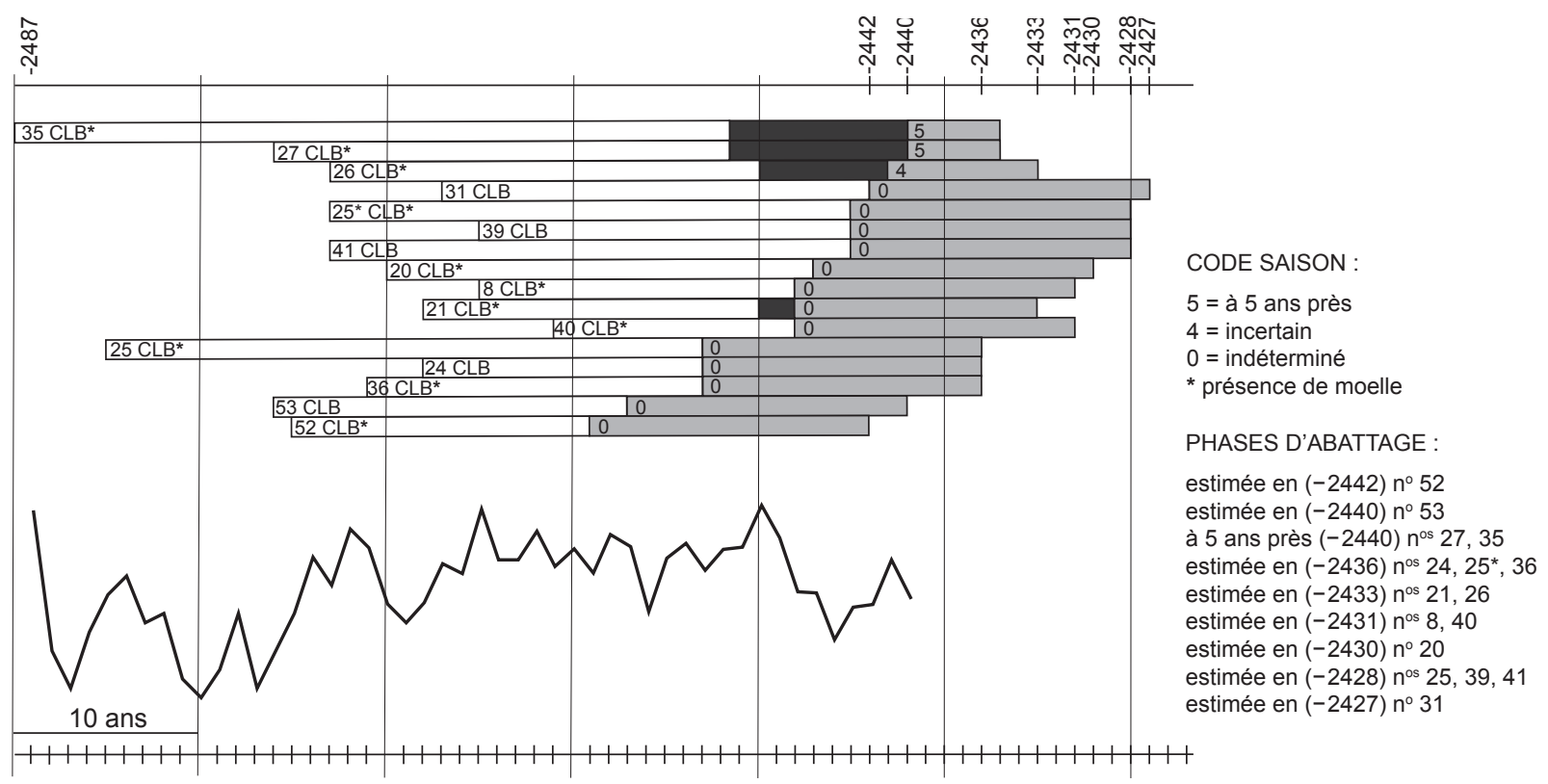

Fig. 6 - Séquence dendrochronologique (Quercus) 9000CLB de 48 ans à partir de 16 échantillons, située entre - 2487 et - 2440 (d'après le rapport LRD5/R1395 du 6 février 1985). Clé de lecture du diagramme : La partie supérieure de la figure représente, sous forme d'une barre horizontale, la longueur de la courbe de chaque échantillon, dans sa position relative (en noir, les cernes d'aubier mesurés; en gris, les cernes estimés en fonction du rythme de croissance des bois étudiés). La partie inférieure montre, sur une échelle annuelle, la courbe moyenne de l'ensemble des échantillons du site (DAO A. Marguet).

Fig. 6 - A 48-year dendrochronological sequence (Quercus) 9000CLB from 16 samples, from 2487 to 2440 (after report LRD5 / R1395 of February 6th, 1985). In the top of the figure, horizontal bars represent the length of the curve of every sample, in its relative position (in black, measured tree rings of sapwood; in grey, tree rings estimated according to the growth rate of the pieces of wood studied). The bottom of the chart shows, on an annual scale, the curve averages of all the samples of the site (CAD A. Marguet).

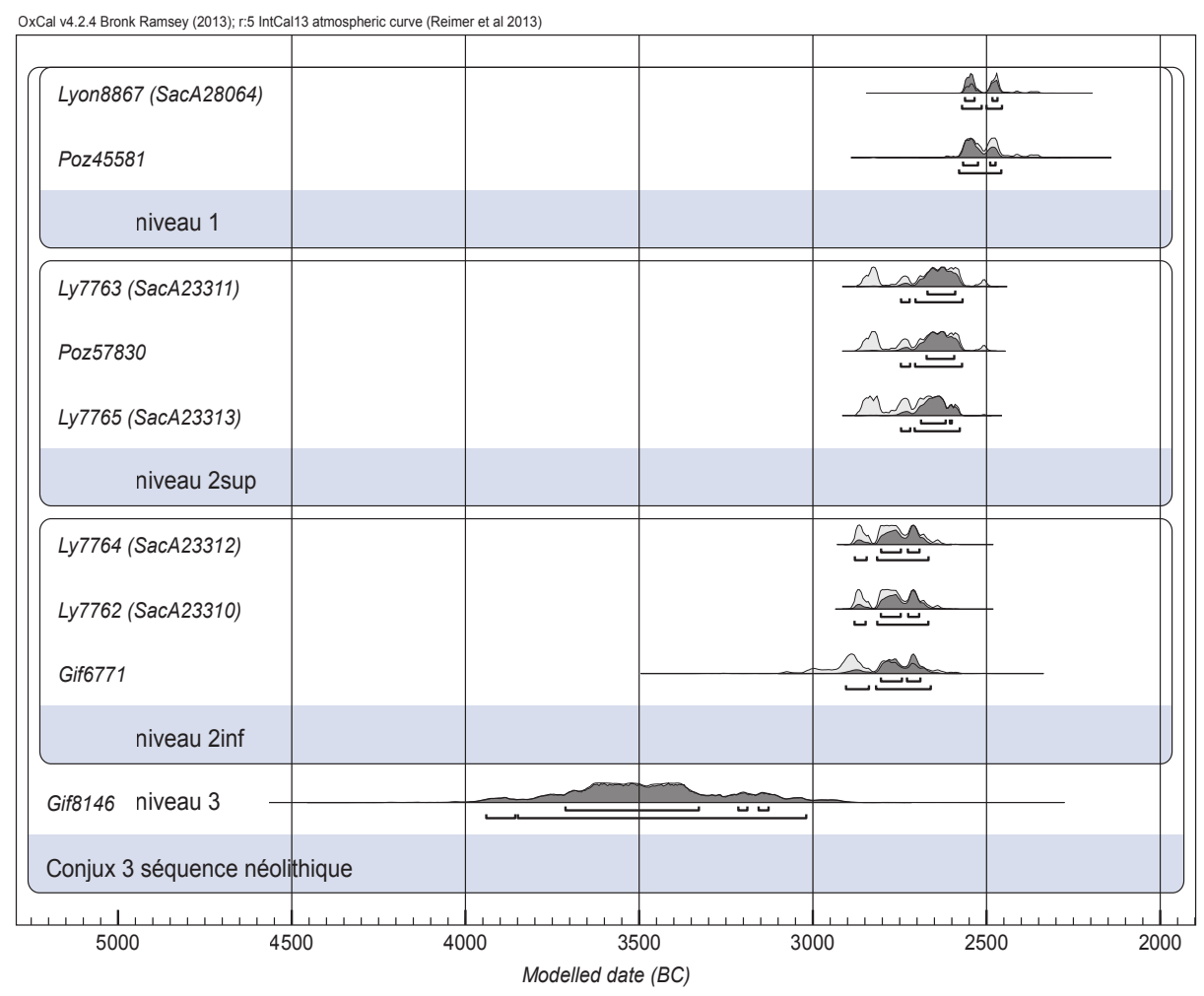

Fig. 7 - Modélisation bayésienne des dates les plus fiables de la séquence néolithique du site de Conjux 3. D'après ce modèle contraint par les informations stratigraphiques, les occupations du Néolithique final se placeraient entre -2905 et -2455 av. n. è.

Fig. 7 - Bayesian modelling of the most reliable dates of the Neolithic sequence of Conjux 3. According to this model, limited by the stratigraphical information available, the Final Neolithic occupations would have taken place between 2905 and 2455 cal BC. 


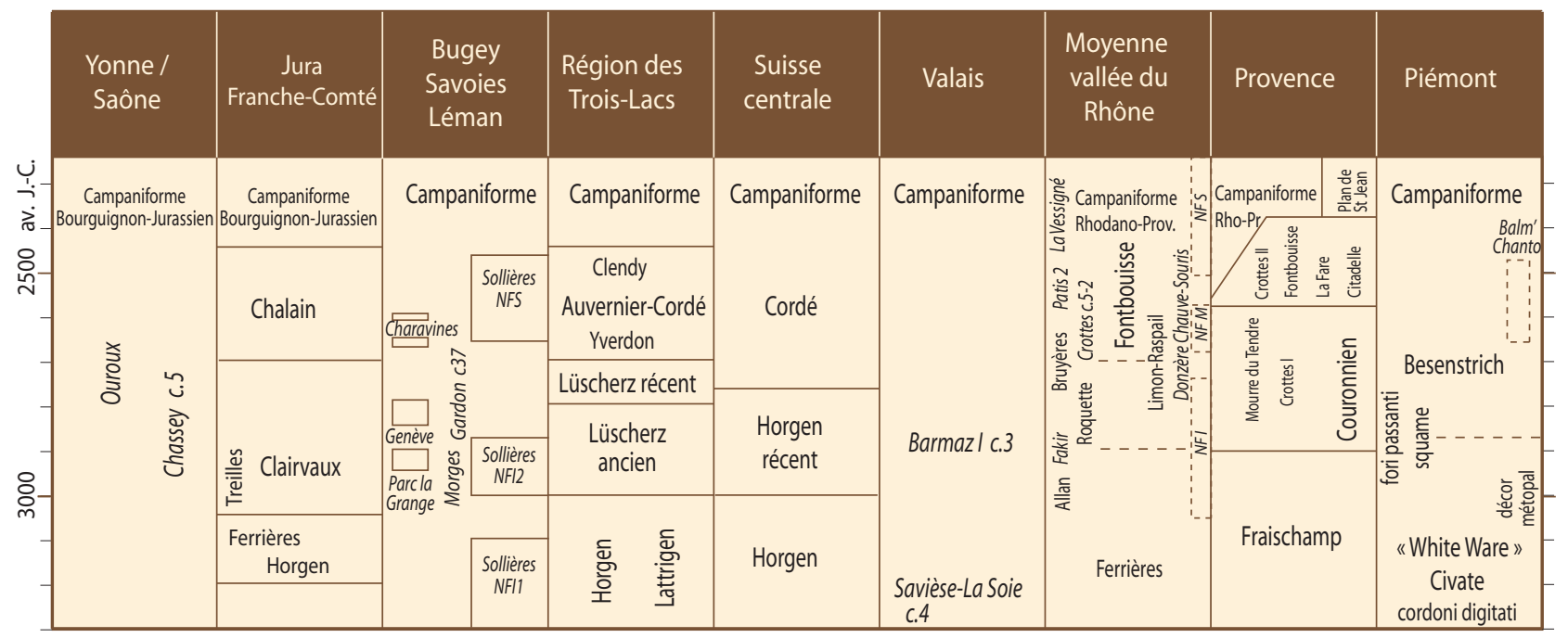

Tabl. 3 - Schéma chronoculturel régional, état 2013 (DAO P.-J. Rey).

Table 3 - Regional chronological and cultural table, situation as of 2013 (CAD P.-J. Rey).

Dans les vallées alpines, la stratigraphie de la grotte des Balmes en Maurienne, Sollières-Sardières, Savoie, a livré deux ensembles successifs. Le plus ancien (Néolithique final inférieur) recouvre l'intervalle xxxIII ${ }^{\mathrm{e}}$ $\mathrm{XXX}^{\mathrm{e}}$ siècle et témoigne d'une extension des influences nord-alpines du Horgen, du Lattrigen et du Sipplingen. Daté entre le XXVII siècle et le $\mathrm{XXVI}^{\mathrm{e}}$ siècle, l'ensemble Néolithique final supérieur témoigne de liens avec l'Auvernier-Cordé sur un fond hérité du Lüscherz (Vital et Benamour, dir., 2012). Des relations avec l'AuvernierCordé sont également perceptibles de l'autre côté de la ligne de crête à Balm'Chanto, Roure, Piémont, Italie, dans le mobilier céramique des couches 10 à 6 , datées entre 2660 et 2480 av. n. è. (Nisbet et Biagi, 1987). En Valais, des connexions nord-orientales sont perceptibles vers le $\mathrm{XXXI}^{\mathrm{e}}$ siècle à la Soie, Savièse, Valais, Suisse (Baudais, 1995). Un peu plus tard, le Néolithique final du site de Barmaz I, Collombey-Muraz, Valais, Suisse, daté entre 2900 et 2700 av. n. è., montre un fort impact Ferrières ou Clairvaux (Honegger, 1995 et 2001). Le « dégraissant blanc » des récipients de Barmaz mériterait d'ailleurs une détermination pétrographique.

\section{LA CÉRAMIQUE DE CONJUX 3}

\section{Présentation du corpus et individualisation des ensembles stratigraphiques}

Le sondage a livré $29 \mathrm{~kg}$ de fragments de céramique prélevés par lots successifs. Si le niveau 1 a été facilement individualisé sur le terrain, la limite entre la partie supérieure et la partie inférieure du niveau 2 a été plus difficile à suivre dans les triangles $\mathrm{ABD} a$ et $\mathrm{b}$ (fig. 3), malgré la présence d'un litage discontinu de craie intercalé. Dans le petit triangle $\mathrm{ABC} / \mathrm{E}$, les couches ont été prélevées sans distinction stratigraphique, lors de l'extraction des carottes sédimentaires. Au final, 21,5 $\mathrm{kg}$ de céramiques peuvent être rattachés au niveau 2, 3,1 kg au niveau 1 et $4,35 \mathrm{~kg}$ de tessons demeurent sans rattachement précis. Les remontages et appariements ont été recherchés en mélangeant l'ensemble des lots, permettant la constitution de 106 unités de collages et d'appariements. Ces unités représentent $83 \%$ du poids total des tessons. Elles incluent 416 tessons intégrés dans des remontages et 276 tessons appariés selon l'ensemble des critères accessibles visuellement. Le nombre important des remontages et la diversité des céramiques, permettent de considérer ces unités de collages et d'appariements comme des récipients distincts dès lors qu'une restitution graphique est possible.

Seulement cinq remontages et six appariements associent des tessons issus des niveaux 1 et 2 . L'individualisation de l'ensemble supérieur paraît donc globalement excellente. La date ${ }^{14} \mathrm{C}$ d'un récipient (Poz.45582 : $4105 \pm 35 \mathrm{BP}$, soit entre -2866 et -2503 cal. BC) montre qu'une incertitude subsiste sur le rattachement des deux derniers lots d'objets attribués sur le terrain à la base du niveau 1 , mais cela ne concerne qu'un nombre réduit de tessons. La distinction entre les ensembles 2 inf et 2 sup est par contre plus difficile. Sur 76 groupes de tessons recollés issus du niveau 2, cinquante présentent une provenance homogène de leurs éléments dans le sommet ou la base du niveau 2 alors que vingt-six remontages associent des tessons issus de toute l'épaisseur de cette couche. Le rattachement fin des récipients du niveau 2 a donc été évalué d'après la répartition stratigraphique et la taille des tessons inclus dans les collages. Le rattachement des unités de collages et d'appariement constituées de plusieurs tessons est donc plus solide que celui des éléments isolés, qui reste proposé avec réserves.

Le mobilier du niveau 1 semble moins bien conservé. Il est davantage fragmenté et les résidus carbonisés y sont plus rares, signe probable d'une altération plus importante de la couche.

Soixante-treize des 106 unités d'appariements sont mobilisées dans la suite de l'étude (dont vingt-neuf ratta- 
chées à l'ensemble 2inf, quatorze à l'ensemble 2sup, dix au niveau 2 sans précision et quatorze au niveau 1). Les figures 9 à 11 illustrent les différents ensembles obtenus.

\section{Analyse morphologique et technique}

\section{Paramètres morphologiques des céramiques de Conjux 3}

Le rapport entre diamètre à l'embouchure et hauteur minimale est calculable pour treize récipients seulement (fig. 8). Le mobilier des trois ensembles est nettement dominé par les jarres (récipients dont la hauteur est supérieure à $15 \mathrm{~cm}$ et le diamètre à l'embouchure est compris entre 0,5 et une fois la valeur de la hauteur), souvent très élancées. Il comprend également quelques petits pots (hauteur et diamètre à l'embouchure de moins de $15 \mathrm{~cm}$ ). La distinction nette entre deux classes de jarres, visible sur la projection (l'une de 4 à 6 litres, l'autre de 30 à 40 litres de contenance), est moins évidente lorsque l'on considère uniquement les diamètres à l'embouchure. Dans ce cas, on observe trois regroupements entre 12 et $14 \mathrm{~cm}$, entre 17 et $19 \mathrm{~cm}$ et entre 23 et $33 \mathrm{~cm}$ (pour vingtneuf individus pris en compte). Dans les trois ensembles stratigraphiques, quelques récipients de type bols ou coupes à paroi assez mince ne peuvent être intégrés à ce diagramme en raison de leur forte fragmentation.

Les fonds sont arrondis ou plus rarement aplatis dans les ensembles 1 et 2 inf. Un seul fond plat est connu dans l'ensemble $2 \inf$ (fig. 9, $\mathrm{n}^{\circ} 25$ ). Les formes de la céramique grossière sont cylindriques, ovoïdes, en tonneau, bien plus rarement tronconiques. Les cols sont droits ou légèrement rentrants, exceptionnellement évasés. Les lèvres sont généralement arrondies. Quelques lèvres équarries se rencontrent dans les petits récipients. Deux grands vases de l'ensemble 2 sup présentent des lèvres impressionnées avec un outil large (fig. 10, $\mathrm{n}^{\circ} 17$ et fig. 12, $\mathrm{n}^{\circ} 4$ ) ou tranchant (fig. 10, no 18 et fig. 12, n ${ }^{\circ} 5$ ). Un tesson isolé de l'ensemble 2 inf semble également porter un décor du même type (fig. $9, \mathrm{n}^{\circ} 8$ et fig. 12, $\mathrm{n}^{\circ} 1$ ).

Dans les trois ensembles, les éléments plastiques sont principalement constitués de languettes horizontales proéminentes, en symétrie binaire, et plus rarement ternaire. Des languettes horizontales, à embase ovale et extrémité circulaire, se rencontrent dans les ensembles 2inf et 2sup (fig. 9, $\mathrm{n}^{\circ} 1$ et fig. 10, $\mathrm{n}^{\circ} 14$ ). Des languettes particulièrement saillantes, à contour trapézoïdal voire rectangulaire, se rencontrent dans l'ensemble 2 sup et le niveau 1 (fig. $10, \mathrm{n}^{\text {os }} 15$ et 18 ; fig. $11, \mathrm{n}^{\text {os }} 1$ et 4 ). L'exemplaire issu du niveau 1 est doté d'une perforation verticale. Dans la même couche, on relève également la présence de petits mamelons circulaires, en symétrie binaire, sur une petite tasse (fig. 11, $\mathrm{n}^{\circ}$ 5).

Les ensembles du niveau 2 se singularisent par la présence de cordons horizontaux, lisses et proéminents, unique sous le bord ou multiples sur la panse. Il y a probablement plus de deux cordons sur au moins deux récipients de Conjux 3, rattachés à l'ensemble 2 inf et au niveau 2 sans précision. Une jarre à cordon unique sous le bord est rattachée à l'ensemble 2 sup avec une datation ${ }^{14} \mathrm{C}$ à l'appui (fig. 10, no 19). Ce même ensemble 2sup livre également de petits fragments de cordons lisses proéminents et discontinus (fig. 10, $\mathrm{n}^{\circ} 12$ ), ou peu proéminents et en apparence continus (fig. 10, no 11), ainsi qu'une grande jarre dotée de mamelons proéminents en symétrie binaire (fig. 10, $\mathrm{n}^{\circ} 18$ ).

Une jarre cylindrique à cordons saillants multiples du niveau 2 est rattachée à l'ensemble 2 inf par datation ${ }^{14} \mathrm{C}$ (fig. 10, $\mathrm{n}^{\mathrm{o}} 1$ ). L'insertion stratigraphique des autres cordons multiples ou simples, le plus souvent très saillants, ne peut malheureusement être précisée entre 2 inf et 2 sup (fig. $10, n^{\text {os }} 3$ à 5). Il en va de même pour un petit fragment de cordon lisse peu proéminent orné de digitations à l'ongle (fig. $10, \mathrm{n}^{\circ} 7$ et fig. $12, \mathrm{n}^{\circ} 3$ ) et pour un fragment de cordon discontinu (fig. $10, \mathrm{n}^{\circ} 6$ et fig. 12, $\mathrm{n}^{\circ} 2$ ).

Un tesson à cordon discontinu de l'ensemble 2sup montre un coup d'outil oblique, qui pourrait être une trace technique ou un élément de décor (fig. 10, $\mathrm{n}^{\circ} 12$ et fig. 12, $\mathrm{n}^{\circ} 7$ ).

\section{Approche technique des céramiques de Conjux 3}

Le bon état de conservation des profils céramiques et des états de surface permet une approche des techniques de façonnage. L'interprétation des stigmates est basée sur les référentiels établis par Olivier Gosselain (2002), Alexandre Livingstone-Smith (Livingstone-Smith et al., 2005) et surtout Rémi Martineau (2000, 2004, 2005 et 2006), dont les

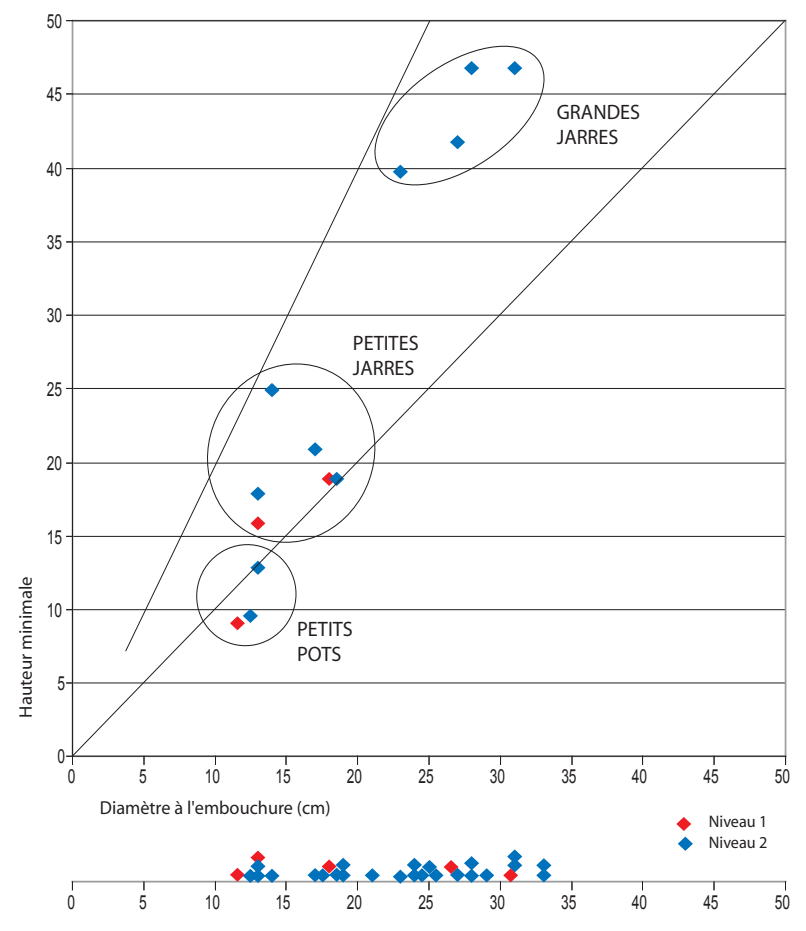

Fig. 8 - Céramiques de Conjux 3. Dispersion des unités de collage et d'appariement selon leur diamètre à l'embouchure et leur hauteur minimale en haut, selon leur seul diamètre à l'embouchure en bas (DAO P.-J. Rey).

Fig. 8 - Ceramics from Conjux 3. Distribution of assemblage and matching units according to the mouth's diameter and minimal height (top of the chart), and the mouth's diameter alone (bottom of the chart) (CAD P.-J. Rey). 

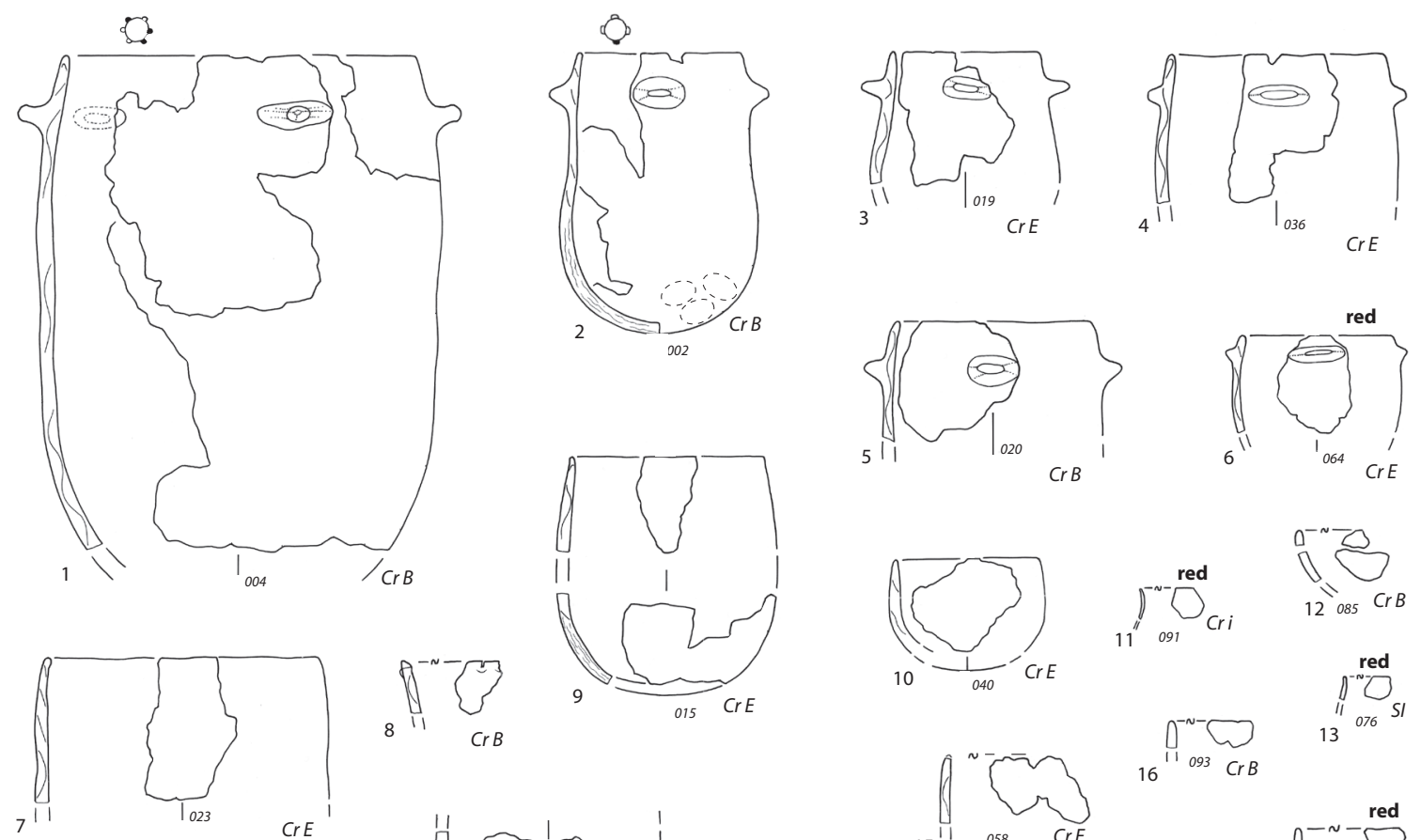

$\frac{1}{040} \mathrm{CrE}$
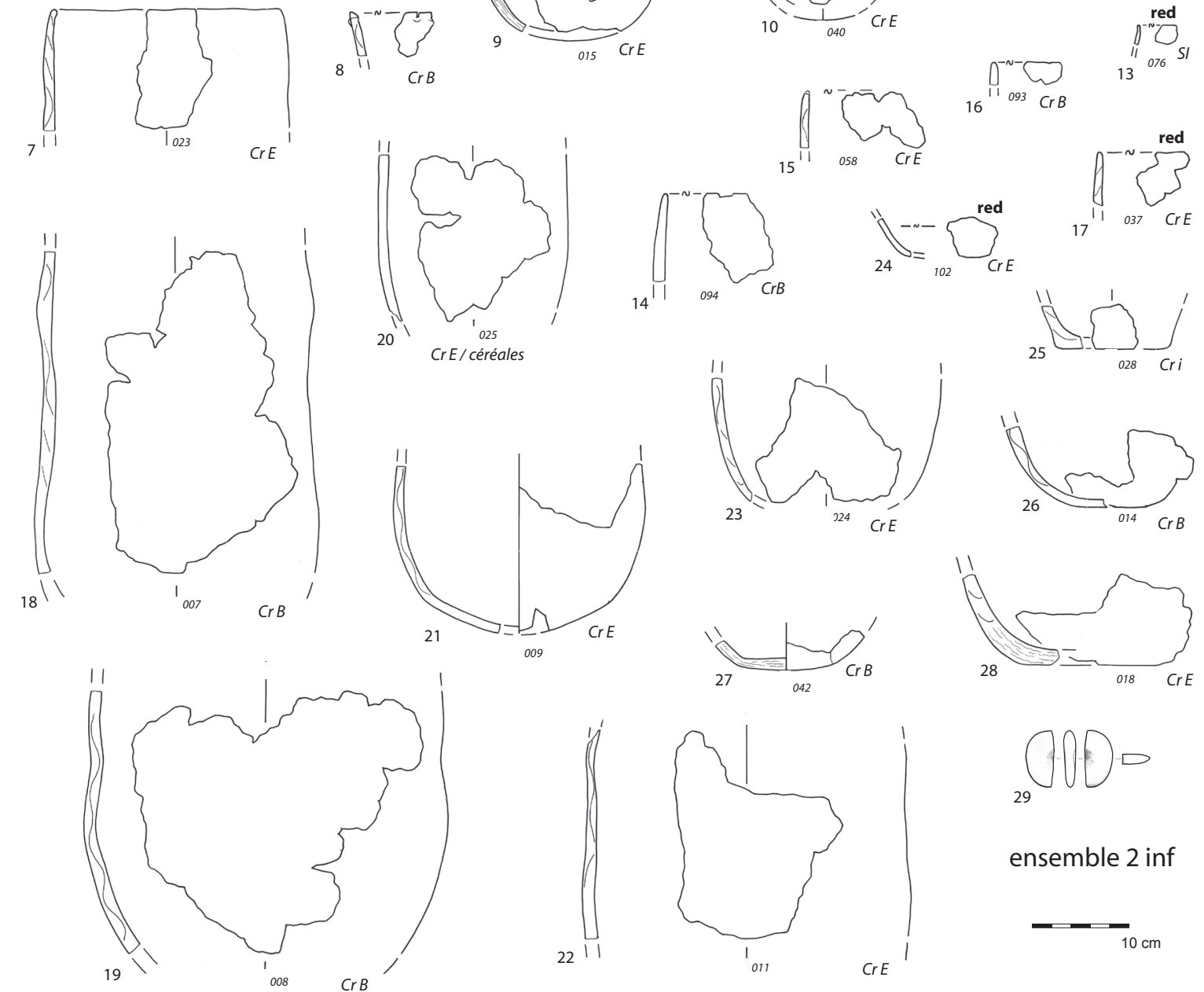

ensemble 2 inf

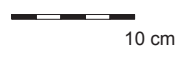

Fig. 9 - Céramiques et fragment de galet en cours de perforation ( $\left.{ }^{\circ} 29\right)$ issus de Conjux 3, niveau 2, ensemble 2inf. Les abréviations décrivent la nature des inclusions principales (voir légende sur la figure 17). Les numéros en petits caractères correspondent aux numéros des unités de collage et d'appariement (dessins P.-J. Rey).

Fig. 9 - Ceramics and fragment of pebble broken during perforating (no. 29) from Conjux 3, level 2, set 2inf. Abbreviations describe the nature of the main inclusions (see legend on figure 17). The numbers in small print correspond to the numbering of the assemblage and matching units (drawings P.-J. Rey). 


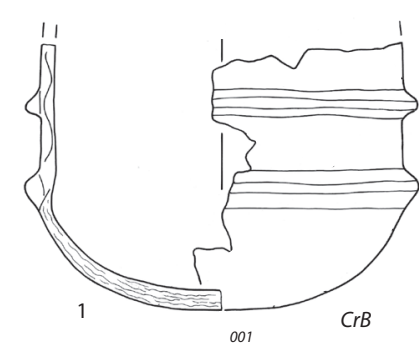

ensemble 2 inf (après ${ }^{14} \mathrm{C}$ )
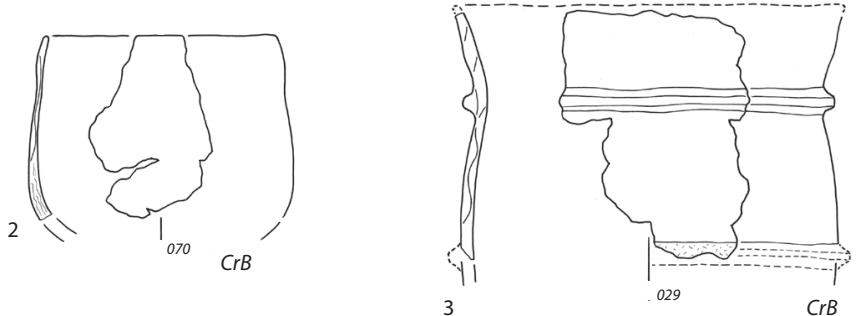

niveau 2 sans précision
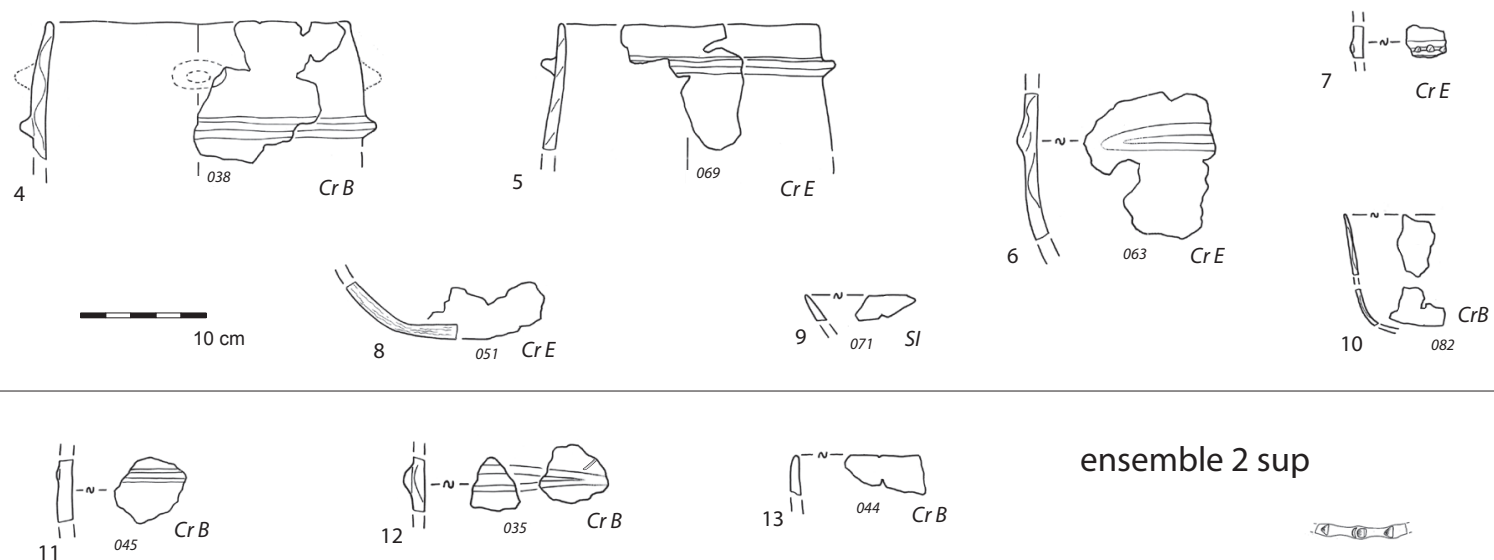

ensemble 2 sup
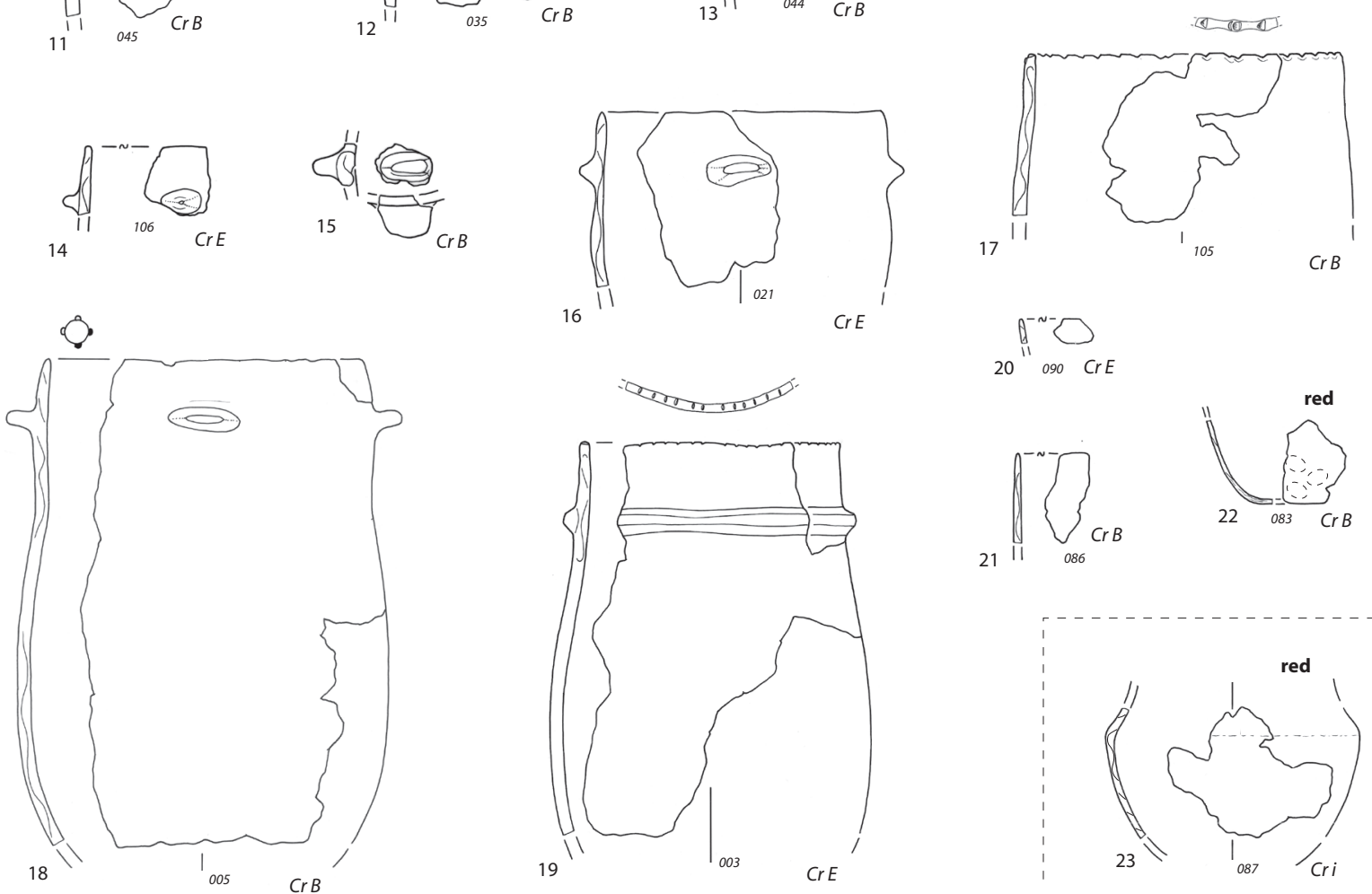

16
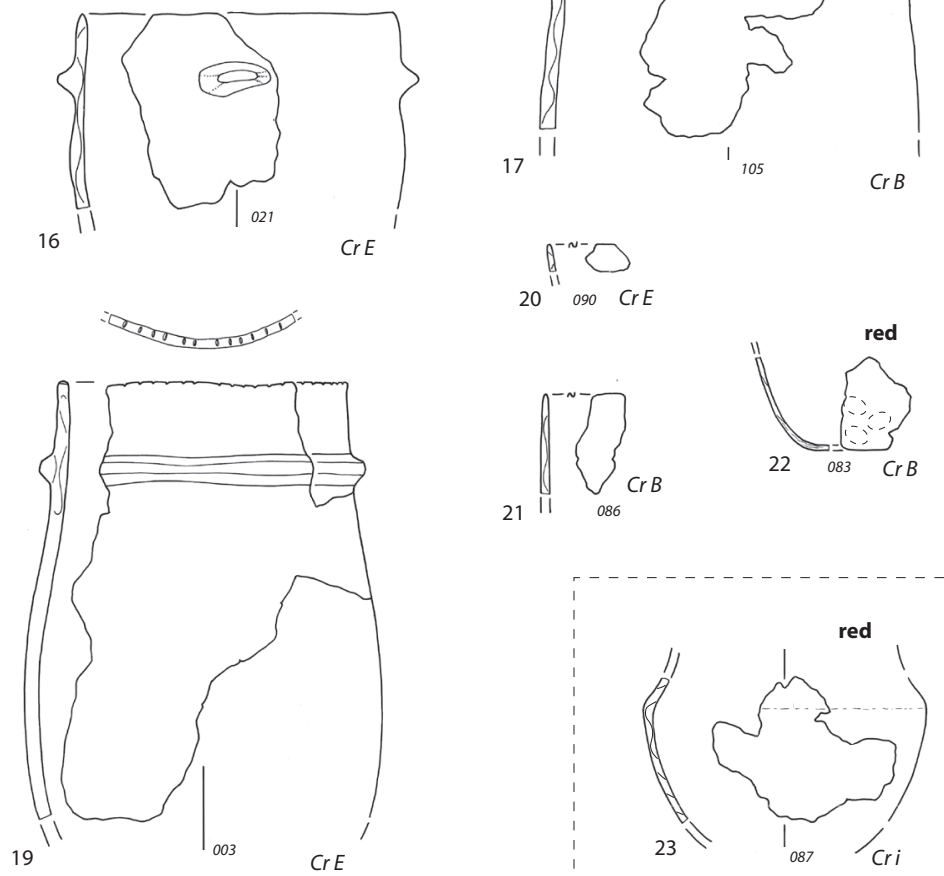

Fig. 10 - Céramiques issues du niveau 2 de Conjux 3 (le no 23 était attribué à la base du niveau 1 selon les données de terrain, mais le résultat précoce de sa datation ${ }^{14} \mathrm{C}$ permet de le rattacher à l'ensemble 2 sup). 1 : récipient rattaché au niveau 2 et attribué à l'ensemble 2 inf d'après le résultat d'une datation radiocarbone sur résidus carbonisés; 2-10 : niveau 2 sans précision; 11-23: ensemble 2sup. Les abréviations décrivent la nature des inclusions principales (voir légende sur la figure 17). Les numéros en petits caractères correspondent aux numéros des unités de collage et d'appariement (dessins P.-J. Rey).

Fig. 10 - Ceramisc from level 2 of Conjux 3 (no. 23 was first attributed to the base of level 1 according to field data, but the early dates obtained by radiocarbon dating allows it to be linked to set 2sup). 1: bowl related to level 2 and attributed to set 2 inf in view of the results of radiocarbon dating on carbonized residues; 2-10: level 2, no precise details; 11-23: set 2sup. Abbreviations describe the nature of the main inclusions (see legend on figure 17). The numbers in small print correspond to the numbers of the assemblage and matching units (drawings P.-J. Rey). 


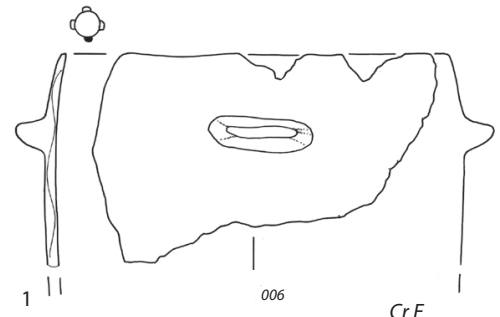

CrE
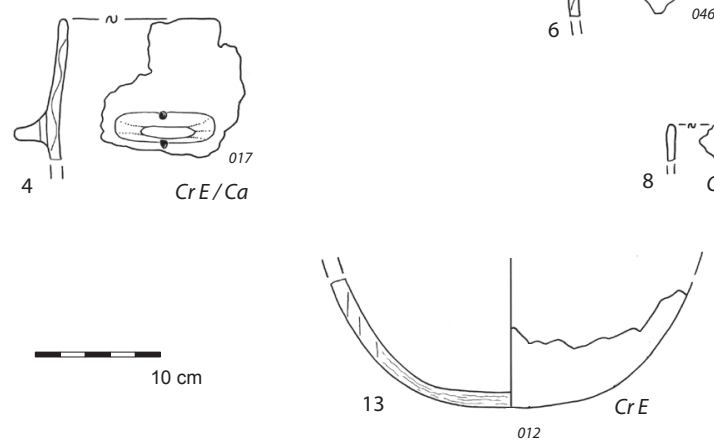

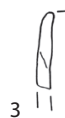<smiles>CC1CCCC1I</smiles>
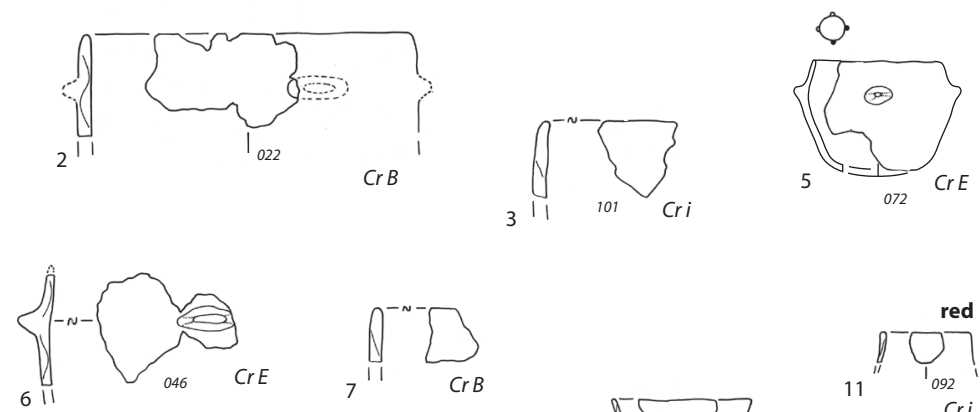

$9^{11}{ }_{C r E}^{-N-}$

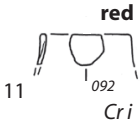

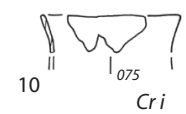

Cri

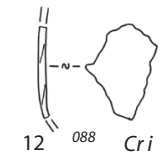

Cri

niveau 1
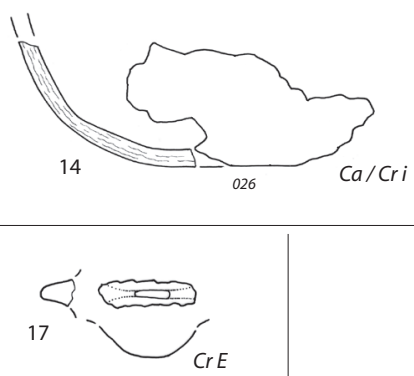

niveaux 1-2

CrE
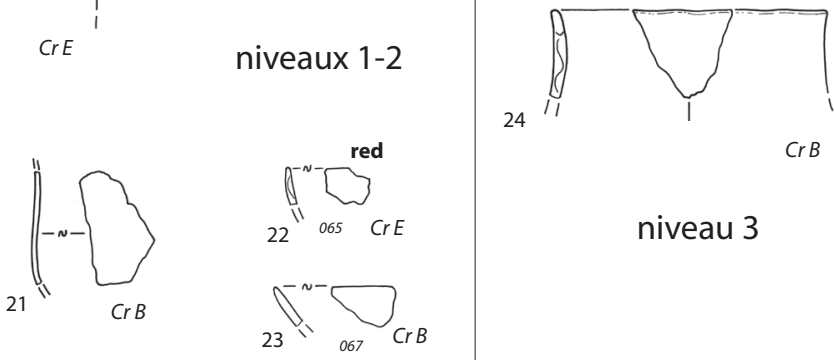

$\operatorname{Cr} B$

niveau 3<smiles>O=C1CC2CCC1C2</smiles>

$\operatorname{Cr} B$

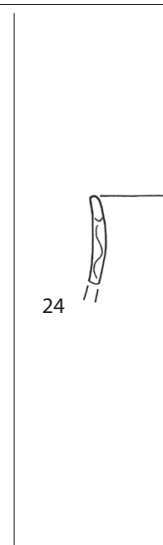

niveau 3

Fig. 11 - 1-14 : céramiques issues du niveau 1 de Conjux 3;15-23 : céramiques issues des niveaux 1-2 sans précision; 24 : céramique issue du niveau 3. Les abréviations décrivent la nature des inclusions principales (voir légende sur la figure 17). Les numéros en petits caractères correspondent aux numéros des unités de collage et d'appariement (dessins P.-J. Rey).

Fig. 11 - 1-14: ceramics from level 1 of Conjux 3; 15-23: ceramics from levels 1-2, no precise details; 24: ceramic from level 3. Abbreviations describe the nature of the main inclusions (see legend on figure 17). The numbers in small print correspond to the numbers of the assemblage and matching units (drawings P.-J. Rey).

travaux concernent des séries jurassiennes contemporaines de nos ensembles. Nos observations visuelles ont été complétées par un examen à la loupe binoculaire et des tests à l'acide pour la détermination des inclusions.

La nature des inclusions est presque exclusivement cristalline (tabl. 4). Le niveau 2 se caractérise par l'emploi fréquent d'inclusions anguleuses d'une roche blanchâtre à micas dorés, vraisemblablement une variété de granit (fig. 14b), qui a été broyée avant d'être intégrée à l'argile. La réutilisation de pierres de chauffe ou d'instruments de mouture en fin de vie est envisageable suivant les exemples documentés dans le Jura (Pétrequin et Rossy, 1997). L'unique fragment de meule découvert à Conjux 3, issu du niveau 1 , est constitué d'une roche granitique. Pour une seconde série de récipients, la présence d'éléments plus émoussés et plus hétérogènes en taille comme en couleur évoque davantage un sable dont l'ajout intentionnel est moins évident. Il pourrait être originaire des placages morainiques qui tapissent le pied du mont Landard, à proximité immédiate du site (Gidon, 1970).

Dans les deux ensembles du niveau 2, il semble exister une corrélation entre diamètre à l'embouchure et nature des inclusions. L'emploi de sable est très majoritaire en-dessous de $26 \mathrm{~cm}$ de diamètre, alors que l'usage de roche blanche cristalline concassée est prépondérant parmi les plus grands vases du niveau 2, au-delà de $26 \mathrm{~cm}$ de diamètre. L'emploi de roche blanche cristalline concassée est à son maximum dans l'ensemble 2sup; il est moins fréquent dans le niveau 1 qui présente, en outre, deux cas d'inclusions principales carbonatées (calcaire et éléments cristallins minoritaires pour le premier, calcaire et calcite pour le second). De manière ponctuelle, une petite jarre 

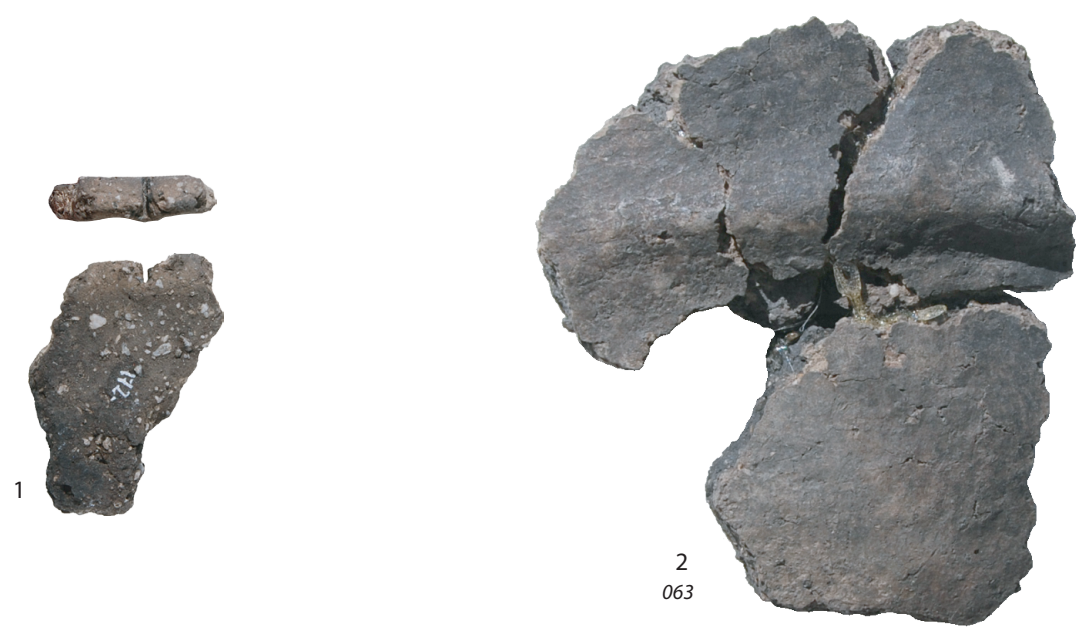

3
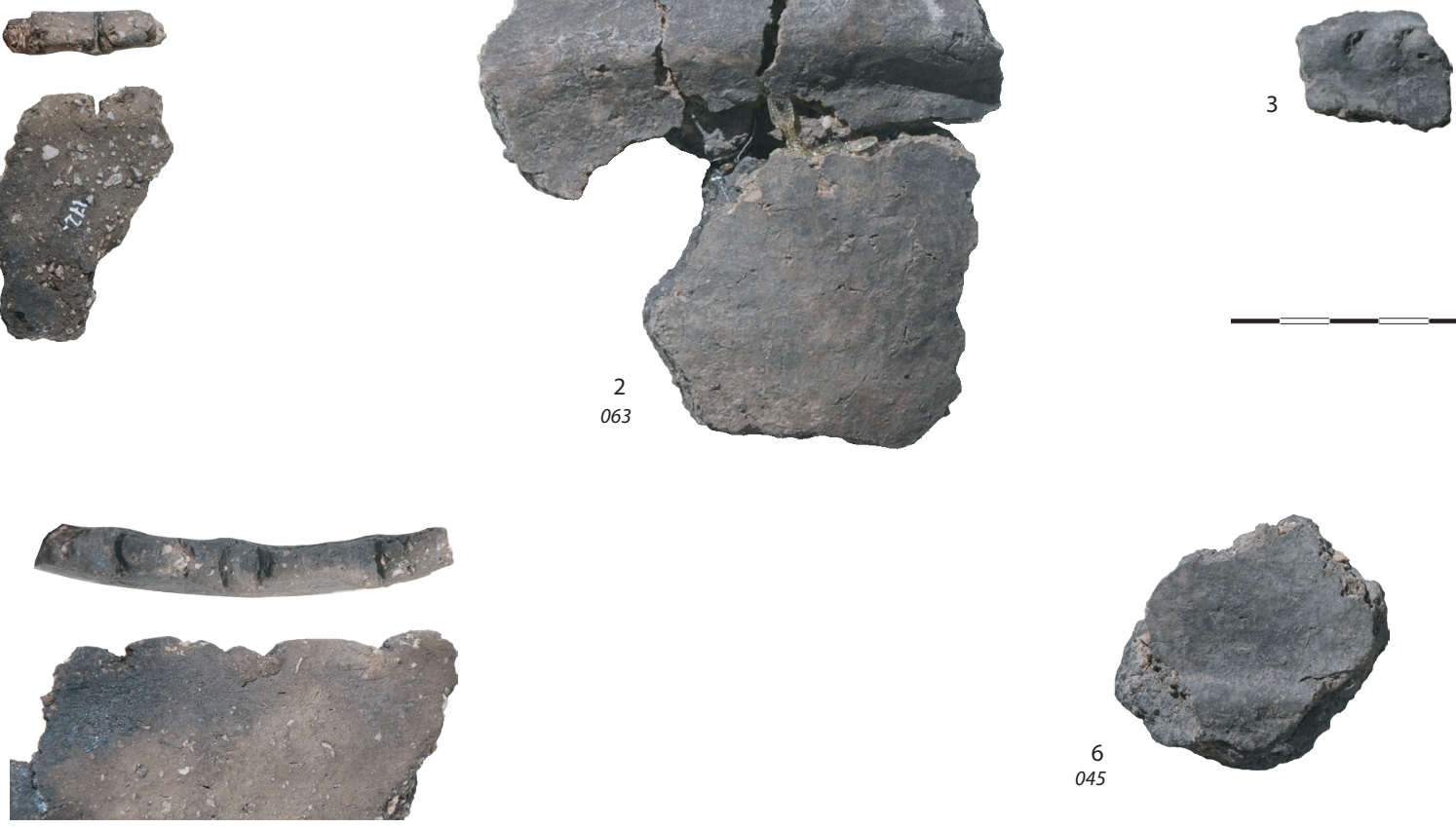

105

$-$
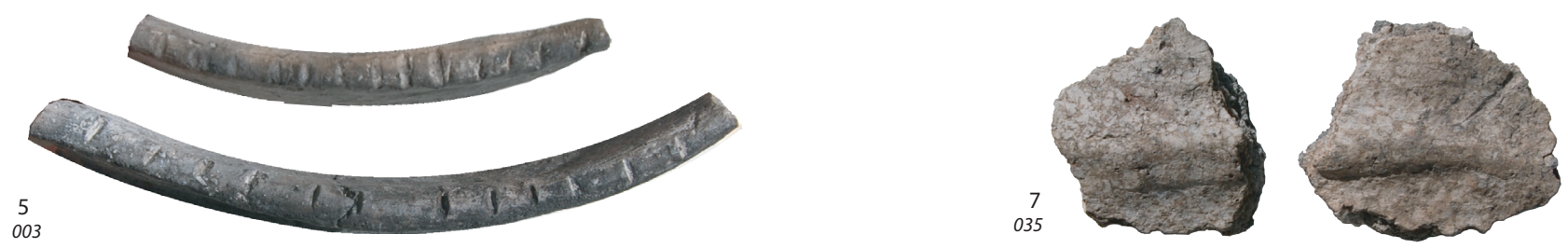

Fig. 12 - Mobiliers céramiques de Conjux 3. Photographies des bords encochés et des cordons lisses peu proéminents ou discontinus. 1 : ensemble 2inf; 2 et 3 : niveau 2 sans précision; $4-7$ : ensemble 2sup (clichés et DAO P.-J. Rey).

Fig. 12 - Ceramics from Conjux 3. Photos of the slightly prominent or intermittent smooth cords, and of the notched edges. 1: set 2inf; 2-3: level 2, no precise details; 4 to 7: set 2sup (photos and CAD P.-J. Rey).

à inclusions cristallines de l'ensemble 2inf montre, dans sa pâte, de nombreuses graines de céréales nues (fig. 9, $\mathrm{n}^{\circ} 20$ ). Cette observation peut être anecdotique mais elle se retrouve sur un récipient probablement contemporain du site des Bourres à Tresserve (voir infra), et un peu plus tôt sur un récipient issu de la couche 43 de la grotte du Gardon à Ambérieu-en-Bugey (Rey, 2013), datée du premier tiers du IVe millénaire av. n. è. S'il ne s'agit pas d'un ajout intentionnel, impossible à démontrer pour l'instant, la présence accidentelle de céréales nues dans l'argile constitue probablement un indice d'un contexte de production domestique. Enfin, quelques tessons de Conjux, à pâte fortement micacée, n'ont pu être rattachés à une couche précise. Par ailleurs, aucun fragment de coquille n'a été observé dans les pâtes employées.

Les quelques fonds observables sont façonnés par modelage (tabl. 5). Des aplats coalescents externes, visibles sur deux petits récipients (fig. $9, \mathrm{n}^{\circ} 2$ et fig. 10, n²2), pour- raient constituer des indices de l'utilisation du battage dans les deux ensembles du niveau 2. Ce critère seul est toutefois insuffisant et nous n'avons pas identifié sur les récipients de Conjux les autres critères dont l'association permet de démontrer l'emploi de cette technique (Martineau, 2005).

Le montage des parois se fait généralement au colombin étiré posé alternativement sur l'intérieur ou l'extérieur du colombin précédent (tabl. 5). Cela se traduit par des plans de joint obliques. La moindre représentation de ce mode de pose dans le niveau 1 est d'abord un effet de la fragmentation qui empêche d'observer correctement les parois. Associés à des changements dans les structures perceptibles en tranche, quelques cas de raccords mal lissés à mi-hauteur de la panse montrent un façonnage en deux étapes, aussi bien sur des très grandes jarres que sur des pots de taille moyenne (fig. 13a et b). Sur les récipients les plus grands, le poids des matériaux provoque parfois des déformations en cours de séchage. 
Le façonnage des cols du niveau 2 repose le plus souvent sur l'emploi de colombins étirés à plans de joint obliques disposés alternativement sur la face interne ou externe du précédent (tabl. 5). Les colombins posés systématiquement sur la face interne du précédent sont également utilisés assez souvent dans l'ensemble 2inf pour des cols droits ou légèrement rentrants. Les cols du niveau 1 présentent une variabilité un peu plus grande du mode de pose des colombins.

La description des états de surface se base sur les travaux de Rémi Martineau (Martineau, 2000 et 2010; Martineau et Maigrot, 2010). Les actions de raclages ont été pratiquement totalement effacées par les étapes ultérieures de la finition. Parmi les différents stigmates de lissage, le lissage à la main mouillée (qui se traduit par des traces fines, en relief, régulièrement espacées et par des empâtements sur les irrégularités de surface : fig. 14c et d), et le lissage sur pâte plastique dure (caractérisé par des traces larges et des stries profondément marquées dans la pâte : fig. 14e et $\mathrm{f}$ ) sont particulièrement bien représentés. Deux autres types de stigmates de lissage ne se retrouvent pas dans les catégories de Rémi Martineau. Le premier se caractérise par le dégagement des inclusions les plus importantes qui apparaissent très en relief et non recouvertes à la surface de la pâte, environnées par des stries fines, nombreuses et orientées (fig. 14g). Il s'agit vraisemblablement de l'action d'une poignée de fibres végétales sur pâte humide, qui enlève une pellicule superficielle d'argile en dégageant les inclusions. Le second type, beaucoup moins fréquent, se caractérise par la présence de cannelures et d'aplats en légers reliefs parallèles, par la régularisation douce des micro-irrégularités et par l'effacement partiel des inclusions (fig. 14h). Il pourrait résulter de l'emploi d'une peau ou d'un tissu très humide. Des expérimentations seraient nécessaires pour valider ces hypothèses.

Réalisé sur une pâte à consistance cuir, le brunissage a été identifié par la présence de cannelures irrégulières associées à de très nombreuses traces fines, avec un toucher doux et une brillance des surfaces (fig. 14i et j). Nous avons distingué en outre des polis sans traces avec deux degrés d'intensité : un poli partiel lorsque subsistent des irrégularités minimes et un poli total lorsque toute irrégularité a disparu (fig. 14k). Nous ne sommes pas capables de préciser si ces polis sans traces résultent d'un brunissage réalisé à consistance cuir, d'un polissage effectué sur pâte à consistance sèche ou d'un autre type de finition.

Nos principales observations sont synthétisées sur des dessins techniques schématiques (fig. 15 à 17).

Le lissage à la main mouillée semble fortement employé dans une première étape de finition. Les autres actions de lissage semblent intervenir dans un second temps. Sur les dessins techniques, nous n'avons représenté que la dernière étape qui recouvre et efface plus ou moins totalement les traces des actions antérieures. Lorsque le traitement des surfaces externes s'est limité à un lissage, le travail sur pâte plastique dure domine dans les trois ensembles (tabl. 5). Dans le niveau 2, il est parfois associé à l'observation de pellicules superficielles qui suggèrent la possibilité de l'emploi ponctuel de barbotine. Brunissage et polis sans traces concernent presque la moitié des récipients. Dans les ensembles du niveau 2, les parois externes des plus grands récipients sont préférentiellement lissées sur pâte plastique dure. Seules les jarres à cordons multiples semblent traitées par brunissage (fig. 14i). Pour quelques récipients, la mise en œuvre d'une finition soignée ne concerne que la panse; le col n'a pas été retouché après un lissage à la main mouillée ou aux fibres (fig. 13c). Un unique cas de col plus soigné que la panse se rencontre sur une jarre à cordons multiples du niveau 2 (fig. 16, nº 3 ).

Les surfaces internes sont principalement traitées par le lissage aux fibres végétales, par brunissage ou par la réalisation de polis sans traces. Les parois internes trai-

\begin{tabular}{|c|c|c|c|c|c|c|c|c|c|}
\hline & \multicolumn{4}{|c|}{ Conjux, Conjux 3} & \multirow{2}{*}{$\begin{array}{c}\text { Brison- } \\
\text { St-Innocent, } \\
\text { Mémars 1 }\end{array}$} & \multirow{2}{*}{$\begin{array}{c}\text { Tresserve, } \\
\text { Les Bourres }\end{array}$} & \multirow{2}{*}{$\begin{array}{c}\text { Talloires, } \\
\text { Angon }\end{array}$} & \multirow{2}{*}{$\begin{array}{c}\text { Annecy, } \\
\text { Port } 1\end{array}$} & \multirow{2}{*}{$\begin{array}{c}\text { Veyrier-d.-L., } \\
\text { Vieugy - } \\
\text { S.-l.-Guerres }\end{array}$} \\
\hline & & $\begin{array}{l}\text { ivea } \\
\text { sup. }\end{array}$ & & Niveau 1 & & & & & \\
\hline Cristallin concassé blanc (à mica) & 13 & 9 & 28 & 2 & & & & & \\
\hline Cristallin concassé & & & & & 9 & & & & \\
\hline Cristallin hétérogène émoussé (sable) & 13 & 4 & 20 & 5 & 1 & & & & \\
\hline Cristallin indifférencié & 2 & 1 & 3 & 5 & & 2 & & & \\
\hline Cristallin et calcite & & & & & & 1 & & & \\
\hline Calcaire et cristallin & & & & 1 & & 1 & & & \\
\hline Calcaire et calcite & & & & 1 & 4 & 4 & 1 & & \\
\hline Calcite & & & & & 1 & 4 & 1 & 3 & 2 \\
\hline Calcite et calcaire & & & & & & 2 & 1 & & \\
\hline Total & 28 & 13 & 51 & 14 & 12 & 14 & 3 & 3 & 2 \\
\hline
\end{tabular}

Tabl. 4 - Types d'inclusions principales observés dans les récipients des ensembles de Conjux 3 et des sites contemporains des avantpays savoyards. À Talloires, Angon, en complément aux trois récipients dénombrés, il faut signaler la présence d'une douzaine de tessons non appariés appartenant à plusieurs récipients et tous dégraissés à la calcite pilée (DAO P.-J. Rey).

Table 4 - Main types of inclusions observed in pots from Conjux 3 and contemporary sites of the Savoy foreland. In the case of Talloires, Angon, we note the presence of a dozen fragments belonging to several bowls and containing crushed calcite (CAD P.-J. Rey). 


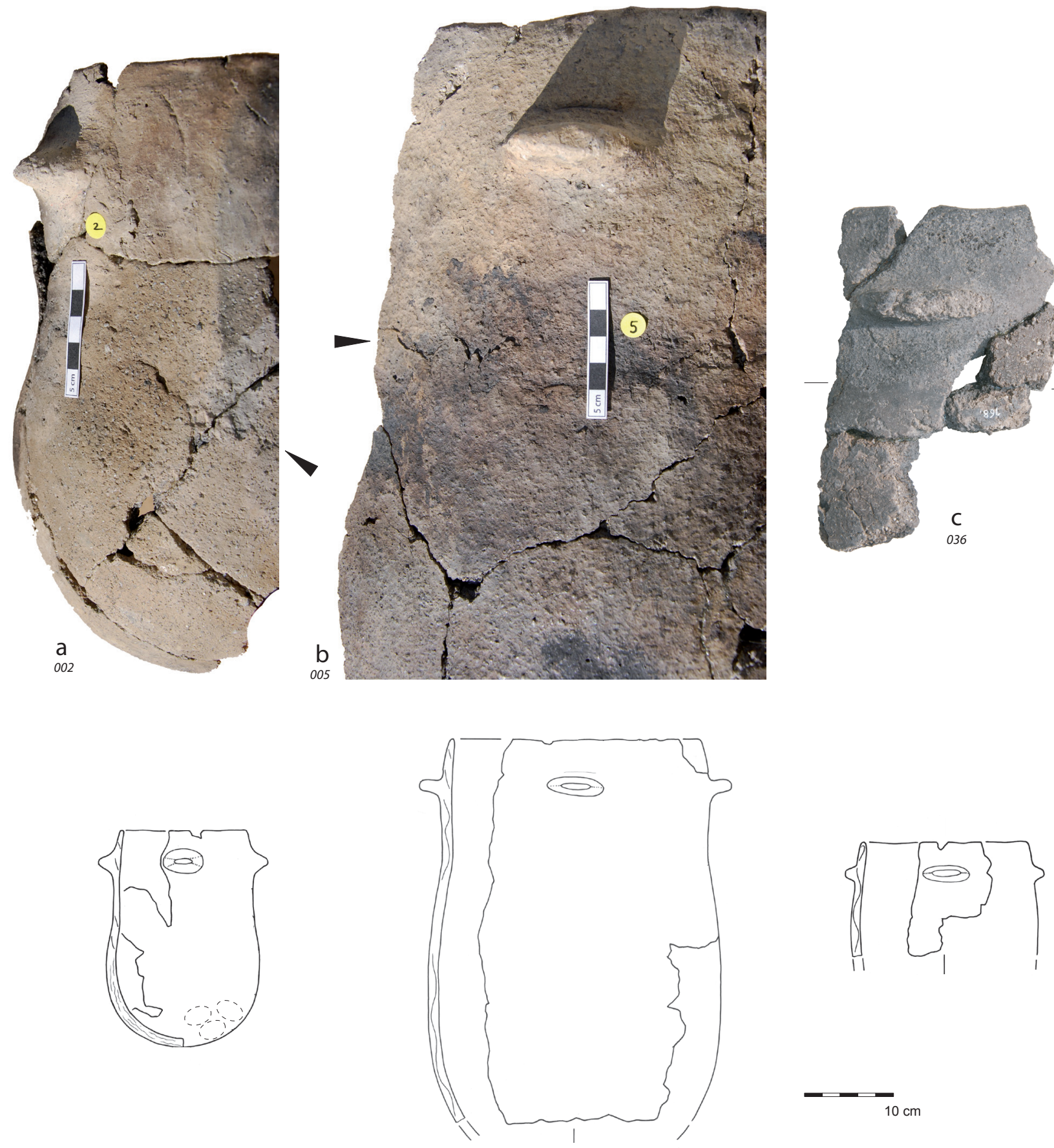

Fig. 13 - Mobiliers céramiques de Conjux 3, niveau 2. a et b : indices de montage en deux parties sur des jarres de petite comme de grande taille; c : réalisation d'un poli partiel limité à la panse sur un petit récipient (clichés P.-J. Rey).

Fig. 13 - Ceramics from Conjux 3, level 2. $a$ and b: signs of a two-part assembly on small and large jars; $c$ : partial polishing limited to the body of a small bowl (photos P.-J. Rey).

tées par la réalisation de polis ou par brunissage semblent se raréfier dans le niveau 1.

La cuisson partiellement oxydante domine, avec une répartition équilibrée entre l'oxydation incomplète externe et l'oxydation incomplète externe et interne. Les fragments de vases à pâte noire, probablement cuits en ambiance réductrice, sont un peu plus fréquents dans le niveau 2 inf, que dans les deux ensembles supérieurs (tabl. 5). Il s'agit souvent de petits récipients à paroi fine.
Les autres vases du même type présentent également une teinte superficielle sombre, peut-être obtenue alors par enfumage ou par l'application d'un traitement à chaud, mais qui pourrait également résulter d'une imprégnation de carbone lors de l'utilisation.

Les petits pots brunis et polis se distinguent de l'ensemble des productions céramiques de Conjux 3. Ils témoignent d'un investissement technique particulier et de méthodes spécifiques, probablement dès la sélection de l'ar- 


\begin{tabular}{|c|c|c|c|c|c|}
\hline \multirow{2}{*}{\multicolumn{2}{|c|}{ Techniques de montage }} & \multicolumn{3}{|c|}{ Niveau 2} & \multirow{3}{*}{$\begin{array}{c}\text { Niveau } 1 \\
1 \\
\end{array}$} \\
\hline & & \multirow{2}{*}{$\begin{array}{c}\text { inf. } \\
5\end{array}$} & \multirow{2}{*}{$\begin{array}{c}\text { sup. } \\
1\end{array}$} & \multirow{2}{*}{$\begin{array}{c}\text { total } \\
7 \\
\end{array}$} & \\
\hline $\bar{\tau}$ & Modelage & & & & \\
\hline$\overline{0}$ & Modelage? & 2 & 1 & 4 & 1 \\
\hline \multirow{4}{*}{$\begin{array}{l}\mathscr{D} \\
\tilde{E} \\
\tilde{E}\end{array}$} & Colombins, disposition non précisable & 1 & 2 & 3 & 2 \\
\hline & Colombins étirés à plans de joint obliques alternés & 9 & 7 & 20 & 3 \\
\hline & Colombins étirés appliqués sur la face interne & 3 & & 3 & \\
\hline & Colombins étirés appliqués sur la face externe & & & & 1 \\
\hline \multirow{4}{*}{$\overline{0}$} & Colombins, disposition non précisable & & & & 2 \\
\hline & Colombins étirés à plans de joint obliques alternés & 6 & 6 & 16 & 4 \\
\hline & Colombins étirés appliqués sur la face interne & 5 & & 5 & 1 \\
\hline & Colombins étirés appliqués sur la face externe & 1 & 1 & 3 & 2 \\
\hline
\end{tabular}

\begin{tabular}{|c|c|c|c|c|c|c|c|c|}
\hline \multirow{2}{*}{ Traitements de surface } & \multicolumn{4}{|c|}{ Surface externe } & \multicolumn{4}{|c|}{ Surface interne } \\
\hline & \multicolumn{3}{|c|}{\begin{tabular}{|c|} 
Niveau 2 \\
inf. | sup.| total
\end{tabular}} & \multirow[t]{2}{*}{ Niveau 1} & \multicolumn{3}{|c|}{$\begin{array}{c}\text { Niveau } 2 \\
\text { inf. | sup.| total }\end{array}$} & Niveau 1 \\
\hline Lissage indifférencié & 1 & & 1 & & 1 & 1 & 2 & 1 \\
\hline Lissage à la main mouillée & 3 & 1 & 6 & 3 & 2 & & 4 & 1 \\
\hline Lissage au tissu humide & & & & & 2 & 2 & 4 & \\
\hline Lissage aux fibres végétales & 1 & 1 & 3 & & 5 & 3 & 9 & 6 \\
\hline Lissage sur pâte plastique dure & 8 & 4 & 14 & 5 & 2 & 1 & 3 & \\
\hline Brunissage réalisé à consistance cuir & 3 & 3 & 8 & 1 & 2 & 3 & 9 & 1 \\
\hline Poli partiel & 4 & 1 & 6 & 1 & 3 & 1 & 4 & 1 \\
\hline Poli total & 3 & 2 & 7 & 3 & 2 & 1 & 4 & \\
\hline Présence possible de barbotine & 5 & 1 & 6 & 1 & & & & \\
\hline Aplats externes & 1 & 1 & 2 & & & & & \\
\hline Nombre de récipients décrits & 23 & 12 & 45 & 13 & 19 & 12 & 39 & 10 \\
\hline
\end{tabular}

\begin{tabular}{|c|c|c|c|c|c|c|c|c|}
\hline \multirow{2}{*}{$\begin{array}{l}\text { Synthèse des traitements de } \\
\text { surface }\end{array}$} & \multicolumn{4}{|c|}{ Surface externe } & \multicolumn{4}{|c|}{ Surface interne } \\
\hline & & $\begin{array}{l}\text { iveau } \\
\text { sup. }\end{array}$ & $\begin{array}{l}2 \\
\text { total }\end{array}$ & Niveau 1 & & $\begin{array}{l}\text { veau } \\
\text { sup. }\end{array}$ & $\begin{array}{l}2 \\
\text { total }\end{array}$ & Niveau 1 \\
\hline Lissage & 13 & 6 & 24 & 8 & 12 & 7 & 22 & 8 \\
\hline Brunissage et autres polis & 10 & 6 & 21 & 5 & 7 & 5 & 17 & 2 \\
\hline
\end{tabular}

\begin{tabular}{|l|c|c|c|c|}
\hline Cuisson & \multicolumn{3}{|c|}{ Niveau 2 } & Niveau 1 \\
inf. & sup. & total & \\
\hline Récipients cuits en ambiance réductrice & 5 & 2 & $\mathbf{7}$ & $\mathbf{2}$ \\
\hline Total des récipients décrits & 25 & 14 & $\mathbf{4 9}$ & $\mathbf{1 3}$ \\
\hline
\end{tabular}

Tabl. 5 - Principaux caractères techniques identifiés sur les céramiques de Conjux 3 pour les étapes du montage et de la finition (DAO P.-J. Rey).

Table 5 -Main technical characteristics identified on ceramics of Conjux 3 for the assembly and finishing phases (CAD P.-J. Rey). 


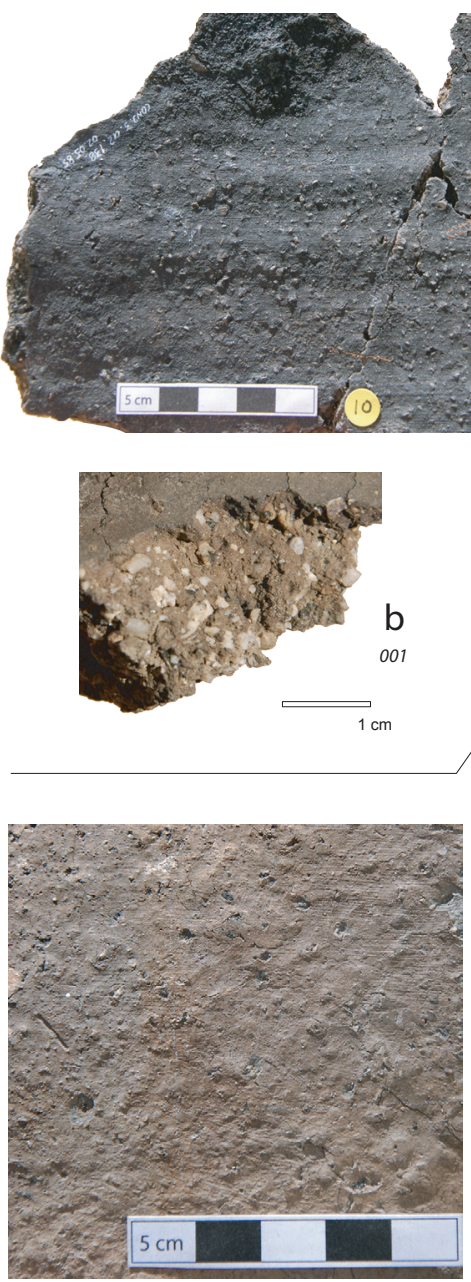

C

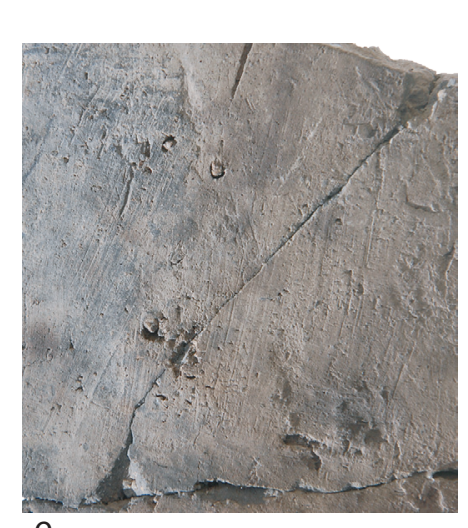

e

011

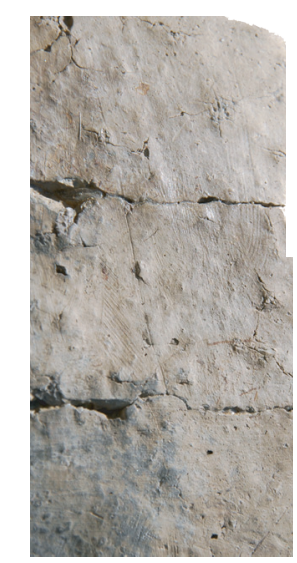

$\mathrm{f}$
026
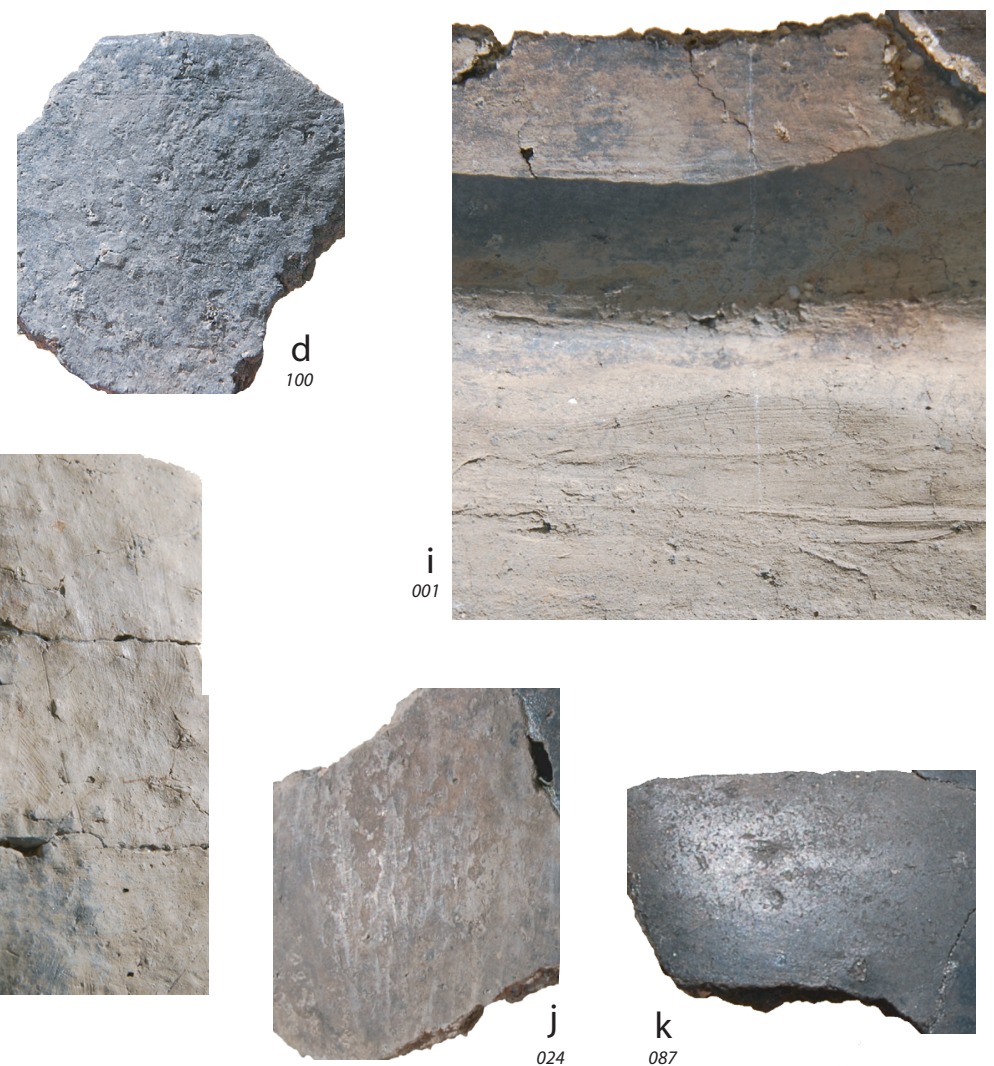

087

Fig. 14 - Mobiliers céramiques de Conjux 3. Quelques exemples des stigmates les plus caractéristiques et interprétations proposées. a : ondulations régulières de la surface caractéristiques d'un montage aux colombins; $b$ : vue en tranche d'un tesson à inclusions de roche cristalline concassée blanche à mica; $\mathrm{c}$ et $\mathrm{d}$ : lissage à la main mouillée; e et $\mathrm{f}$ : lissage sur pâte plastique dure; $\mathrm{g}:$ lissage aux fibres végétales; $\mathrm{h}$ : lissage au tissu humide; $\mathrm{i}$ et $\mathrm{j}:$ brunissage sur pâte à consistance cuir; $\mathrm{k}:$ poli total. Les images $\mathrm{c}$ à $\mathrm{k}$ sont à la même échelle (clichés P.-J. Rey).

Fig. 14 - Ceramics from Conjux 3. Some examples of the most characteristic stigmata and proposed interpretations. a: regular undulations of the surface typical of coiling; $b$ : sectional view of a fragment with inclusions of crushed white crystalline rock with mica; $c$ and $d$ : smoothing using a wet hand; $e$ and f: smoothing on hard plastic paste; g: smoothing using vegetable fibres; $h$ : smoothing using damp fabric; $i$ and $j$ : burnishing on paste with leathery texture; $k$ : total polishing. The images $c$ to $k$ are on the same scale (photos P.-J. Rey). 
gile et jusqu'au traitement de surface et à la cuisson. L'hypothèse d'une importation de ces petits récipients pourrait être envisagée. Toutefois les premiers travaux menés sur la céramique fine des sites du plateau Suisse et des Baigneurs à Charavines indiquent le plus souvent une provenance locale ou très voisine (Benghezal, 1994; Di Pierro, 2002).

Les résidus carbonisés sont très fréquents dans le niveau 2 (vingt-quatre cas sur cinquante-trois vases décrits). Ils se rencontrent sur la quasi-totalité des grandes jarres, sur la majorité des récipients de taille moyenne et sur quelques petits récipients. Dans le niveau 1, ces résidus sont plus rares, probablement pour des raisons taphonomiques, mais se retrouvent également sur le fond d'une très grande jarre. C'est donc bien la fonction de récipient culinaire et non celle de vase de stockage qui doit être envisagée pour la grande majorité des jarres. Ce constat se retrouve sur le site voisin des Bourres à Tresserve (voir infra) et rejoint les observations réalisées sur les lacs de Chalain et Clairvaux (Pétrequin et Pétrequin, 1986). Sur l'une des grandes jarres de Conjux 3, la présence d'une large fissure verticale, en partie colmatée par des résidus carbonisés témoigne d'un usage particulièrement soutenu de ce récipient (fig. 9, $\mathrm{n}^{\circ} 1$ ).

Les grandes jarres de Conjux présentent une grande homogénéité des pâtes et une variabilité technique plus faible que les petites jarres, qui pourrait s'expliquer à la fois par un façonnage obéissant à des règles plus strictes mais aussi, peut-être, par une moindre circulation de ces pièces particulièrement lourdes et impliquées dans les pratiques culinaires.

\section{LES SITES CONTEMPORAINS DES LACS DU BOURGET ET D'ANNECY}

L es rives des lacs savoyards fournissent une série de sites du III ${ }^{\mathrm{e}}$ millénaire. Certains ne sont connus que par des ramassages d'objets sans contexte au XIX ${ }^{\mathrm{e}}$ siècle : le Port 1 à Annecy et Vieugy - Sous-les-Guerres à Veyrier-du-Lac (voir Marguet, 1995, pour la bibliographie et le contexte). La plupart des gisements repérés lors des prospections des deux dernières décennies sont érodés et ne livrent parfois plus que des bois verticaux, par exemple sur le lac du Bourget, les Côtes (str. 2) et Rive 2 au lieudit Marais de la Chatière à Conjux (Marguet, 2008, p. 220-221; Marguet, 2004, p. 121-122 et 2007, p. 149-151). Quatre sites seulement montrent une préservation de niveaux organiques, mais ils n'ont été que très partiellement sondés. Ils ont fourni de petits ensembles de mobiliers qui permettent néanmoins d'affiner la perception de l'industrie céramique du Néolithique final dans les avant-pays savoyards.

\section{Sous-le-Four à Brison-Saint-Innocent (Savoie)}

Dans la partie médiane du lac, sur sa rive orientale, au pied des derniers chaînons jurassiens du massif de la Chambotte, quelques pilotis et de rares vestiges ont été localisés en 2000, au droit du gisement de l'âge du
Bronze final de Grésine-Est. Au pied des enrochements supportant la voie de chemin de fer, sur une emprise longue d'environ seize mètres et large d'à peine cinq, des pilotis sont visibles, dans un secteur fortement soumis à l'érosion régressive des vagues (profondeur - 3,1 m). Très vraisemblablement, on aurait là les lambeaux des premiers vestiges lacustres découverts dans le lac du Bourget en 1856, lors de la construction du chemin de fer de Culoz au mont Cenis (Chantre, 1875-1876, p. 170). Douze pieux ont été prélevés parmi lesquels neuf chênes qui ont été analysés en dendrochronologie (analyses Archéolabs). Une première courte séquence de quarantesept ans (9001BSF) montre la contemporanéité de quatre échantillons dont le $\mathrm{n}^{\circ} 6 \mathrm{BSF}$ qui a fait l'objet d'un calage par le ${ }^{14} \mathrm{C}$. Le résultat (Arc.2061 : $4725 \pm 45 \mathrm{BP}$, soit entre -3635 et -3375 cal. BC), indique la fin du Néolithique moyen, en conformité avec l'attribution culturelle de certains mobiliers lithiques recueillis anciennement (Rey, 1999, p. 863-868). Une deuxième séquence dendrochronologique de trente-sept ans, à partir de deux échantillons, n'est pas encore datée (9002BSF; Marguet, 2002, p. 118 et 120). Par ailleurs, les dévasages réalisés dans un triangle de $5 \mathrm{~m}$ implanté juste en contrebas des enrochements ont mis en évidence, en surface d'une couche organique, plusieurs tessons de céramique grossière. Ils comprennent un fond aplati et un petit vase en tonneau à lèvre amincie sur l'extérieur (fig. 18B), dotés d'inclusions de sable cristallin, qui pourraient évoquer les productions du Lüscherz ancien. L'occupation du site au Néolithique final est également attestée par la majorité des mobiliers lithiques pêchés au XIX ${ }^{\mathrm{e}}$ siècle.

\section{Mémars 1 à Brison-Saint-Innocent (Savoie)}

Sur la rive orientale du lac, au sud de la Pointe de l'Ardre et au nord de l'important cône de déjection formé par le Sierroz, s'étend la baie de Mémard (toponyme actuel). La plateforme littorale, en pente faible, est large d'environ $200 \mathrm{~m}$. Découvert en 1863, le gisement de Mémars fait partie intégrante de l'histoire de l'archéologie subaquatique du lac du Bourget, depuis les premières mentions du XIX ${ }^{\mathrm{e}}$ siècle. jusqu'aux travaux actuels en passant par les premières plongées de R. Laurent ${ }^{(2)}$, dans les années 1950-1970, et les prospections de R. Castel au début des années 1980 qui avaient en particulier permis la découverte d'une longue pirogue monoxyle datée par le ${ }^{14} \mathrm{C}$ : Ly.2305 : $3740 \pm 130 \mathrm{BP}$, soit entre -2559 et - 1775 cal. BC (Rey, 1999, p. 876-918). Dans le cadre d'une évaluation plus systématique du secteur, des prospections ont été réalisées par le CNRAS, à l'automne 1995 et dans l'hiver 1996. Des axes de repérage équidistants de $50 \mathrm{~m}$ ont été installés perpendiculairement et parallèlement au rivage actuel (le premier à $37,8 \mathrm{~m}$ du rivage, le dernier à 187,8 $\mathrm{m}$ de celui-ci), dans les franges méridionales du site. La bathymétrie réalisée suivant les axes de ce maillage montre que les vestiges s'articulent, sous 2 à $6 \mathrm{~m}$ d'eau, autour d'une anomalie topographique formant un léger monticule. Des carottages systématiques tous les $10 \mathrm{~m}$ ont aussi permis une première évaluation de l'état de 

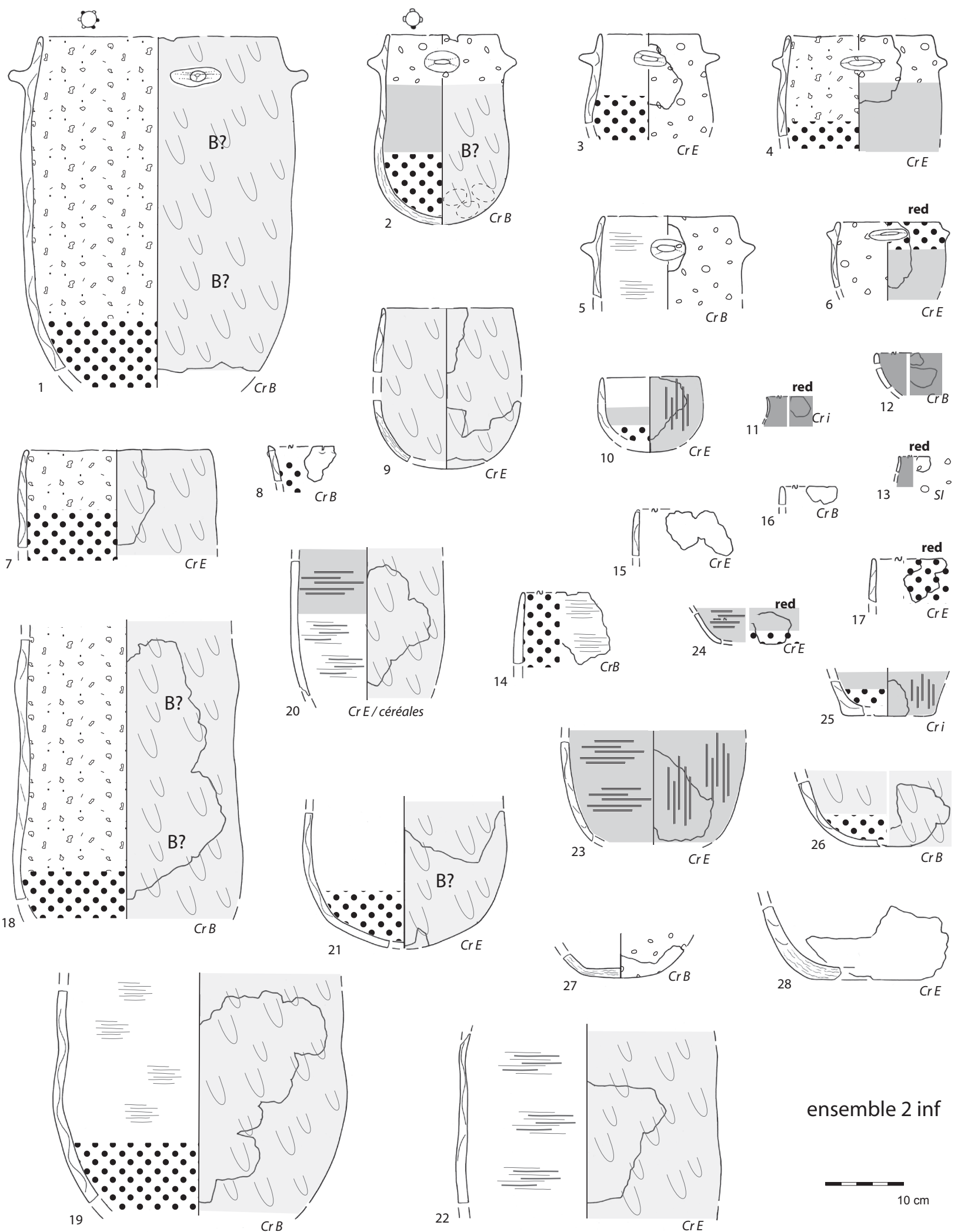

Fig. 15 - Dessins techniques schématiques des céramiques de Conjux 3, niveau 2, ensemble 2inf. La légende se trouve sur la figure 17 (DAO P.-J. Rey).

Fig. 15 - Schematic technical drawings of ceramic from Conjux 3, level 2, set 2inf. See legend on figure 17 (CAD P.-J. Rey). 

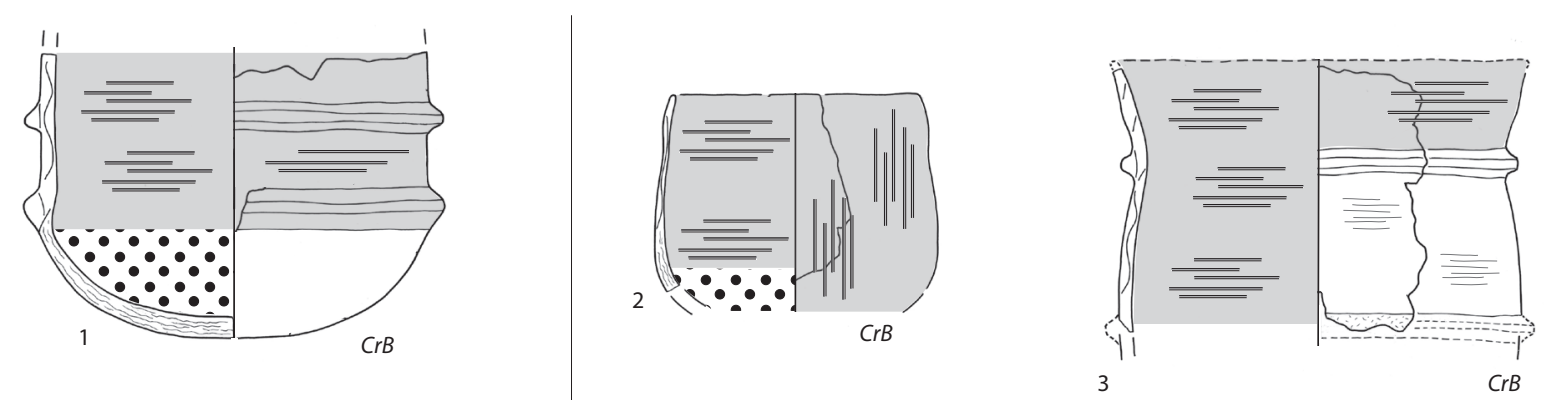

ensemble 2 inf (après C14)
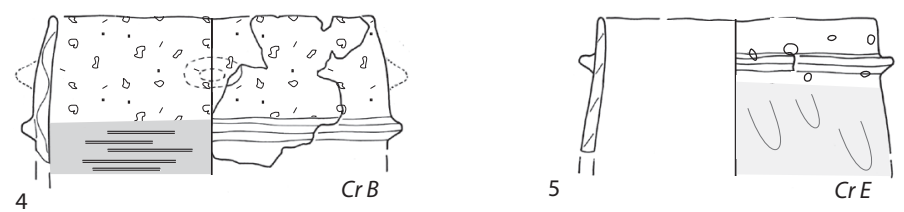

niveau 2 sans précision
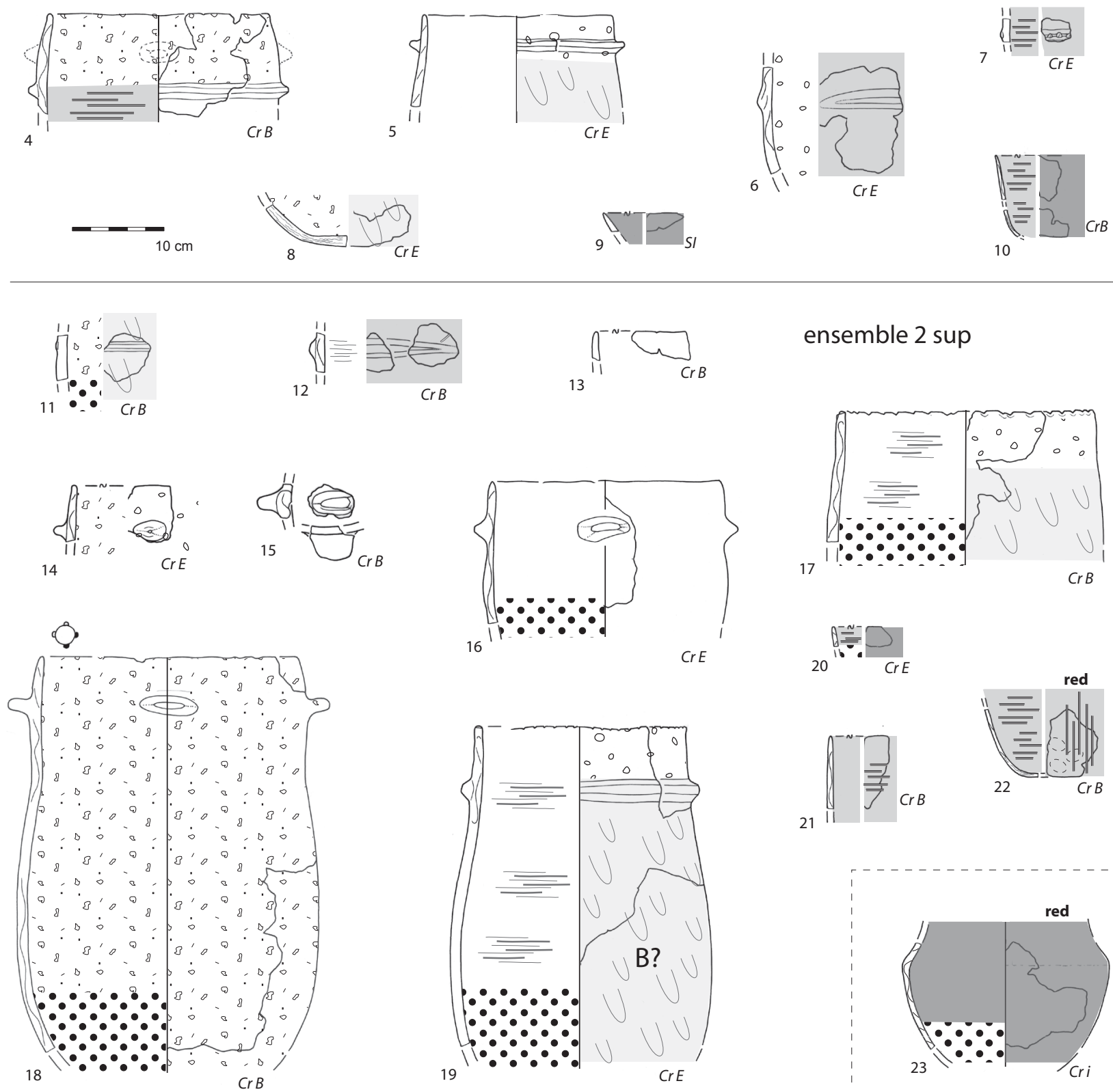

ensemble 2 sup

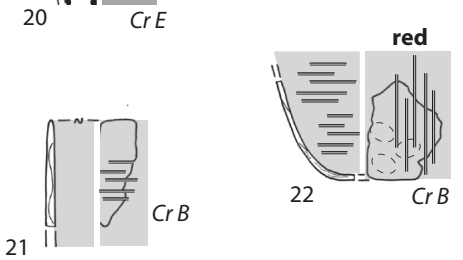

Fig. 16 - Dessins techniques schématiques des céramiques de Conjux 3, niveau 2. 1 : ensemble 2inf; 2-10 : niveau 2 sans précision; 11-23 : ensemble 2sup. La légende se trouve sur la figure 17 (DAO P.-J. Rey).

Fig. 16-Schematic technical drawings of ceramic from Conjux 3, level 2. 1: set 2inf; 2-10: level 2, no precise details; 11-23: set 2sup. See legend on figure 17 (CAD P.-J. Rey). 

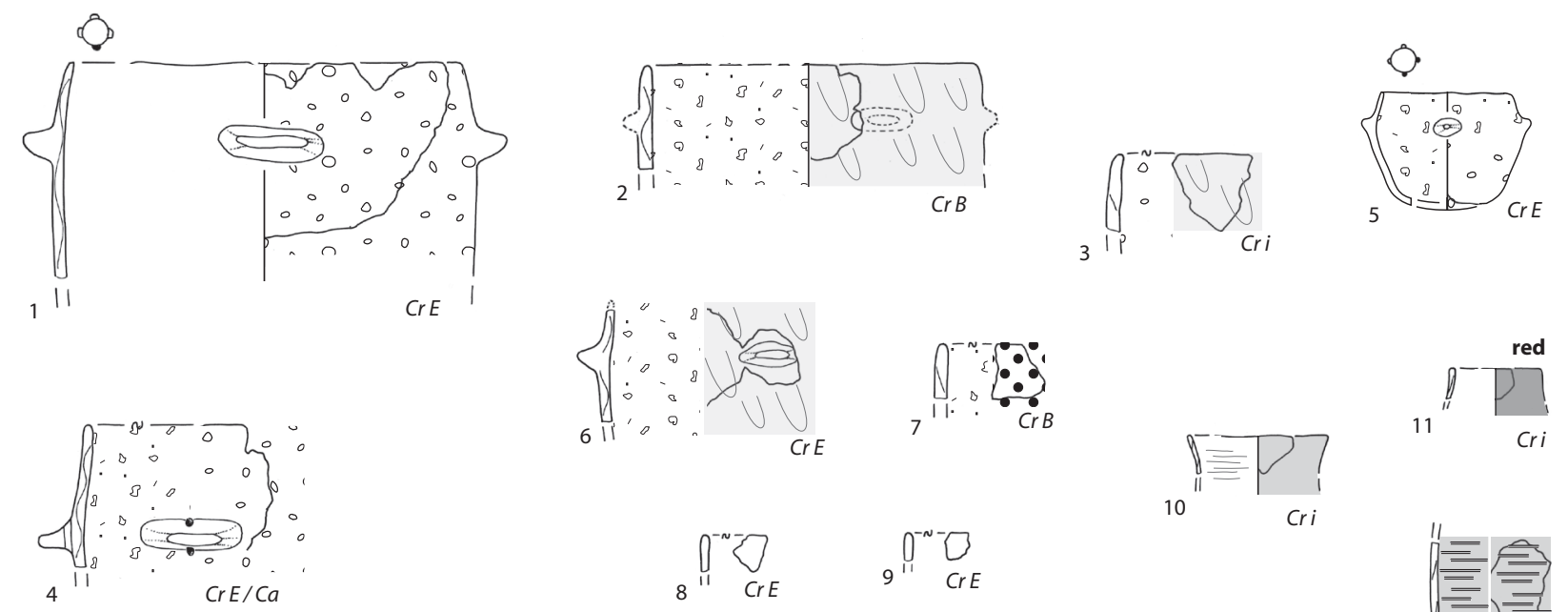

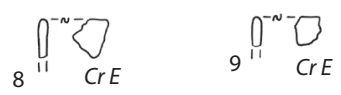
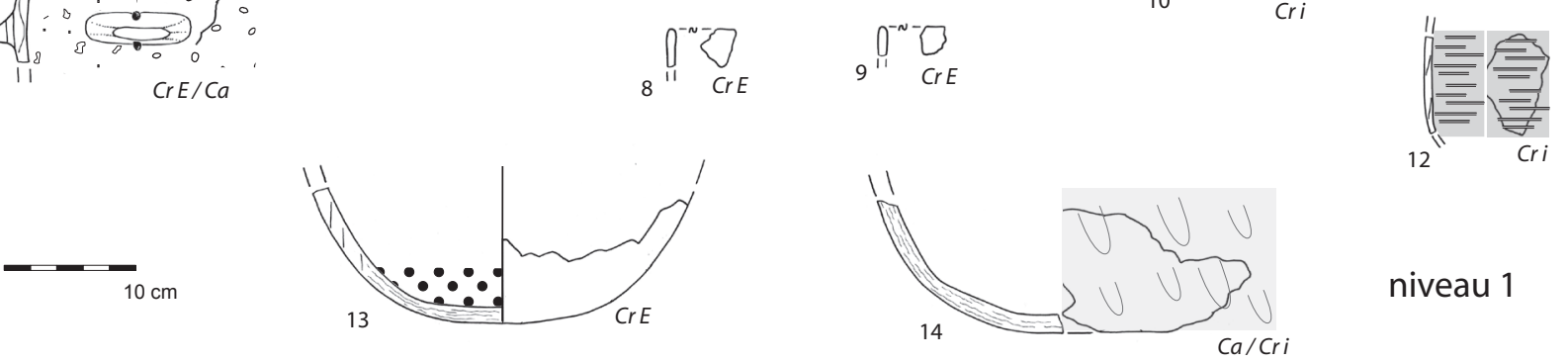

niveau 1
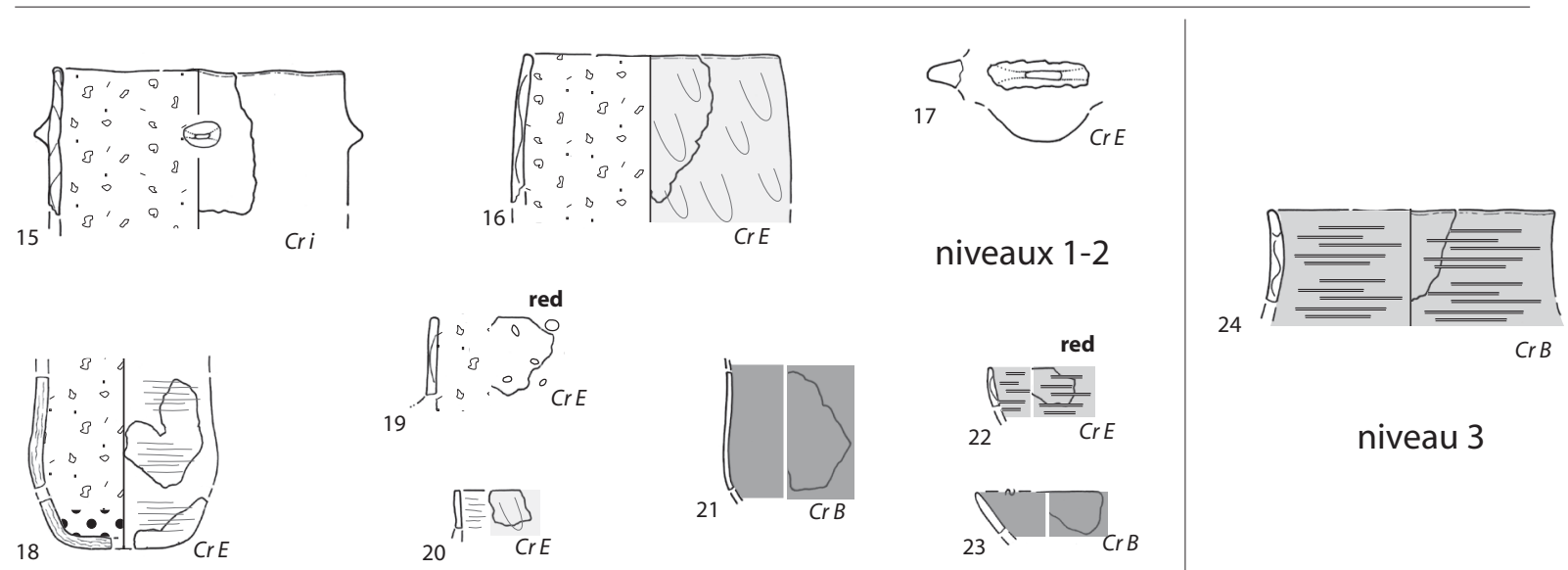

niveau 3

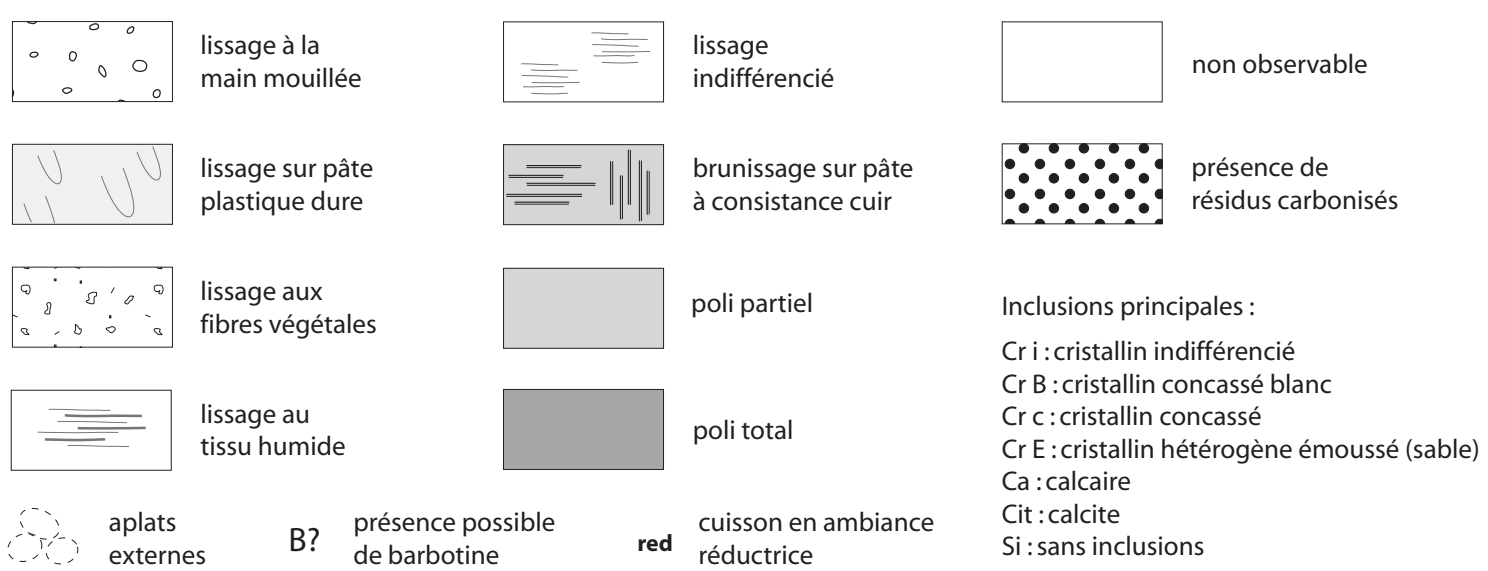

Fig. 17 - Dessins techniques schématiques des céramiques de Conjux 3. 1-14 : céramiques issues du niveau 1; 15-23: céramiques issues des niveaux 1-2 sans précision; 24 : céramique issue du niveau 3 (DAO P.-J. Rey).

Fig. 17 - Schematic technical drawings of ceramic from Conjux 3. 1-14: ceramic from level 1; 15-23: ceramics from levels 1-2, no precise details; 24: ceramic from level 3 (CAD P.-J. Rey). 
conservation des niveaux archéologiques (2,25 ha ont été prospectés dont près de la moitié contiennent des niveaux organiques ou des limons teintés encore conservés). Le levé topographique de 1051 pilotis a été réalisé sur $1678 \mathrm{~m}^{2}$ (155 unités triangulaire de $5 \mathrm{~m}$ de côté). Pour permettre les premières datations, soixante-huit pilotis ont été prélevés dans différents secteurs. Une palissade de petits chênes implantés sur le tombant a été datée par le ${ }^{14} \mathrm{C}$ : Arc.1491 : $4000 \pm 40 \mathrm{BP}$, soit entre -2831 et -2356 cal. BC; elle borde le gisement côté large. Des datations dendrochronologiques ont été obtenues sur des pieux du secteur ouest : phases d'abattage entre -2595 et -2529 , et sur des pilotis de la zone sud : phases d'abattage entre -2582 et -2475 (9017BRM). La date obtenue sur la pirogue se place également dans le même intervalle (Ly.2305 : $3740 \pm 130$ BP). Par ailleurs, au sud du gisement, un repère chronologique encore plus récent témoigne d'une présence au début du Bronze ancien : dix-sept piquets de chêne proviennent d'une palissade, suivie sur une cinquantaine de mètres, disposée perpendiculairement au rivage. L'un d'eux est daté par le ${ }^{14} \mathrm{C}:$ Arc. $1691: 3645 \pm 40 \mathrm{BP}$, soit entre -2137 et -1915 cal. BC (Marguet, 2004, p. 117). Les mobiliers céramiques ont été recueillis lors de différentes phases de travail et dans des secteurs distincts du site. Quelques grands fragments de jarres à cordons lisses très peu proéminents, portant parfois des languettes horizontales en symétrie binaire ou ternaire, proviennent des recherches de R. Laurent (fig. 18C, n ${ }^{\text {os }} 19$ à 21). Le nombre de cordons est incertain sauf pour une jarre qui en porte deux, l'un sous le bord, l'autre à mi panse. Un tesson à carène douce a été recueilli lors des plongées de 1982. Un lot plus conséquent est issu des dévasages réalisés en plusieurs endroits du site au cours des interventions de 1995-1996 (fig. 18C, $\mathrm{n}^{\text {os }} 26$ à 37). Il s'agit de vestiges récupérés au sommet des dépôts organiques, dont l'homogénéité n'est pas certaine. Ils comprennent des jarres cylindriques ou ovoïdes à fond arrondi et languette horizontale portant parfois une ou plusieurs perforations, un grand récipient globulaire à bord rentrant et languettes rectangulaires très proéminentes sous le bord, une jatte, un bol haut à pseudocarène basse (fig. 18, $\mathrm{n}^{\circ} 28$ ) et une tasse carénée à anse unique, à bord rentrant.

La majorité des récipients contient des inclusions concassées de roche cristalline à micas, d'une teinte un peu différente de celle utilisée à Conjux 3. Il pourrait s'agir d'une autre variété de granit mais des analyses plus poussées seraient nécessaires. Par ailleurs, plusieurs récipients présentent un mélange de fragments de calcaire et de calcite pilés.

La jarre à double cordons lisses (fig. 18, $\mathrm{n}^{\circ} 20$ ) trouve une comparaison à fond aplati dans le Lüscherz récent aux Bains des Dames, Saint-Blaise, Neuchâtel, Suisse (Giligny et Michel, 1995, fig. 8, $\mathrm{n}^{\circ}$ 12). Les languettes posées sur un cordon horizontal lisse (fig. $18, \mathrm{n}^{\text {os }} 19$ et 21 ) sont présentes sur une longue durée dans les contextes méridionaux. Elles ne se rencontrent pas dans le Jura mais existent sur le plateau Suisse (Wolf, 1993), tout comme les bols hauts à fond aplati (Wolf, 1993, pl. 12 et 18).

Les languettes perforées (fig. 18, $\mathrm{n}^{\text {os }} 27$ et 28 ) se multiplient dans la phase ancienne de l'Auvernier-Cordé et dans le groupe de Chalain un peu plus tardivement (Giligny et al., 1995). Les languettes perforées ou multiforées (dont une quadriforée) sont bien représentées à l'Avenue des Sports à Yverdon-les-Bains, entre 2730 et 2620 av. n. è. (Wolf, 1993, pl. 20 et 31), sur des formes assez petites à bord droit, comparables à celles de Mémars 1. Ces types de préhension disparaissent ensuite du plateau Suisse lors de la généralisation des influences cordées. De rares languettes multiforées apparaissent également dans les deux niveaux des Baigneurs à Charavines, au cours du XXVII ${ }^{\mathrm{e}}$ siècle (Ferrer-Joly, 2005).

La coupe profonde (fig. 18, $\mathrm{n}^{\circ}$ 30) semble absente dans la sphère helvético-jurassienne. Présente très ponctuellement dans l'ensemble inférieur de Charavines (Ferrer-Joly, 2005, fig. 2, $\mathrm{n}^{\mathrm{o}}$ 1), elle est par contre très commune dans les différents faciès du Néolithique final de Provence (D’Anna, 1995; Cauliez, 2011). Le récipient globulaire à bords rentrants et forte languette horizontale (fig. 18, $\mathrm{n}^{\circ} 34$ ) renvoie plus nettement au groupe des Bruyères (Gilles, 1975, fig. 10, n 4). Un récipient à bord rentrant et languette peu proéminente est connu dans la couche B3 de Balme Rousse (Choranche, Isère), qui a livré également des jattes à carène peu marquée et des vestiges campaniformes de style rhodano-provençal (Vital et Bintz, 1999, fig. 22).

La présence d'une tasse à carène haute, à bord nettement rentrant, à fond arrondi et anse en ruban sous la carène (fig. 18, $\mathrm{n}^{\circ} 32$ ), ne trouve aucune comparaison exacte, ni dans le Néolithique final, ni dans le Campaniforme, ni dans le Bronze ancien du versant nord-ouest des Alpes. Les rapprochements que nous avions présentés antérieurement (Marguet et Rey, 2007) restent peu convaincants. C'est peut-être vers l'Italie qu'il faut se tourner pour trouver des petits récipients de ce type (Cocchi Genick, 2008), mais l'association d'un bord rentrant avec une anse sous la carène n'a pu être retrouvée.

Enfin, mentionnons les deux tasses en bois découvertes au XIX ${ }^{\mathrm{e}}$ siècle (Rabut, 1872, pl. II) et lors des plongées de R. Laurent dans les années 1970 (Combier, 1959; Castel, 2004, p. 172). Si la vaisselle en bois est peu représentée à Charavines, elle est nettement plus fréquente dans le Jura et sur le plateau Suisse (Pétrequin et al., 1988). Les analogies stylistiques entre récipients en bois et en céramiques ont déjà été soulignées (Pétrequin et Pétrequin, 1986; Pétrequin et al., 1988). La forme générale de l'exemplaire découvert par R. Laurent et la présence d'une préhension unique à perforation horizontale sur les deux récipients évoque les anses tubulaires ou en demi-bobines fréquentes sur les céramiques de la sphère méridionale en particulier dans les sites apparentés au groupe des Bruyères, sur le site éponyme (Gilles, 1975), mais aussi au Puits du Fakir, Balazuc, Ardèche (Mouyon et al., 2001), ou dans l'abri de la Vessignée, Saint-Marceld'Ardèche, Ardèche (Beaume, 1996). La découverte à Mémars 1 de deux cuillères en bois (Castel, 2004, p. 172), très semblables à celles de Charavines (Bocquet, 2005, vol. V, pl. 6 à 10) mérite également d'être rappelée.

En conclusion, les occupations documentées dans les mobiliers décrits se placeraient entre le début du XXVIII ${ }^{\mathrm{e}}$ 

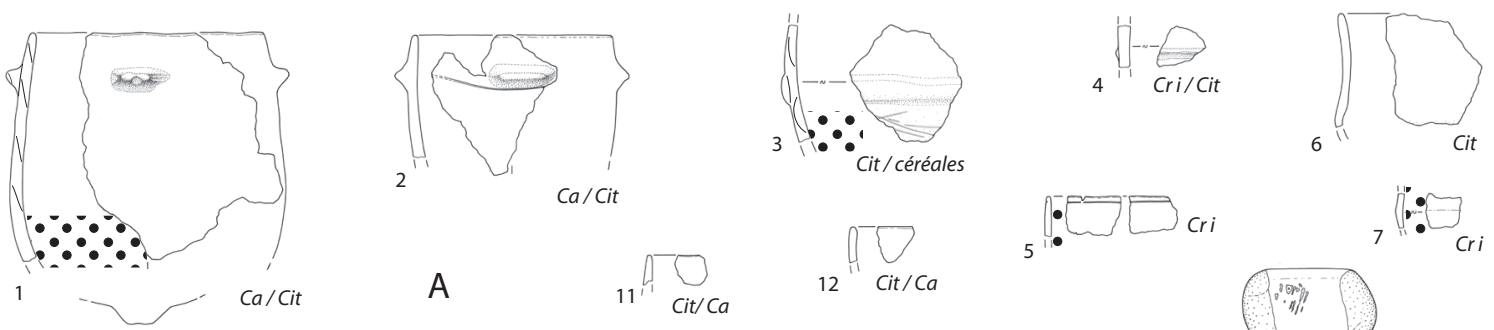

$\mathrm{Ca} / \mathrm{Cit}$

A
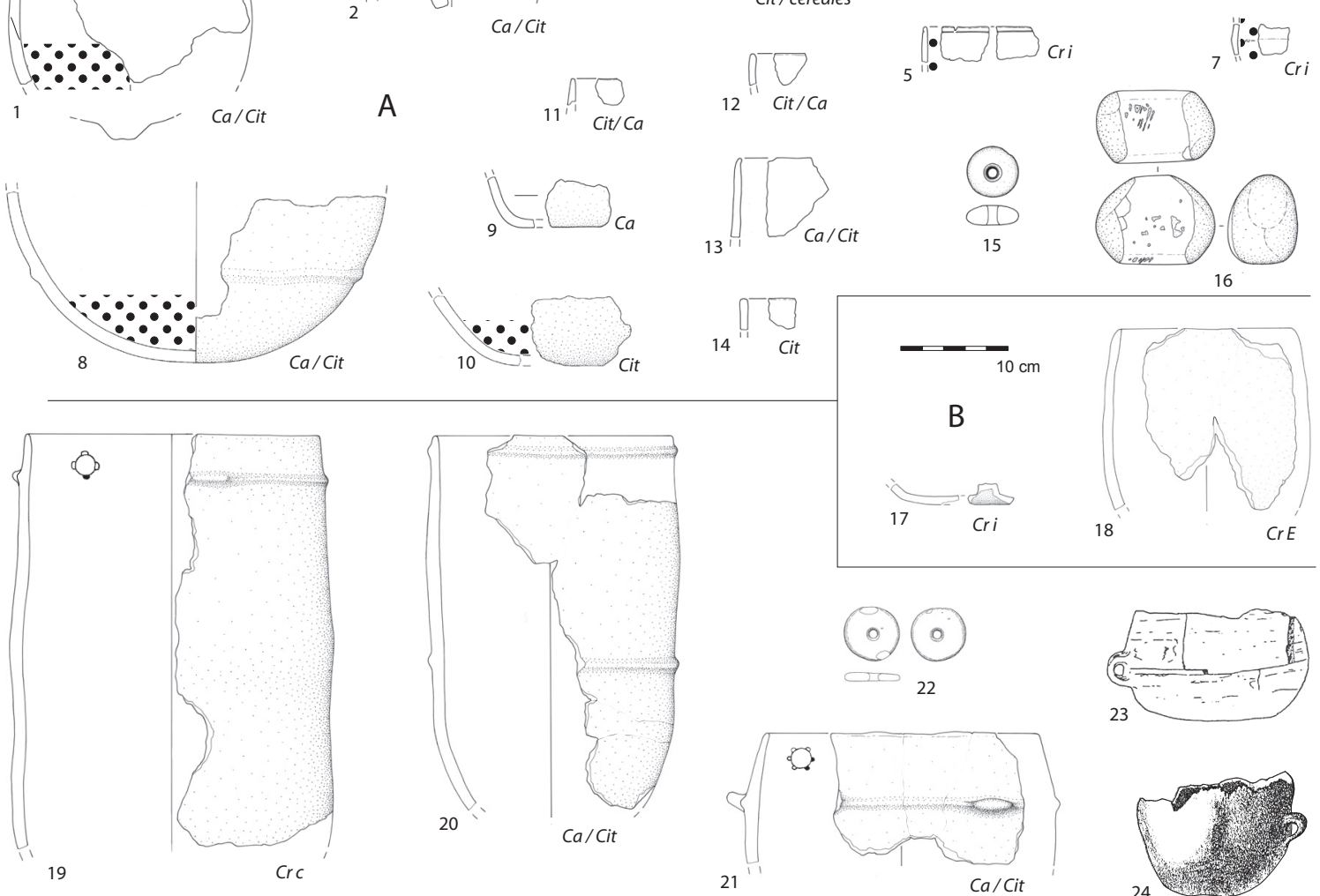

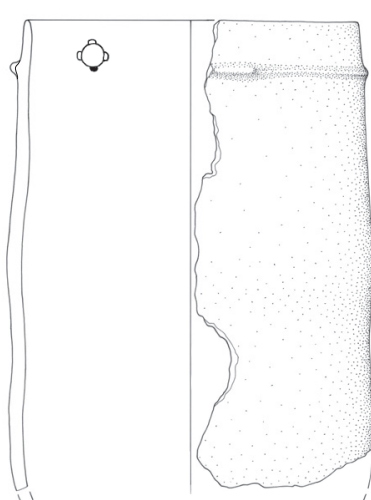

$\mathrm{CrC}$
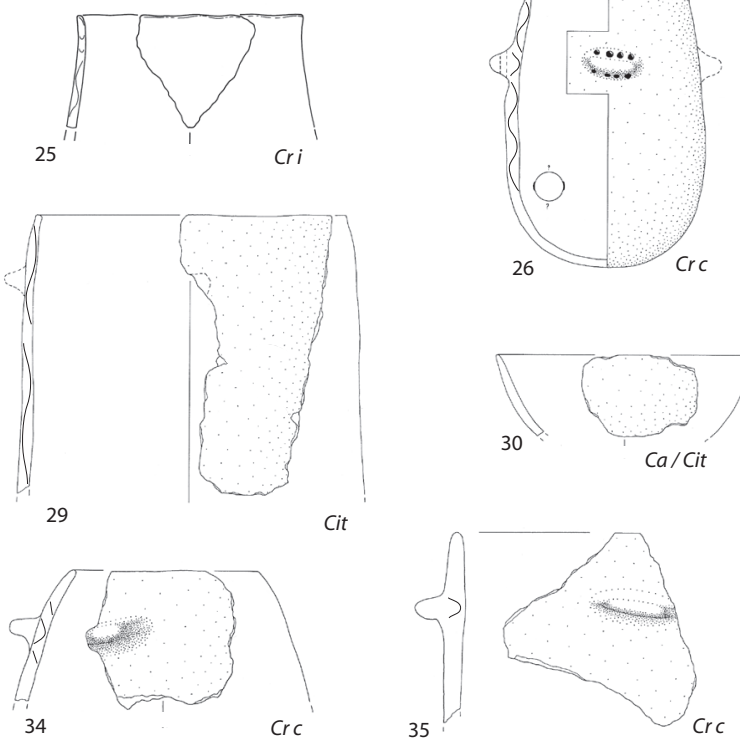
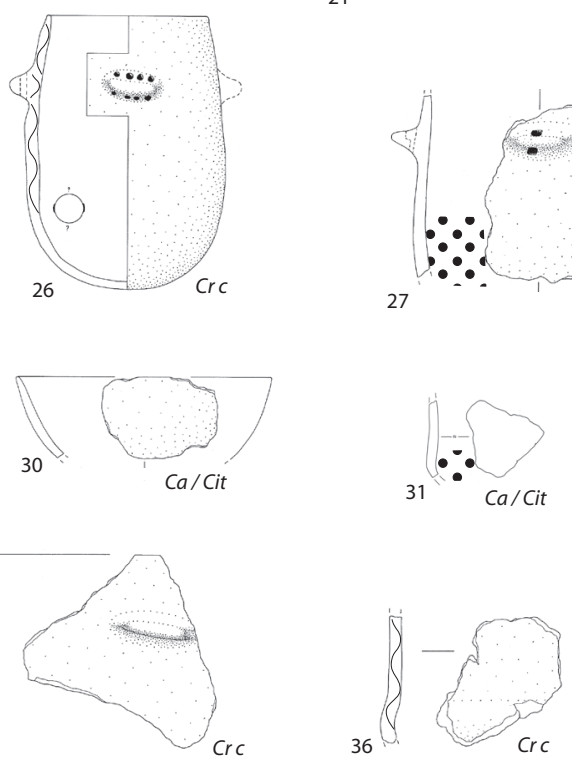
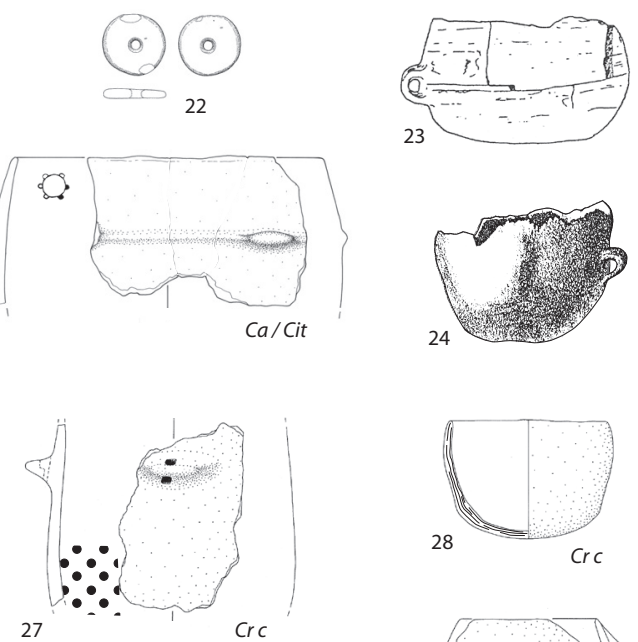

C
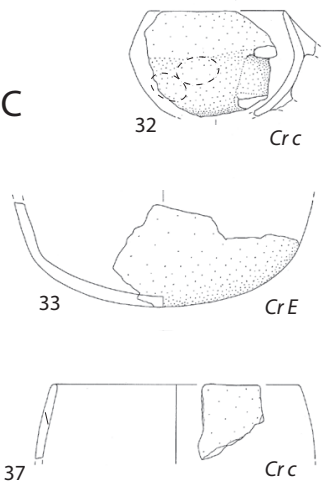

Fig. 18 - Céramiques, fusaïoles en terre cuite $\left(n^{\circ} 15\right)$ ou en pierre $\left(n^{\circ} 22\right)$, percuteur $\left(n^{\circ} 16\right)$ et récipients en bois $\left(n^{\circ s} 23-24\right)$ livrés par les sites contemporains du lac du Bourget. A : Tresserve, les Bourres; B : Brison-Saint-Innocent, Sous-le-Four; C : Brison-Saint-Innocent, Mémars (19 à 23 : plongées de R. Laurent entre 1950 et 1970; 24 : dragages du XIX ${ }^{e}$ siècle; 25 : plongées de R. Castel en $1980 ; 26$ à 37 : interventions du CNRAS en 1982 et 1995-1996). Les abréviations décrivent la nature des inclusions principales (voir légende sur la figure 17). La présence de résidus carbonisés est indiquée par une trame de points noirs (dessins P.-J. Rey sauf no 23 : Combier, 1959 , fig. 2, et $\mathrm{n}^{\circ} 24$ : Rabut, 1872, pl. II, $\mathrm{n}^{\circ} 3$ ).

Fig. 18 - Pottery, ceramic (no. 15) and stone (no. 22) spindles, hammerstone (no. 16) and wooden bowls (nos. 23-24) from the contemporary pile dwellings of Lake Bourget. A: Tresserve, Les Bourres; B: Brison-Saint-Innocent, Sous Le Four; C: Brison-Saint-Innocent, Mémars (nos. 19 to 23: dives by R. Laurent between 1950 and 1970; no. 24: dredging during the 19th century; no. 25: dive by R. Castel in 1980; nos. 26 to 37: interventions by the CNRAS in 1982 and 1995-1996). Abbreviations describe the nature of the main inclusions (see legend on figure 17). The presence of carbonized residues is indicated by a frame of black dots (drawings P.-J. Rey except no. 23: Combier, 1959, fig. 2, and no. 24: Rabut, 1872, pl. II, no. 3). 
et la fin du $\mathrm{XXVI}^{\mathrm{e}}$ siècle. Les meilleures comparaisons s'établissent avec le plateau Suisse et la moyenne vallée du Rhône. Les liens avec le Jura paraissent moins nets. Ce mobilier est probablement en partie légèrement antérieur aux phases d'abattages reconnues dans la première moitié du XXVI ${ }^{\mathrm{e}}$ siècle. Des influences méridionales sont également perceptibles, mais renvoient à des contextes moins bien datés. Les éventuelles occupations contemporaines du Campaniforme et de la phase ancienne du Bronze ancien, suggérées par le ${ }^{14} \mathrm{C}$ (dates uniques, non confirmées) ne semblent pas représentées de manière indiscutable dans le mobilier céramique.

\section{Les Bourres à Tresserve (Savoie)}

Dans la partie sud de la rive orientale du lac, le littoral communal de Tresserve a été totalement prospecté en 1999. Plus étroite dans la partie nord du secteur $( \pm 100 \mathrm{~m})$, la plateforme sous-lacustre s'élargit considérablement dans la moitié sud $( \pm 400 \mathrm{~m})$. À hauteur de ce changement marqué de la topographie, des vestiges néolithiques inédits ont été identifiés, à environ $130 \mathrm{~m}$ du bord (profondeur moyenne $-3,8 \mathrm{~m}$ ). Deux triangles de $10 \mathrm{~m}^{2}$ ont été implantés aux extrémités d'un axe longitudinal parallèle au rivage actuel (longueur $74 \mathrm{~m}$ ). Au sud (profondeur $-3,9 \mathrm{~m}$ ), onze pieux de chêne ont été prélevés et analysés en dendrochronologie. Une courte séquence de vingt-huit ans (9002TVB) n'a pu être datée en absolu. Le calage par le ${ }^{14} \mathrm{C}$ de l'échantillon $\mathrm{n}^{\circ} 10$, intégré à cette séquence, permet de la situer au Néolithique final : Arc.1987 : $4095 \pm 45$ BP, soit entre -2871 et -2494 cal. BC. Un autre chêne de ce secteur a fait l'objet d'un nouveau calage par $1{ }^{14} \mathrm{C}$. L'âge obtenu est très voisin du premier résultat : Arc.2133 : 4205 $\pm 50 \mathrm{BP}$, soit entre -2907 et -2631 cal. BC. Une nouvelle analyse a été réalisée sur des échantillons provenant du triangle nord (profondeur $-3,3 \mathrm{~m}$ ). Ici, les piquets sont plus petits (diamètre de 6 à $12 \mathrm{~cm}$ ). Les bois sont souvent épannelés, ce qui a fait disparaître l'aubier et le dernier cerne de croissance. Malgré leur différence morphologique, ces bois semblent bien être contemporains de ceux du secteur sud: Arc. $2199: 4155 \pm 50$ BP, soit entre -2885 et -2582 cal. BC. Les carottages implantés perpendiculairement au point central de l'axe ont montré l'existence de dépôts organiques préservés sur une vingtaine de centimètres d'épaisseur. Des amoncellements de galets formant ténevière sont apparents sur une trentaine de mètres de largeur (Marguet, 2003, p. 117).

Un petit lot de mobilier a été prélevé lors du dévasage des triangles; il provient de la surface des dépôts organiques. Une compaction de plusieurs phases n'est donc pas exclue et son homogénéité ne peut être considérée comme certaine. Une première datation sur résidu carbonisé réalisée sur le fond de grande jarre à cordon (fig. 18, $\mathrm{n}^{\circ} 8$ ) a d'ailleurs livré un résultat plus récent (Poz.70518: $3955 \pm 35 \mathrm{BP}$, soit entre -2572 et $-2342 \mathrm{cal}$. BC) qui indique l'existence de plusieurs phases d'occupations.

Le mobilier céramique recueilli comprend :

- deux petits pots, l'un cylindrique, l'autre à paroi légèrement convergente, dotés de languettes horizontales sous le bord (fig. 18, $\mathrm{n}^{\text {os }} 1$ et 2 ). L'une des languettes présente une ligne incisée peut-être accidentelle qui souligne sa base, l'autre est très légèrement impressionnée;

- plusieurs fragments de très grandes jarres à cordons lisses très peu proéminents (fig. $18, \mathrm{n}^{\text {os }} 3,4$ et 8 ). L'une présente de fines cannelures sans orientation nette, visibles sur une panse polie, dont il est difficile cependant d'affirmer le caractère intentionnel ;

- des fonds ronds ou aplatis (fig. 18, $\mathrm{n}^{\text {os }} 8$ à 10).

Les inclusions carbonatées sont très majoritairement employées. Elles sont constituées de calcaire et de calcite pilés, généralement associés. L'usage d'éléments cristallins concerne seulement trois fragments de récipients dont l'un porte un décor incisé.

Les quelques vases restituables graphiquement sont assez comparables aux récipients découverts à Conjux 3, dans le Jura ou en Suisse entre le XXIX $^{\mathrm{e}}$ et la fin du $\mathrm{XXVI}^{\mathrm{e}}$ siècle, mais n'apportent guère de précision chronologique. Deux fragments de récipients à carène peu marquée (fig. 18, nos 6 et 7) ne sont pas totalement surprenants durant toute cette période, mais pourraient appartenir à des occupations assez tardives, sous influences méridionales. Enfin, un bord fin doté d'une ligne horizontale profondément incisée sur la paroi externe, sous la lèvre du vase (fig. $18, \mathrm{n}^{\circ} 5$ ) reste relativement difficile à comparer. Des lignes multiples et rapprochées, disposées sur des bords plus affinés et souvent légèrement rentrants, sont fréquentes dans le Horgen. Elles apparaissent encore ponctuellement sur des bords plus arrondis dans le Lüscherz récent, par exemple à Portalban II, Delley-Portalban, Fribourg, Suisse (Giligny et Michel, 1995, fig. 7, n 14). La rainure horizontale unique est connue dans le Horgen de Platzbünden, Muntelier, Fribourg, Suisse (Ramseyer et Michel, 1990, pl. 11). Une occurrence moins convaincante existe également à Chamboud, Montalieu-Vercieu, Isère, sur un vase orné de chevrons incisés (Chastel et Voruz, 1988, fig. 16, no 10 ) qui a été rapproché de l'Auvernier-Cordé. L'emploi d'inclusions cristallines dans le tesson de Tresserve est assez cohérent avec les influences plutôt septentrionales qui viennent d'être évoquées.

\section{Angon à Talloires (Haute-Savoie)}

Sur la rive orientale du lac d'Annecy, au pied du versant ouest des Dents de Lanfon, la morphologie de la beine littorale est fortement façonnée par le cône alluvial formé par le Nant d'Oy. Les remblaiements récents ont diminué la largeur de la plateforme littorale, réduite ici à $25 \mathrm{~m}$ environ. Le gisement néolithique s'étend parallèlement au rivage, sur $180 \mathrm{~m}$ de long et $20 \mathrm{~m}$ de large. Le CNRAS est intervenu en 1986 dans la partie sud-est de ce cône, à environ 160 m de l'embouchure actuelle du ruisseau. À cette occasion, un niveau organique préservé de l'érosion a été mis en évidence sur une étroite bande, en limite de la plateforme. Fouillé sur une faible surface $\left(2 \mathrm{~m}^{2}\right)$, il a livré quelques tessons de poteries, deux fusaïoles en pierre calcaire, une armature de flèche losangique en silex et des fragments de faune (Marguet et al. 1995, p. 193). Cinquante-quatre bois ont été positionnés sur $140 \mathrm{~m}^{2}$, à l'est du site. Les analyses dendrochronologiques 
ont permis la constitution d'une séquence (9004AGQ) qui montre deux périodes d'abattage, dans les années - 2446 et $-2435 / 2434$. En avril 2001, un triangle de $10 \mathrm{~m}^{2}$ a été implanté au nord du gisement, en limite du tombant, à une vingtaine de mètres du rivage et à $80 \mathrm{~m}$ du sondage de 1986 (profondeur $-2,3 \mathrm{~m}$ ). La reprise de l'étude dendrochronologique des premières analyses a permis la datation d'un échantillon du secteur sondé en 1986 (9005AG); ce pieu marquerait une phase d'occupation plus ancienne du gisement, vers - 2582 (Marguet, 2002, p. 128). La corrélation entre les mobiliers prélevés et les différents bois datés étant mal assurée, des datations ${ }^{14} \mathrm{C}$ ont été tentées sur plusieurs échantillons issus du niveau organique. Une première analyse effectuée sur matière organique a livré un résultat compatible avec les résultats dendrochronologiques : Gif.8145 : $3910 \pm 50$ BP, soit entre -2565 et -2209 cal. BC. Une seconde analyse réalisée sur un résidu carbonisé prélevé sur un petit tesson donne une fourchette nettement plus ancienne : Poz. 70517 : $4330 \pm 35$ BP, soit entre -3078 et -2890 cal. BC, cohérente avec la typologie de l'armature en silex. Le calage chronologique et l'homogénéité du petit lot de mobilier prélevé en 1986 restent donc incertains.

\section{INSERTION DANS LE CONTEXTE RÉGIONAL}

\section{Les paramètres techniques}

Seules les inclusions ont pu être observées systématiquement sur les séries issues des rives des lacs du Bourget et d'Annecy. La situation est très contrastée sur le Bourget, où l'on observe une nette différence entre Conjux 3 au nord, où l'emploi d'inclusions cristallines est presque exclusif et les Bourres au sud, où dominent les inclusions carbonatées, très fréquemment constituées de calcite pilée. Le site de Mémars 1, en position intermédiaire, montre une représentation plus équilibrée des deux techniques avec cependant une majorité d'inclusions cristallines concassées issues d'une roche qui diffère légèrement de celle utilisée à Conjux. Elle contient également des particules micacées qui indiquent qu'il pourrait s'agir d'une autre variété de roche granitique. En Haute-Savoie, les rares vestiges céramiques issus de trois sites du lac d'Annecy présentent presque exclusivement des inclusions de calcite pilée (tabl. 4). Au Port 1 à Annecy et à Vieugy - Sous-les-Guerres à Veyrier-du-Lac, la typologie des vestiges découverts anciennement ne permet pas d'écarter la possibilité d'une occupation du Bronze ancien.

L'emploi d'inclusions cristallines est très majoritaire sur le plateau Suisse durant tout le Néolithique final (Rodot et Martineau, 2007), avec une présence minoritaire de la chamotte. Lorsque la nature des inclusions cristallines est précisée, il s'agit le plus souvent d'une roche granitique (Di Pierro, 2002). Cette pratique trouve sa source dans les occupations antérieures du Horgen et présente une très forte stabilité sur le plateau Suisse, ce qui permet de la considérer comme une véritable régula- rité culturelle (Rodot et al., 2006). À l'intérieur des Alpes, vers les $\mathrm{XXVII}^{\mathrm{e}}-\mathrm{XXVI}^{\mathrm{e}}$ siècles, l'ensemble Néolithique final supérieur de la grotte des Balmes à Sollières-Sardières, présente des connexions morphologiques avec l'Auvernier-Cordé et des inclusions constituées de matériaux cristallins locaux (Vital et Benamour, dir., 2012).

Dans le Jura, après la phase initiale du Clairvaux ancien, les inclusions cristallines sont très peu utilisées (Pétrequin et Rossy, 1997; Rodot et Martineau, 2007). Dans le Clairvaux récent et le groupe de Chalain, la présence d'inclusions carbonatées ou parfois l'absence d'inclusions ajoutées caractérisent la plupart des céramiques observées. Par ailleurs à Charavines, sur quarante-huit récipients en céramique grossière et fine analysés, quarante-six contiennent des inclusions cristallines (Benghezal, 1994, p. 72). L'observation d'une certaine hétérogénéité permet de supposer l'emploi de sable, dans une proportion qui ne peut être précisée.

Dans le Néolithique final du Sud-Est de la France, l'emploi de calcite pilée est très fréquent (Convertini, 1998). Cette pratique est presque exclusive en basse Provence alors que la situation de la moyenne vallée du Rhône reste mal connue (Cauliez et al., 2011). Les travaux de Fabien Convertini tendent à accorder une valeur culturelle au choix du dégraissant dans la sphère méridionale.

Enfin, au Bronze ancien, l'utilisation d'inclusions carbonatées est une pratique très fréquente dans le contexte régional, sur les sites des piémonts comme dans les gisements des vallées internes, par exemple à la grotte des Balmes (Vital et al., 2012).

Le montage aux colombins à plans de joint obliques alternés est très fréquent dans le Jura au cours du Clairvaux ancien et récent. À Conjux 3, le lissage aux fibres végétales des surfaces internes fait ressortir les inclusions et a pour effet de rendre les parois particulièrement rugueuses. Cette technique, qui a peut-être une justification utilitaire, n'a pas été identifiée dans le Jura. Le lissage sur pâte plastique dure employé sur les parois externes des jarres, semble davantage mis en œuvre à Conjux 3 que sur les sites jurassien. Il est vraisemblablement bien représenté sur les autres sites du Bourget (fig. 18) mais l'altération plus importante des surfaces ne permet pas de certitude. Le brunissage sur pâte à consistance cuir est extrêmement employé dans le Ferrières ardéchois (Martineau, 2000, p. 231; Martineau, 2004) mais aussi ailleurs dans le Midi. Les surfaces traitées par brunissage ou par la réalisation de polis sans traces sont plus fréquentes à Conjux que dans les séquences jurassiennes postérieures au XXXI ${ }^{\mathrm{e}}$ siècle.

Si le mode de pose des colombins observé à Conjux paraît donc partagé avec les sites de la Combe d'Ain, les techniques de traitement des surfaces semblent présenter des différences parfois importantes.

\section{Les paramètres morphologiques et les décors}

\section{Les ensembles du niveau 2}

Les jarres à cordons lisses multiples (fig. 9 et 10) sont fréquentes dans les mobiliers du Ferrières central 
et du groupe caussenard des Treilles. Particulièrement nombreuses également dans le Jura, elles caractérisent la phase récente du groupe de Clairvaux datée des XXIX ${ }^{\mathrm{e}}$ et XXVIII ${ }^{\mathrm{e}}$ siècles (Giligny et al., 1995), en association avec des jarres à cannelures. On les retrouve localement aux Bourres et à Mémars 1 (fig. 18), supportant des languettes horizontales sur ce dernier site. Ces grandes jarres à cordons associés à des languettes horizontales existent également sur le Léman et le plateau Suisse, dans des ensembles attribués au Lüscherz, Vers l'Église à Morges (Corboud et Pugin, 1992, pl. 1) et dans les complexes 1 à 3 de l'Avenue des Sports à Yverdon-les-Bains, depuis - 2760 et jusque vers la fin du XXVIII ${ }^{\mathrm{e}}$ siècle (Wolf, 1993 pl. 6-7 et 14-15). Elles existent à Barmaz I en Valais, sur des formes plus globuleuses, dans un ensemble qui livre également des jarres à cannelures (Honegger, 1995, fig. 40; Honegger, 2001, fig. 173), à la grotte des Balmes en Maurienne (Vital et Benamour, dir., 2012), à Balm'Chanto en Piémont (Nisbet et Biagi, 1987) et plus à l'est, dans les couches 41 à 38 de Via Decio Celeri, Lovere, Lombardie, Italie (Poggiani-Keller, 2000). Les meilleures comparaisons pour notre jarre cylindrique à cordons multiples (fig. 10, $\mathrm{n}^{\circ} 1$ ) s'établissent toutefois en direction du groupe des Treilles (Costantini, 1984) où la proéminence de ces appendices semble très importante avec une forte représentation de jarres cylindriques.

La jarre à languette installée sous le bord au-dessus d'un cordon lisse (fig. 10, $\mathrm{n}^{\circ} 4$ ) trouve également une comparaison avec une forme un peu plus évasée de la phase récente du groupe des Treilles (Costantini, 1984, fig. $\left.35 \mathrm{C}, \mathrm{n}^{\circ} 1\right)$ ou avec des récipients du début du groupe de Chalain, à Chalain station 2/3-5 niveau /5, Marigny, Jura (Giligny et al., 1995, fig. 20). Une forme rentrante, plus proche de notre exemplaire, apparaît en Provence, sur un site appartenant au style Plan de Saint-Jean (Cauliez, 2011, fig. 41), considéré toutefois comme nettement plus tardif.

La jarre à cordons multiples, panse en tonneau et col évasé (fig. 10, no 3 ) trouve peu de comparaisons dans le Jura. Une forme à cordon unique déjà citée, issue de Chalain station 2/3-5 niveau $/ 5$, est davantage sinueuse que segmentée, à l'inverse de l'exemplaire de Conjux 3. Un rapprochement peut être envisagé avec les productions de la phase ancienne de l'Auvernier-Cordé qui ne portent cependant que très rarement des cordons multiples lisses. Mentionnons pour l'exemple, un récipient plus sinueux, issu du complexe I de la Saunerie à Auvernier (Ramseyer, 1988, pl. 15, no 4), dont le calage dendrochronologique débute en -2634 , mais dont le matériel serait un peu plus précoce pour François Giligny et Robert Michel (Giligny et Michel, 1995, p. 356).

La raréfaction des cordons multiples au profit des cordons uniques sous le col, que l'on pressent entre les deux ensembles du niveau 2 de Conjux, correspond à une tendance forte sur le plateau Suisse comme dans le Jura (Pétrequin et al., 1988; fig. 17-18; Wolf, 1993). La jarre à panse en tonneau et cordon unique sous un bord droit (fig. 10, $\mathrm{n}^{\circ} 19$ ) trouve des comparaisons incomplètement satisfaisantes dans la phase moyenne (Wolf, 1993, pl. 33, $\mathrm{n}^{\circ} 3$ et pl. 47, $\mathrm{n}^{\circ} 7$ ) ou le début de la phase tardive (Wolf, 1993, pl. 59, no 3) de l'Auvernier-Cordé de l'Avenue des Sports à Yverdon-les-Bains.

Les cordons de Conjux 3 sont généralement très proéminents. Leur épaisseur est supérieure à l'épaisseur de la paroi du récipient. Un seul fragment de cordon peu saillant dont la continuité n'est d'ailleurs pas assurée, provient du niveau 2 sup (fig. $10, \mathrm{n}^{\circ} 11$ ). Ces cordons très proéminents trouvent de bons parallèles dans le groupe des Treilles. Localement, les éléments plastiques de Mémars 1 ou des Bourres se caractérisent plutôt par la fréquence des cordons peu saillants. Les deux sortes de cordons paraissent associées dans toute la séquence jurassienne (Giligny et al., 1995), même si les types proéminents semblent surtout présents dans les complexes les plus anciens de l'Avenue des Sports (Wolf, 1993). Les sites alpins de comparaison livrent par contre surtout des cordons peu saillants, pour autant que l'on puisse en juger sur les dessins publiés (Barmaz I; grotte des Balmes; Balm'Chanto et Via Decio Celeri). Enfin, dans le Fontbouisse, la grande majorité des cordons lisses semblent très peu proéminents (Gutherz et Jallot, 1995).

Les cordons très saillants de Conjux 3 s'inscrivent donc plutôt dans une ambiance méridionale, assez précoce, mais sont également bien représentés dans l'aire helvético-jurassienne.

Les lèvres impressionnées se rencontrent ponctuellement dans les séries méridionales de la première moitié du III ${ }^{e}$ millénaire. On en connaît plusieurs sur le site de la Roquette à Tresques (Georjon et al., 1999, fig. 22) mais il s'agit, pour la moitié d'entre eux, d'impressions digitales. La céramique peu décorée de ce site se placerait entre le Ferrières et le Fontbouisse. Les lèvres ornées d'impressions apparaissent assez ponctuellement dans les groupes de la moyenne vallée du Rhône : Allan, Bruyères (Beeching, 1980; Gilles, 1975). Elles sont par contre assez fréquentes dans le Fontbouisse ardéchois à Beaussement c3, Chauzon, Ardèche (Montjardin, 1992, fig. 33, n 1).

Ce type de décor est très discret dans les séries numériquement importantes des Baigneurs à Charavines. Une jarre du niveau inférieur présente une lèvre finement scandée par des impressions très rapprochées. Un bord droit profondément encoché est connu dans le niveau supérieur appartenant à un récipient de très grand diamètre (Ferrer-Joly, 2005, pl. 18, n 1).

En Italie du Nord, les lèvres impressionnées apparaissent dès la fin du Néolithique moyen dans les faciès Chassey-Lagozza (Bernabo Brea et al., 2002) et restent bien présentes au Néolithique final (Barfield et al., 2002; Poggiani Keller et al., 2002). Elles ne sont cependant pas connues sur les sites alpins de la grotte des Balmes en Maurienne et de Balm'Chanto en Piémont, qui pourraient servir de relais géographiques.

Plus au nord, les lèvres impressionnées semblent absentes dans le Jura. Elles apparaissent ponctuellement dans la phase ancienne et moyenne de l'Auvernier-Cordé (Giligny et Michel, 1995, fig. 11-12). Elles deviennent bien plus fréquentes à partir du début de la phase tardive de cette culture vers 2630 av. n. è. Elles se retrouvent 
surtout sur des vases à profil en $\mathrm{S}$, mais on en connaît aussi sur des jarres cylindriques dans le complexe I de la Saunerie à Auvernier, datée de la seconde moitié du XXVII ${ }^{\mathrm{e}}$ siècle (Ramseyer, 1988; Giligny et Michel, 1995, p. 356). C'est probablement dans cette direction qu'il faut chercher les meilleures comparaisons pour les fines incisions qui ornent la lèvre d'une grande jarre en tonneau de Conjux 3, niv. 2sup. Les coups d'outils plus appuyés observés sur la lèvre d'une jarre cylindrique constitueraient plutôt un caractère d'origine méridionale.

Les cordons lisses discontinus peu proéminents, à délimitation assez floue (fig. $10, \mathrm{n}^{\text {os }} 6$ et 12 ), sont malheureusement souvent difficiles à identifier sur les dessins publiés. Une bonne comparaison existe à Balm'Chanto, dans un ensemble à cordons lisses peu proéminents et parfois multiples (Nisbet et Biagi, 1987, fig. 21-P10). On rencontre également des éléments plastiques apparentés à Chalain 3 niv. IIc/ (Giligny et al., 1995, fig. 6), dans un ensemble plus ancien que notre niveau 2 sup. Ces éléments sont peu fréquents mais existent dans le Fontbouisse caussenard, dans la grotte de Bramabiau, SaintSauveur-des-Pourcils, Gard, par exemple (Gutherz et Jallot 1995, fig. 14E).

Les mamelons disposés en symétrie ternaire (fig. 9, $\mathrm{n}^{\circ}$ 1) sont fréquents dans le Clairvaux ancien de Chalain 2 AC niveau C (Giligny et al., 1995, fig. 7-8). Ils semblent absents ensuite dans la phase récente du Clairvaux. On les rencontre par contre sur le plateau Suisse, dans le Lüscherz récent aux Bains des Dames à Saint-Blaise (Giligny et Michel, 1995, fig. 8). Les dessins publiés ne permettent pas de retrouver la forme particulière de nos languettes.

La petite jarre cylindrique à languette courte proche du bord (fig. 9, $\mathrm{n}^{\circ} 2$ ), trouve des comparaisons un peu plus volumineuses, non datées cependant, à la grotte de la Balme, à La Balme-les-Grottes (Bocquet et Reymond, 2007), ainsi que dans le Lüscherz récent aux Bains des Dames (Giligny et Michel, 1995, fig. 8).

Le fragment de bord profondément encoché et le fond plat (fig. $9, \mathrm{n}^{\text {os }} 8$ et 25 ) constituent deux éléments isolés de petite taille dont le rattachement stratigraphique est moins sûr. Les fonds plats sont fréquents sur le plateau Suisse, dans les ensembles soumis à l'influence cordée bien marquée après 2700 av. n. è. Ce caractère semble cependant apparaître plus précocement, de manière discrète. Quelques fonds plats sont connus au Pont de Thielle, Thielle-Wavre, Neuchâtel, Suisse (Schwab, 1999, fig. 27), sur un site dont les phases d'abattages se répartissent entre - 2789 et -2736 . On en rencontre également dans le complexe 3 de l'Avenue des Sports à Yverdon-les-Bains, à partir de 2730 av. n. è. (Wolf, 1993, pl. 16).

Des languettes très proéminentes non perforées sont fréquentes dans le groupe de Chalain, en particulier à Chalain 2/3-5 niveau /3 (Giligny et al., 1995, fig. 23) mais aussi aux Baigneurs à Charavines, où l'on retrouve les languettes rectangulaires ou trapézoïdales (FerrerJoly, 2005, pl. 9, no 6, pl. 11, no 1 , pl. 15, n 1 et pl. 24, $\mathrm{n}^{\circ} 1$, par exemple) et les languettes à embase ovale et extrémités circulaires (Ferrer-Joly, 2005, pl. 17, no 4 et pl. 20, no 3 ) qui se rencontrent dans notre ensemble 2sup.
Les préhensions proéminentes rectangulaires sont également bien représentées dans le Néolithique final inférieur de la Chauve-Souris à Donzère (Vital, 2006, fig. 12, nº 6) et dans le groupe médio-rhodanien des Bruyères (Gilles, 1975, fig. 13 et 14).

Les pots tronconiques à inflexion basse marquée (fig. $9, \mathrm{n}^{\circ} 3$ et fig. 10, no 2) trouvent de bonnes comparaisons dans le Néolithique final inférieur de la ChauveSouris (Vital, 2006, fig. 12, n ${ }^{\text {os }} 3$ et 12) et dans la première occupation des Baigneurs (Ferrer-Joly, 2005, pl. 7 et 9). Le brunissage soigné du second de nos exemplaires pourrait également évoquer des productions plus méridionales, comme celles de la Roquette à Tresques par exemple (Georjon et al., 1999, fig. 17, nº 4).

Le petit pot globuleux à ouverture légèrement rentrante et languette horizontale sous le bord du niveau $2 \mathrm{inf}$ (fig. 9, $\mathrm{n}^{\circ}$ 6) se retrouve dans le Lüscherz récent de l'Avenue des Sports (Wolf, 1993, pl. 4, n 1), mais apparaît également sur le même site au début de la phase moyenne de l'Auvernier-Cordé (Wolf, 1993, pl. 27, nº 15).

Le cordon peu proéminent, légèrement impressionné au doigt (fig. 10, n ${ }^{\circ} 7$ ) trouve une bonne comparaison à Barmaz I (Honegger, 2001, fig. 173). Des décors apparentés sont également connus dans le Jura, dans le groupe de Clairvaux récent, et particulièrement nombreux dans la phase ancienne du groupe de Chalain. Mais les cordons sont plus proéminents et les digitations nettement plus appuyées dans les ensembles jurassiens (Pétrequin et al., 1988, fig. 19; Giligny et al., 1995, fig. 20).

Les bords de l'ensemble 2 inf sont toujours légèrement rentrants, alors que les bords de l'ensemble 2sup sont davantage verticaux et rectilignes. Une évolution tout à fait comparable intervient dans le Jura, entre le Clairvaux ancien et le début du groupe de Chalain (Pétrequin et al., 1988, fig. 12).

Le récipient à épaule et col resserré, probablement cuit en ambiance réductrice (fig. 10, $\mathrm{n}^{\circ} 23$ ), rattaché au niveau 2sup par le ${ }^{14} \mathrm{C}$, semble relever d'influences beaucoup plus lointaines. Des récipients apparentés qui existent en contexte Artenac, par exemple dans le niveau 9 de la grotte du Quéroy, Chazelles, Charente (Gomez et Laporte, 1990, fig. 18-5), semblent un peu plus anciens. $\mathrm{Au} \mathrm{XXVII}{ }^{\mathrm{e}}$ siècle, une comparaison existe à Chalain station 2/3-5 niveau 5 (Giligny et al., 1995, fig. 21) et des formes un peu plus nettement segmentées sont connues dans le niveau supérieur des Baigneurs à Charavines (Ferrer-Joly, 2005, pl. 13). On retrouve des récipients du même type au Patis II (Montboucher-sur-Jabron, Drôme) et à Beaussement c3 à Chauzon, (Vital, 2011). Ces récipients du Jura et de moyenne vallée du Rhône présentent des affinités avec les productions du Rinaldone d'Italie centrale. Des récipients inornés apparentés se rencontrent également en basse vallée du Rhône, en contexte Mourre du Tendre et Fontbouisse (Cauliez, 2011, fig. 32 et 33).

\section{L'ensemble du niveau 1}

La céramique du niveau 1 constitue un petit lot malheureusement assez fragmenté. Les formes cylindriques 
à languette horizontale sous le col sont tout à fait comparables à celles du site des Baigneurs ou du groupe de Chalain. Les fonds ronds se retrouvent dans les deux groupes même s'ils ne sont pas prépondérants à Chalain.

Le petit bol à bord légèrement rentrant, fond aplati et mamelons (fig. 11, $\mathrm{n}^{\circ} 5$ ) est difficile à comparer. Un récipient morphologiquement proche mais deux fois plus volumineux existe dans le niveau supérieur des Baigneurs. Le Néolithique final provençal de style Couronnien présente quelques bols à bord redressé mais à fond rond, moins profonds et sans mamelon (Courtin, 1974, fig. 64). Il pourrait être tentant d'évoquer une parenté avec les coupes à bord rentrant qui attestent de contacts avec l'Italie du Nord sur plusieurs sites de la moyenne vallée du Rhône (Vital, 2006 et 2011). Dans cette hypothèse, ce récipient pourrait s'inscrire dans le même courant d'influences que les bouteilles du niveau supérieur des Baigneurs ou de la Chauve-Souris (Vital, 2006, fig. 12, no 11 et fig. 13, no 16). L'exemplaire de Conjux 3 paraît cependant trop irrégulier et doté d'un bord trop peu rentrant pour être parfaitement convaincant dans ce rôle, bien que quelques comparaisons existent en Italie centrale (Cocchi Genick, 2008, fig. 30, $\mathrm{n}^{\circ}$ 91B et fig. $\left.63, \mathrm{n}^{\circ} 272 \mathrm{C}\right)$.

La multiplication des préhensions perforées après 2700 av. n. è. est une tendance générale sur le plateau Suisse et dans le Jura (Pétrequin et al., 1988; Giligny et Michel, 1995). Des appendices multiforés se rencontrent dès le niveau inférieur des Baigneurs à Charavines, mais restent relativement discrets. La languette rectangulaire monoperforée (fig. 11, n ${ }^{\circ}$ ) ne trouve pas de comparaisons directes dans l'aire septentrionale. On la rencontre par contre dans l'ensemble inférieur des Baigneurs, avec un contour triangulaire (Ferrer-Joly, 2005, pl. 9, no 5) et dans le Fontbouisse caussenard de l'aven des Corneilles, Prades, Lozère (Gutherz et Jallot, 1995, fig. 14A). Elle existe dans le style tardi-Ferrières des Vautes, sur le site éponyme de Saint-Gély-du-Fesc, Hérault (Timsit et Escallon, 2003, fig. 13, no 2) mais il s'agit plutôt d'une anse horizontale en boudin. Une languette rectangulaire monoforée verticalement se rencontre localement sur le site voisin de Mémars 1 (fig. 16, n 27), malheureusement sans contexte stratigraphique.

Les cols concaves à paroi mince (fig. $11, \mathrm{n}^{\text {os }} 10$ et 11 ) ne trouvent que peu de comparaisons dans les céramiques de Charavines. Des cols de ce type existent assez ponctuellement sur le plateau Suisse, dans l'Auvernier-Cordé moyen-tardif de Portalban II à Delley-Portalban (Ramseyer, 1987, fig. 39) et dans le Jura, dans le groupe de Chalain (Giligny et al., 1995, fig. 27). Mais la fragmentation de nos céramiques interdit d'aller plus loin dans les comparaisons.

\section{Synthèse des observations sur Conjux 3}

Le premier ensemble de Conjux 3 se place au début du $\mathrm{III}^{\mathrm{e}}$ millénaire, dans une période marquée par un phénomène de régionalisation des influences méridionales. Ces évolutions se traduisent par le développement du Clair- vaux récent dans le Jura et du Lüscherz, en léger décalage, dans la région des Trois-Lacs. En moyenne vallée du Rhône, prennent place des ensembles inornés assez différents morphologiquement (Beeching, 2002; Vital, 2006 et 2012).

L'ensemble 2inf de Conjux 3 constitue un intermédiaire entre les groupes de moyenne vallée du Rhône et le Lüscherz. L'absence de décor de cannelures rend les connexions avec le Jura moins évidentes, même s'il pourrait s'agir d'un problème d'échantillonnage. Des cannelures sont en effet connues dans les régions alpines à Barmaz I et peut-être à Saint-Saturnin, Saint-AlbanLeysse, Savoie (Rey, 2015, pl. 4, $\mathrm{n}^{\text {os }} 6$ et 7). Des contacts avec le Midi de la France sont cependant nettement perceptibles dans les jarres à cordons multiples, peut-être issues du groupe des Treilles, et dans des petits pots tronconiques, probablement originaires de la partie inférieure de la moyenne vallée du Rhône. Les traits techniques des céramiques de l'ensemble 2inf évoquent bien les deux pôles d'influences cités. D'une part, l'usage exclusif des inclusions cristallines et la forte proportion de granit concassé renvoient davantage au plateau Suisse qu'au Jura. D'autre part, l'importance des surfaces traitées par brunissage ou par la réalisation d'un poli sans traces, ainsi que la présence probable de récipients probablement cuits en ambiance réductrice, évoquent plutôt la sphère méridionale (Martineau, 2000). Les formes hautes plus ou moins cylindriques à languettes horizontales trouvent surtout des comparaisons sur le plateau Suisse et se retrouveront plus tard aux Baigneurs à Charavines. La faible fréquence des petites formes pourrait évoquer préférentiellement le plateau Suisse et le Jura où la vaisselle en bois prend la place de la terre cuite pour les récipients de petite dimension (Pétrequin et al., 1988), mais la superficie réduite du sondage et la fragmentation importante des récipients les plus petits ne permettent pas de trancher. Cette rareté des petites formes, mais aussi l'absence de lèvre amincie et de décors pastillés, tranchent avec la composition des ensembles du Lüscherz ancien. Les connexions stylistiques et techniques de notre série semblent davantage orientées en direction du Lüscherz récent. La présence d'une ébauche de fusaïole plate en pierre nous livre un autre élément de chronologie. Ces modèles apparaissent au XXIX ${ }^{\mathrm{e}}$ siècle en Suisse occidentale, dans le Lüscherz, et se multiplient nettement dans l'Auvernier-Cordé, après 2750 av. n. è. (Pétrequin et al., 2006).

Le mobilier de l'ensemble 2sup semble recevoir un nouvel influx septentrional, vraisemblablement issu de la phase ancienne de l'Auvernier-Cordé du plateau Suisse, perceptible dans les formes et décors de la céramique (formes en tonneau à col droit ou éversé, lèvre finement impressionnée à l'outil), comme dans les traits techniques (accroissement de l'usage de roche cristalline concassée, baisse de la fréquence des récipients cuits en ambiance réductrice). Conformément à la position géographique de Conjux, les influences septentrionales paraissent un peu plus marquées dans notre niveau 2 sup que sur le site contemporain de Charavines. Le maintien d'un taux élevé 
de traitement soigné des surfaces par brunissage ou par la réalisation de polis sans traces ainsi que la présence d'un bord profondément encoché attestent toutefois de la persistance des liens avec le monde méridional. Par ailleurs un petit décor impressionné sur cordon évoque davantage les décors peu marqués de Barmaz I en Valais que les digitations très appuyées qui connaissent une grande vogue dans le groupe de Chalain (Giligny et al., 1995). Enfin, la présence d'un récipient tronconique à carène haute et ouverture rétrécie pourrait suggérer des contacts avec l'Italie.

Bien que restreint, le petit lot de mobilier du niveau 1 ne s'inscrit plus dans la dynamique évolutive de l'Auvernier-Cordé, dont le développement se poursuit sur le plateau Suisse (Wolf, 1993; Giligny et Michel, 1995). Quelques comparaisons avec Charavines témoignent du développement d'un style local dans une ambiance plutôt méridionale. En parallèle, l'emploi d'inclusions de roche cristalline concassée diminue très nettement au profit du sable cristallin et l'utilisation d'inclusions carbonatées fait une timide apparition. L'emploi de la chamotte n'a pas été identifié mais sa distinction à l'œil nu reste difficile. Brunissage et polis sans traces demeurent fréquemment appliqués aux surfaces externes. La présence d'un petit récipient à bord légèrement rentrant pose la question d'une influence italienne, bien documentée au même moment en moyenne vallée du Rhône.

On notera l'absence d'éléments campaniformes dans notre niveau supérieur, même si un petit col évasé peut susciter quelques interrogations. Un pot trapu à inflexion basse, hors stratigraphie, pourrait aussi rappeler le gobelet inorné découvert à Balme Rousse à Choranche (Vital et Bintz, 1999, fig. 22, no 3).

L'absence de carène dans le niveau 1 de Conjux 3 constitue une différence avec les ensembles des Bourres et de Mémars 1, mais ceci est peut-être à mettre au compte de notre effectif très réduit et de l'absence, dans les Alpes du Nord française, de la phase ancienne des groupes apparentés au Fontbouisse. Dans les deux ensembles des Baigneurs à Charavines (Ferrer-Joly, 2005), les carènes restent globalement discrètes mais leur fréquence croit dans l'occupation la plus récente. Dans la stratigraphie de la Chauve-Souris, les éléments décorés Fontbouisse apparaissent tardivement, en décalage avec la diffusion plus précoce des formes inornées (Vital, 2006).

Ces comparaisons et ces observations sont davantage en adéquation avec les deux dates ${ }^{14} \mathrm{C}$ du niveau 1 plutôt qu'avec le calage dendrochronologique obtenu sur des bois verticaux. Les couches correspondant aux occupations les plus récentes ont vraisemblablement été totalement érodées. On rappellera pour mémoire la découverte hors contexte d'un gobelet campaniforme de style rhodano-provençal quasiment intact, à faible distance du site de Conjux 3 (Bocquet et al., 1987, fig. 2A).

De manière générale, les comparaisons évoquées pour les céramiques des trois ensembles de Conjux 3 sont tout à fait compatibles avec les intervalles proposés par la modélisation bayésienne.

\section{CONCLUSION}

T es ensembles de Conjux retracent plus de trois siècles d'évolutions stylistiques et techniques. Comme dans le Jura, les caractères techniques présentent des variations rapides qui semblent suivre la dynamique des influences culturelles. Malheureusement, le manque d'études détaillées en dehors des séries de Chalain et Clairvaux handicape pour l'instant l'analyse de nos observations. Seules les inclusions sont suffisamment souvent décrites dans les publications pour permettre d'avancer quelques hypothèses. Le choix préférentiel d'inclusions cristallines présente une remarquable stabilité dans toute la séquence de Conjux 3 et se rattache vraisemblablement à une tradition helvétique. La nature des inclusions varie cependant entre granit concassé et sable cristallin. À Conjux 3, l'usage d'un dégraissant de roche granitique concassée pourrait être directement corrélé à la vigueur des influx du plateau Suisse. Les traitements de surface présentent quelques différences par rapport aux sites jurassiens et aux quelques données disponibles sur le Ferrières ardéchois : fréquence plus élevée du lissage sur pâte plastique dure, lissage aux fibres végétales des surfaces internes.

Entre le début du XXIX ${ }^{e}$ et la première moitié du $\mathrm{XXVII}^{\mathrm{e}}$ siècle, dans une période marquée par la régionalisation des influences méridionales, l'ensemble 2inf de Conjux 3 témoigne de liens assez marqués avec le Lüscherz, vraisemblablement également perceptibles à Sous-le-Four, et pour lesquelles le site du Parc La Grange (Pugin et Corboud, 2006) offre un bon relais. Comme dans le Jura mais avec moins d'ampleur, des éléments issus du groupe des Treilles se surimposent à ce courant nord-sud.

D'après quelques formes et décors plastiques, un impact limité de la phase ancienne de l'AuvernierCordé (entre 2720 et 2630 av. n. è.) est perceptible dans l'ensemble 2sup de Conjux 3. Cela coïncide assez bien avec l'intervalle proposé par la modélisation bayésienne (entre le milieu du XXVIII ${ }^{\mathrm{e}}$ et le premier tiers du XXVI ${ }^{\mathrm{e}}$ siècle). L'extension des influences du Cordé semble donc atteindre le nord du Bourget sans décalage chronologique important avec la région des Trois-Lacs sur le plateau Suisse. Dans la même fourchette chronologique, le site de de Charavines, installé $45 \mathrm{~km}$ plus au sud, montre davantage de liens avec la sphère méridionale. L'apparente réticence à l'acquisition des décors, qu'ils soient d'origine méridionale, jurassienne ou septentrionale, et l'emploi d'inclusions cristallines constituent des caractères partagés entre Conjux 3 et les Baigneurs à Charavines. L'ensemble 2sup de Conjux 3 reste cependant trop réduit pour apprécier parfaitement les relations et les écarts entre ces deux sites occupés simultanément.

Le petit ensemble du niveau 1 de Conjux 3, daté entre le début du XXVI et le milieu du XXV ${ }^{\mathrm{e}}$ siècle, paraît déconnecté de la dynamique helvétique et présente des affinités avec le niveau supérieur des Baigneurs. Il témoigne du développement d'un groupe local dans une ambiance davantage marquée par l'influx méridional. 
La séquence de Conjux décrit l'affaiblissement progressif des influences septentrionales dans la première moitié du $\mathrm{III}^{\mathrm{e}}$ millénaire. Aux fortes interactions qui existent pendant le Lüscherz récent succèdent des liens plus limités durant la phase ancienne de l'Auvernier-Cordé, puis une déconnexion assez claire, moins nette cependant dans les paramètres techniques. La montée en puissance des influences méridionales et italiennes, qui se lit à partir du XXvi ${ }^{\mathrm{e}}$ siècle dans la stratigraphie de la Chauve-Souris comme dans les deux ensembles successifs des Baigneurs, constitue vraisemblablement l'une des causes de cette évolution.

L'impact de l'Auvernier-Cordé dans les deux Savoie et le Dauphiné est probablement à réévaluer, en accord avec la stratigraphie de la grotte des Balmes à SollièresSardières et avec la multiplication des indices mobiliers autour des lacs d'Annecy et du Bourget. La céramique cordée n'est pas documentée sur le Léman, mais des ateliers de fabrication de haches-marteaux sont connus jusque sur les sites palafittiques genevois. Plus au sud, en Savoie et Dauphiné, on ne rencontre plus que des haches-marteaux achevées et isolées (Thirault, 2004, fig. 133). Connues à partir du XXIX ${ }^{\mathrm{e}}$ siècle en Suisse occidentale, dans le Lüscherz, les fusaïoles plates en pierre se multiplient nettement dès la phase ancienne de l'Auvernier-Cordé. La carte de ces artefacts montre une nette extension le long du Rhône et de la vallée de l'Isère (Pétrequin et al., 2006, fig. 24). Les découvertes sont relativement nombreuses sur les rives des lacs savoyards (inventaire dans Marguet et Rey, 2007). Un fragment de galet aplati découvert dans le niveau 2 inf de Conjux (fig. 9, $n^{\circ}$ 29) constitue vraisemblablement une ébauche d'un objet de ce type. L'ensemble Néolithique final supérieur de la grotte des Balmes, montre également des vestiges céramiques et deux fusaïoles plates en pierre qui témoignent de liens avec le domaine nordalpin (Vital et Benamour, dir., 2012). Il est possible que la résistance aux décors manifestée en moyenne vallée du Rhône vis à vis des cultures méridionales soit également à l'œuvre dans la réception des influences septentrionales, et qu'elle en occulte partiellement la lisibilité. La présence d'une céramique décorée de style cordé à Balme Rousse niveau B3 (Vital et Bintz, 1991, fig. 22, no 4), dans un contexte campaniforme un peu plus tardif, ne contredit pas cette proposition.

L'influence dans les Alpes du Nord des groupes jurassiens de Clairvaux récent et de Chalain nous semble plus difficile à percevoir dans l'état actuel des connaissances. Les documents publiés issus des couches 37 et 36 de la grotte du Gardon (Voruz et al., 2004; Boret, 2013) ne nous paraissent pas convaincants à cet égard et pourraient tout autant se placer dans une sphère Auvernier-Cordé incorporant des éléments méridionaux.

L'arrivée de traits stylistiques et techniques (emploi d'un dégraissant de calcite pilée) d'origine méridionale sur la rive sud-est du lac du Bourget et jusque sur les rives du lac d'Annecy montre la complexité des interactions culturelles et le rôle des grands axes géographiques (vallée du Rhône, sillon alpin). L'extension de l'usage de la calcite pilée est vraisemblablement à relier aux épisodes d'expansion des influences méridionales. Les données chrono- logiques restent encore rares : cette pratique est datée au $\mathrm{XXX}^{\mathrm{e}}$ siècle sur le lac d'Annecy, à Angon et entre le $\mathrm{XXVI}^{\mathrm{e}}$ et le milieu du XXIV ${ }^{\mathrm{e}}$ siècle au Bourget, sur le site des Bourres. De nouvelles datations sur des résidus carbonisés appartenant à ces deux gisements sont en cours pour confirmer ces premiers résultats. Enfin, à Mémars 1, l'emploi de la calcite n'est pas daté directement, mais pourrait être compatible avec les datations centrées sur le $\mathrm{XXVI}^{\mathrm{e}}$ siècle.

Dans les avant-pays, l'importance des influences septentrionales a été récemment mise en avant pour les Baigneurs, et au-delà pour l'ensemble des faciès inornés de moyenne vallée du Rhône (Cauliez 2011). Cette hypothèse reste cependant contestée (Vital et Benamour, dir., 2012). Sans permettre véritablement de conclure, l'étude de la céramique de Conjux 3 souligne la filiation septentrionale de l'usage des inclusions cristallines, bien représenté à Charavines.

La discussion de la géographie culturelle du Néolithique final reste donc ouverte en moyenne vallée du Rhône. Elle nécessitera la prise en compte d'autres catégories de mobilier et d'ensembles plus importants et, si possible, mieux datés que les petits lots livrés par Mémars 1, les Bourres et Angon. Du côté de la céramique, un réexamen stylistique et surtout technique des séries du Lyonnais, de moyenne vallée du Rhône et du site des Baigneurs à Charavines, paraît indispensable et prometteur à ce stade. Pour l'industrie lithique, l'étude des lots importants livrés par les deux sites du lac d'Aiguebelette permettrait également d'apporter assez rapidement des éléments nouveaux.

Remerciements : Les datations ${ }^{14} \mathrm{C}$ ont été subventionnées par le conseil général de la Savoie, par le DRASSM et sur les budgets du ministère de la Culture alloués à l'UMR 6249 "Chrono-environnement ». Les remontages céramiques ont été réalisés dans le cadre d'un contrat d'étude financé par le DRASSM. Une première version de cette étude a été présentée au colloque international " Autour du Petit-Chasseur », à Sion (Valais, Suisse), en octobre 2011. L'excellent accueil que nous a réservé Marie Besse, professeure à l'université de Genève, a largement contribué au bon achèvement de ce travail. Enfin la mise en œuvre de la modélisation bayésienne a bénéficié des conseils avisés de Thomas Perrin et la traduction du résumé en anglais a été effectuée par Laurie Tremblay-Cormier.

\section{NOTES}

(1) Ces travaux préliminaires avaient donné lieu à un premier calage des niveaux néolithiques par le ${ }^{14} \mathrm{C}:$ Ly.1325 : 3820 $\pm 140 \mathrm{BP}$, soit entre -2835 et $-1885 \mathrm{cal}$. BC (piquet 1 , niveau - 1,50 m); Ly.1323: $3970 \pm 140 \mathrm{BP}$, soit entre -2886 et -2062 cal. BC (solive b, niveau - 1,90 m); Ly.1324 : $3970 \pm 140$ BP, soit entre -2886 et -2062 cal. BC (clayonnage, niveau $-1,90 \mathrm{~m}$ ).

(2) À cette occasion fut découverte une tasse monoxyle dotée d'une préhension unique (Combier, 1959, fig. 2), assez proche d'un premier exemplaire signalé au XIX ${ }^{\mathrm{e}}$ siècle (Rabut, 1872, pl. II, no 3). Elle a été datée par le ${ }^{14} \mathrm{C}:$ Ly.190 : $4060 \pm 120 \mathrm{BP}$, soit entre -2905 et -2286 cal. BC. (voir fig. $18, \mathrm{n}^{\text {os }} 23$ et 24 ). 


\section{RÉFÉRENCES BIBLIOGRAPHIQUES}

Barfield H., Borrello M.-A., Buteux S., Ciaraldi M. (2002) - Scavi preistorici sulla Rocca di Manerba, Brescia, in A. Ferrari et P. Visentini (dir.), Il declino del mondo neolitico: ricerche in Italia centro-settentrionale fra aspetti peninsulari, occidentali e nord-alpini, actes du colloque (Pordenone, 5-7 avril 2001), Pordenone, Museo delle Scienze (Quaderni del Museo Archeologico del Friuli Occidentale, 4), p. 291-309.

BAudais D. (1995) - Le camp néolithique de Savièse, La Soie, in A. Gallay (dir.), Dans les Alpes, à l'aube du métal. Archéologie et bande dessinée, catalogue de l'exposition "Le Soleil des morts. Archéologie et bande dessinée » (Sion, septembre 1995-janvier 1996), Sion, Musées cantonaux du Valais, p. 91-96.

Beaume C. (1996) - Le site néolithique final de l'abri de la Véssignée, Saint-Marcel d'Ardèche, Ardèche archéologie, 13 , p. 36-44.

BeECHING A. (1980) - Introduction à l'étude des stades néolithique et chalcolithique dans le bassin du Rhône moyen : quatre fouilles récentes dans leur contexte régional, thèse de $3^{\text {e }}$ cycle, université Lyon 2, 3 vol.

Beeching A. 2002 - La fin du Chasséen et le Néolithique final dans le bassin du Rhône moyen, in A. Ferrari et P. Visentini (dir.), Il declino del mondo neolitico: ricerche in Italia centro-settentrionale fra aspetti peninsulari, occidentali e nord-alpini, actes du colloque (Pordenone, 5-7 avril 2001), Pordenone, Museo delle Scienze (Quaderni del Museo Archeologico del Friuli Occidentale, 4), p. 67-83.

Benghezal A. (1994) - Provenance et techniques de la céramique du Néolithique final de stations des trois lacs jurassiens (Suisse), thèse de doctorat, université de Fribourg (Suisse), $174 \mathrm{p}$.

Bernabo-Brea M., Catagna D., Cremona M.-G., Ferrari E., Maffi M., Mazzieri P., Occhi S. (2002) - Strutture e aspetti culturali dei siti Chassey-Lagozza nel Piacentino, in A. Ferrari et P. Visentini (dir.), Il declino del mondo neolitico: ricerche in Italia centro-settentrionale fra aspetti peninsulari, occidentali e nord-alpini, actes du colloque (Pordenone, 5-7 avril 2001), Pordenone, Museo delle Scienze (Quaderni del Museo Archeologico del Friuli Occidentale, 4), p. 379-402.

Bocquet A., dir. (2005) - Site néolithique de Charavines, les Baigneurs (Isère, France). Études scientifiques (19722005), Grenoble, Centre de documentation de la Préhistoire alpine, 10 vol., non paginés.

Bocquet A., Reymond J. (2007) - La Grotte de la Balme (La Balme-les-Grottes, Isère), d'un ossuaire au Néolithique moyen à un Champ d'urnes souterrain au Bronze final, in R. Desbrosse et A. Thévenin (dir.), Arts et cultures de la Préhistoire. Hommages à Henri Delporte, Paris, CTHS (Documents préhistoriques, 24), p. 237-271.

Bocquet A., avec la collab. de Ballet F., Bintz P., CAstel R. Ginestet J.-P. (1987) - Nouveaux témoins de la civilisation campaniforme dans les Alpes françaises du Nord, Bulletin d'études préhistoriques alpines, 19, p. 9-22.
Boret B. (2013) - La céramique du Néolithique final et du Bronze ancien : présentation typologique du mobilier des couches 37, 36, 34 et 33, in T. Perrin et J.-L. Voruz (dir.), La grotte du Gardon, II. Du Néolithique moyen II au Bronze ancien (couches 46 à 33), Toulouse, CNRS et EHESS (Archives d'écologie préhistorique), p. 357-378.

CASTEL R., dir. (2004) - Le lac du Bourget. 50 ans de recherches archéologiques, 5000 ans d'histoire, Montmélian, La Fontaine de Siloé et Aix-les-Bains, Centre d'archéologie lacustre d'Aix en Savoie, p. 85-101.

Cauliez J. (2011) - Restitution des aires culturelles au Néolithique final dans le Sud-Est de la France : dynamiques de formation et d'évolution des styles céramiques, Gallia Préhistoire, 53, p. 85-202.

Cauliez J., Blaise É., Bressy C., Convertini F., Gilabert C., Hamon C., Lazard N., Negroni S., Ollivier V., Pelissier M., Pétrequin P., Piatscheck C., ProvenZano N., Renault S. (2011) - Le site du Limon-Raspail à Bédoin dans le Vaucluse et le Néolithique final de moyenne vallée du Rhône, Bulletin de la Société préhistorique française, 108, 2, p. 263-330.

Chastel J., Voruz J.-L. 1988 - Le site de Chamboud (Isère) et la transition NMB-CSR, in P. Pétrequin (dir.), Du Néolithique moyen II au Néolithique final au nord-ouest des Alpes, actes du $12^{\mathrm{e}}$ Colloque interrégional sur le Néolithique de l'Est de la France (Lons-le-Saunier, 11-13 octobre 1985), Lons-le-Saunier, musée d'archéologie de Lonsle-Saunier et Cercle Girardot (Section d'archéologie de la Société d'émulation du Jura), p. 89-113.

Chantre E. (1875-1876) - Études paléoethnologiques dans le bassin du Rhône. Âge du Bronze. Recherches sur l'origine de la métallurgie en France, 2. Gisements de l'âge du Bronze, Paris, Baudry, 170 p.

Cocchi-Genick D. (2008) - La tipologia in funzione della ricostruzione storica: le forme vascolari dell'etaİ del rame dell'Italia centrale, Florence, Istituto Italiano di Preistoria e Protostoria, $367 \mathrm{p}$.

Combier J. (1959) - Informations archéologiques. Circonscription de Grenoble. Savoie, Gallia Préhistoire, 2, p. 193-195.

Convertini F. (1998) - Identification de marqueurs culturels dans la céramique du Néolithique du Sud-Est de la France. Apports pour une meilleure compréhension du phénomène campaniforme, in A. D'Anna et D. Binder (dir.), Production et identité culturelle. Actualité de la recherche, actes des $\mathrm{II}^{\mathrm{es}}$ Rencontres méridionales de Préhistoire récente (Arles, 8-9 novembre 1996), Antibes, APDCA, p. 203-215.

Corboud P., Pugin C. (1992) - Les stations littorales de Morges Vers l'Église et des Roseaux, Annuaire de la Société suisse de Préhistoire et d'archéologie, 75, p. 7-36.

Costantini G. (1984) - Le Néolithique et le Chalcolithique des Grands Causses, I, Étude archéologique, Gallia Préhistoire, 27, 1, p. 121-210.

D’Anna A. (1995) - Le Néolithique final en Provence, in J.-L. Voruz (dir.), Chronologies néolithiques : de 6000 à 2000 avant notre ère dans le bassin Rhodanien, actes de la $\mathrm{XI}^{\mathrm{e}}$ Rencontre sur le Néolithique de la région Rhône-Alpes 
(Ambérieu-en-Bugey, 19-20 septembre 1992), Ambérieuen-Bugey, Société préhistorique rhodanienne (Documents du département d'anthropologie et d'écologie de l'université de Genève, 20), p. 265-286.

Di Pierro S. (2002) - Domestic Production Versus Pottery Exchange during the Final Neolithic: Characterization of the Auvernier-Cordé Ceramics from the Portalban and St. Blaise Settlements, Western Switzerland, thèse de doctorat, université de Fribourg (Suisse), $111 \mathrm{p}$.

Ferrer-Joly F. (2005) - Caractérisation typologique, étude statistique et répartition spatiale de la céramique du site Néolithique final de Charavines-les-Baigneurs (Isère), in A. Bocquet (dir.), Site néolithique de Charavines, les Baigneurs (Isère, France). Études scientifiques (1972-2005), 6. La céramique. Typologie et technologie, Grenoble, Centre de documentation de la Préhistoire alpine, non paginé.

Georjon C., avec la collab. de Forest V., Raux A. (1999) - Le site de La Roquette à Tresques (Gard) et le Néolithique final du bassin bas rhodanien, Gallia Préhistoire, 41, p. 253-297.

Gidon M., dir. (1970) - Carte géologique détaillée de la France à 1/50 000, (701) Rumilly, accompagnée par P. Gidon, Notice explicative Rumilly - XXXIII-31, Orléans, BRGM, $11 \mathrm{p}$.

Giligny F., Michel R. (1995) - L'évolution des céramiques de 2920 à 2440 av. J.-C. dans la région des trois lacs (Suisse occidentale), in J.-L. Voruz (dir.), Chronologies néolithiques : de 6000 à 2000 avant notre ère dans le bassin Rhodanien, actes de la XI ${ }^{\mathrm{e}}$ Rencontre sur le Néolithique de la région Rhône-Alpes (Ambérieu-en-Bugey, 19-20 septembre 1992), Ambérieu-en-Bugey, Société préhistorique rhodanienne (Documents du département d'anthropologie et d'écologie de l'université de Genève, 20), p. 347-361.

Giligny F., Maréchal D., Pétrequin P., Pétrequin A.-M., Saintot S. (1995) - La séquence Néolithique final des lacs de Clairvaux et de Chalain (Jura). Essai sur l'évolution culturelle, in J.-L. Voruz (dir.), Chronologies néolithiques : de 6000 à 2000 avant notre ère dans le bassin Rhodanien, actes de la $\mathrm{XI}^{\mathrm{e}}$ Rencontre sur le Néolithique de la région Rhône-Alpes (Ambérieu-en-Bugey, 19-20 septembre 1992), Ambérieu-en-Bugey, Société préhistorique rhodanienne (Documents du département d'anthropologie et d'écologie de l'université de Genève, 20), p. 313-346.

GiLles R. (1975) - L'habitat du Néolithique final des Bruyères (basse vallée de l'Ardèche), Études préhistoriques, 12, p. 1-13.

Gomez J., LAPORTE L. (1990) - Les niveaux funéraires artenaciens de la grotte du Quéroy à Chazelles (Charente), Gallia Préhistoire, 32, p. 179-235.

Gosselain O. (2002) - Poteries du Cameroun méridional : styles techniques et rapports à l'identité, Paris, CNRS (Monographie du CRA, 26), $254 \mathrm{p}$.

Gutherz X., JALlot L. (1995) - Le Néolithique final du Languedoc méditerranéen, in J.-L. Voruz (dir.), Chronologies néolithiques : de 6000 à 2000 avant notre ère dans le bassin Rhodanien, actes de la XI Rencontre sur le Néolithique de la région Rhône-Alpes (Ambérieu-en-Bugey, 19-20 septembre 1992), Ambérieu-en-Bugey, Société préhistorique rhodanienne (Documents du département d'anthropologie et d'écologie de l'université de Genève, 20), p. 231-263.
Hafner A., Suter P. (1999) - Ein neues Chronologieschema zum Neolithikum des schweizerischen Mittelandes: das Zeit / Raum-Modell, Archäologie im Kanton Bern, 4B, p. 7-36.

Henon P. (1991) - La fosse néolithique du Combard à Trévoux (Ain), Revue archéologique de l'Est, 42, p. 93-103.

Honegger M. (1995) - Barmaz I, Collombey-Muraz, in A. Gallay (dir.), Dans les Alpes, à l'aube du métal. Archéologie et bande dessinée, catalogue de l'exposition «Le Soleil des morts. Archéologie et bande dessinée » (Sion, septembre 1995-janvier 1996), Sion, Musées cantonaux du Valais, p. 85-90.

Honegger M. (2001) - L'industrie lithique taillée du Néolithique moyen et final de Suisse, Paris, CNRS (Monographie du CRA, 24), $354 \mathrm{p}$.

Livingstone-Smith A., Bosquet D., Martineau R. dir. (2005) - Pottery Manufacturing Processes. Reconstitution and Interpretation, actes du $14^{\mathrm{e}}$ Congrès de $1^{\prime}$ UISPP (Liège, 2-8 septembre 2001), Oxford, Hadrian Books (British Archaeological Reports, International series 1349), 228 p.

Marguet A. (2002) - Savoie. Lac du Bourget. Élaboration de la carte archéologique des gisements du lac du Bourget, Bilan scientifique du département des Recherches archéologiques subaquatiques et sous-marines, 26, 2000, Paris, ministère de la Culture et de la Communication, p. 117-137.

Marguet A. (2002) - Haute-Savoie. Lac d'Annecy. Élaboration de la carte archéologique des gisements du lac d'Annecy, Bilan scientifique du département des Recherches archéologiques subaquatiques et sous-marines, 26, 2001, Paris, ministère de la Culture et de la Communication, p. 128.

Marguet A. (2003) - Savoie. Lac du Bourget. Mise à jour de la carte archéologique des gisements du lac du Bourget : analyses complémentaires, Bilan scientifique du département des Recherches archéologiques subaquatiques et sousmarines, 26, 2002, Paris, ministère de la Culture et de la Communication, p. 116-118.

Marguet A. (2004) - Savoie. Lac du Bourget. Elaboration de la carte archéologique des gisements du lac du Bourget, Bilan scientifique du département des Recherches archéologiques subaquatiques et sous-marines, 26, 1999, Paris, ministère de la Culture et de la Communication, p. 113-125.

Marguet A. (2007) - Savoie. Conjux. Lac du Bourget : Marais de la Chatière, Les Côtes, Bilan scientifique du département des Recherches archéologiques subaquatiques et sousmarines, 26, 2005, Paris, ministère de la Culture et de la Communication, p. 149-151.

Marguet A. (2008) - Savoie. Conjux, Marais de la Chatière, Les Côtes, Bilan scientifique de la région Rhône-Alpes, 22, 2006, 1, Paris, ministère de la Culture et de la Communication, p. 220-221.

Marguet A., avec la collab. de Billaud Y., Magny M. (1995) - Le Néolithique des lacs alpins français. Bilan documentaire, in J.-L. Voruz (dir.), Chronologies néolithiques : de 6000 à 2000 avant notre ère dans le bassin Rhodanien, actes de la XI ${ }^{\mathrm{e}}$ Rencontre sur le Néolithique de la région Rhône-Alpes (Ambérieu-en-Bugey, 19-20 septembre 1992), Ambérieu-en-Bugey, Société préhistorique rhodanienne 
(Documents du département d'anthropologie et d'écologie de l'université de Genève, 20), p. 167-196.

Marguet A., Rey P.-J. (2007) - Le Néolithique dans les lacs alpins français : un catalogue réactualisé, in $\mathrm{M}$. Besse (dir.), Sociétés néolithiques, des faits archéologiques aux fonctionnements socio-économiques, actes du $27^{\mathrm{e}}$ Colloque interrégional sur le Néolithique (Neuchâtel, 1-2 octobre 2005), Lausanne, CAR (Cahiers d'archéologie romande, 108), p. 379-406.

Martineau R. (2000) - Poterie, techniques et sociétés : études analytiques et expérimentales à Chalain et à Clairvaux (Jura), entre 3200 et 2900 av. J.-C, thèse de doctorat, université de Franche-Comté, Besançon, 268 p.

Martineau R. (2004) - La fabrication des poteries Ferrières de l'Ardèche et du Jura. Étude technologique comparative, in Pirineus $i$ veïns al 3er milllenni AC. De la fi del neolític a l'edat del bronze entre l'Ebre i la Garona, actes $\mathrm{du} \mathrm{XII}{ }^{\mathrm{e}}$ Colloque international d'archéologie (Puigcerdà, 10-12 novembre 2000), Puigcerdà, Institut d'Estudis Ceretans, p. $447-474$.

Martineau R. (2005) - Identification of the "Beater an Anvil" Technique in Neolithic Contexts: Experimental Approach, in A. Livingstone-Smith, D. Bosquet et R. Martineau (dir.), Pottery Manufacturing Processes. Reconstitution and Interpretation, actes du $14^{\mathrm{e}}$ Congrès de l'UISPP (Liège, 2-8 septembre 2001), Oxford, Hadrian Books (British Archaeological Reports, International series 1349), p. 147-156.

Martineau R. (2006) - Identification expérimentale des techniques de façonnage des poteries archéologiques, in Artisanats, sociétés et civilisations. Hommage à Jean-Paul Thévenot, Dijon, RAE (Supplément à la Revue archéologique de l'Est, 24), p. 251-258.

Martineau R. (2010) - Brunissage, polissage et degrés de séchage; un référentiel expérimental, in $\mathrm{F}$. Giligny et S. Méry (dir.), Approche de la chaîne opératoire de la céramique. Le façonnage (Les Nouvelles de l'archéologie, 119), p. 13-19.

Martineau R., Maigrot Y. (2010) - Les outils en os utilisés pour le façonnage des poteries néolithiques de la station 4 de Chalain (Jura, France), in P. Bodu et C. Constantin (dir.), Approches fonctionnelles en Préhistoire, actes $\mathrm{du} \mathrm{XXV}^{\mathrm{e}}$ Congrès préhistorique de France (Nanterre, 24-26 novembre 2000), Paris, Société préhistorique française, p. 83-95.

MontJARdin R. (1992) - Le Chalcolithique dans l'Ardèche, in P. Ambert (dir.), Le Chalcolithique en Languedoc et ses relations extrarégionales, actes du colloque international en hommage au $\mathrm{D}^{\mathrm{r}}$ Jean Arnal (Saint-Mathieu-de-Treviers, 20-22 septembre 1990), Soubès, fédération archéologique de l'Hérault (Archéologie en Languedoc, 1990-1991), p. $227-244$

Nisbet R., Biagi P. (1987) - Balm'Chanto: un ripario sottoroccia dell'età del Rame nelle Alpi cozie, Como, New Press Edizioni (Archeologia dell'Italia Settentrionale, 4), 154 p.

Mouyon P., Bintz P., Caillat B., Roudil J.-L. (2001) - Le Puits du Fakir, Balazuc, Ardèche archéologie, 18, p. 27-39.

Perrin T. (2014) - Méthodes pour l'appréhension raisonnée d'une série de dates radiocarbones : de l'histogramme cumu- latif à la modélisation bayésienne, in I. Sénépart, F. Leandri, J. Cauliez, T. Perrin et É. Thirault (dir.), Chronologie de la Préhistoire récente dans le Sud de la France, actes des $10^{\text {es }}$ Rencontres méridionales de Préhistoire récente (Porticcio, 18-20 septembre 2012), Toulouse, Archives d'écologie préhistorique, p. 11-22.

Pétrequin A.-M., Pétrequin P. (1986) - 17, La céramique, in P. Pétrequin (dir.), Les sites littoraux néolithiques de Clairvaux-Les-Lacs (Jura), I. Problématique générale : l'exemple de la station III, Paris, Maison des sciences de l'homme (Archéologie et culturelle matérielle), p. 171-183.

Pétrequin P., Pétrequin A.-M., Bailly M. (2006) - Vues du Jura français : les premières tractions animales au Néolithique en Europe occidentale, in P. Pétrequin, R.-M. Arbogast, A.-M. Pétrequin, S. Van Willigen et M. Bailly (dir.), Premiers chariots, premières araires: la diffusion de la traction animale en Europe pendant les $I V^{e}$ et $I I I^{e}$ millénaires avant notre ère, Paris, CNRS (Monographies du CRA, 29), p. 361-398.

Pétrequin P., Rossy M. (1997) - Dégraissant céramique, techniques exogènes et évolutions culturelles, in P. Pétrequin (dir.), Les sites littoraux néolithiques de Clairvaux-les-Lacs (Jura), III. Chalain station 3 : 3200-2900 av. J.-C., Paris, Maison des sciences de l'homme (Archéologie et culturelle matérielle), vol. 2, p. 363-369.

Pétrequin P., Chastel J., Giligny F., Pétrequin A.-M., SAINTOT S. (1988) - Réinterprétation de la civilisation Saône-Rhône. Une approche des tendances culturelles du Néolithique final, Gallia Préhistoire, 30, p. 1-89.

Poggiani-Keller R. (1999-2000) - Lovere (Bergamo): una sequenza stratigrafica esemplare dal Neolitico Antico al Bronzo Finale in area prealpina, Rivista di Scienze Preistoriche, 50, p. 297-374.

Poggiani-Keller R., Baioni M., Lo Vetro D., Martini F. (2002) - Monte Covolo tra tardo Neolitico ed età del Rame : Strutture e materiali degli scavi 1998-1999, in A. Ferrari et P. Visentini (dir.), Il declino del mondo neolitico: ricerche in Italia centro-settentrionale fra aspetti peninsulari, occidentali e nord-alpini, actes du colloque (Pordenone, 5-7 avril 2001), Pordenone, Museo delle Scienze (Quaderni del Museo Archeologico del Friuli Occidentale, 4), p. 311-324.

Pugin C., Corboud P. (2006) - Un habitat littoral du Néolithique final en bordure de la rade de Genève, Annuaire d'archéologie suisse, 89, p. 25-50.

Rabut L. (1864) - Habitations lacustres de la Savoie. Premier mémoire, Mémoire et documents publiés par la Société savoisienne d'histoire et d'archéologie, 8, p. 79-145.

RABut L. (1872) - Histoire des habitations lacustres de la Savoie. Le lac du Bourget, Sabaudia. Revue historique, artistique, scientifique, industrielle et littéraire du pays des Allobroges et de l'ancien duché de Savoie, Chambéry, D'Albane, p. 65-72, 97-103, 161-164, 209-213 et 278-284 IV pl.

Ramseyer D. (1987) - Delley - Portalban II. Contribution à l'étude du Néolithique en Suisse occidentale, Fribourg, Éditions universitaires (Archéologie fribourgeoise, 3), $121 \mathrm{p}$.

RAMSEYER D. (1988) - La céramique néolithique d'AuvernierLa Saunerie (fouilles 1964-1965), Lausanne, Bibliothèque 
historique vaudoise (Cahiers d'archéologie romande, 45; Auvernier, 7), $100 \mathrm{p}$.

RAmseyer D., Michel R. (1990) - Muntelier / Platzbünden. Gisement Horgen, 1. Rapport de fouille - La céramique, Fribourg, Éditions universitaires (Archéologie fribourgeoise, 6), $66 \mathrm{p}$.

Rey P.-J. (1999) - L'occupation de la Savoie au Néolithique, état des connaissances, mémoire de maitrise, université de Savoie, Chambéry, 1147 p.

Rey P.-J. (2013) - Entre Saint-Uze, Chasséen et NMB dans le Bugey : évolutions techniques et culturelles de la céramique des couches 47 à 38, in J.-L. Voruz et T. Perrin (dir.), $L a$ grotte du Gardon, II. Du Néolithique moyen II au Bronze ancien (couches 46 à 33), Toulouse, Archives d'écologie préhistorique, p. 85-164.

Rey P.-J. (2015) - Aperçu du Néolithique terrestre dans l'avantpays savoyard et la cluse de Chambéry : Saint-Saturnin (Saint-Alban-Leysse), la Grande Gave (La Balme), Bellevue (Francin), la Grande Barme de Savigny (La Biolle), la grotte à Mandrin (Vérel-de-Montbel), les Sarradins (Traize), in P.-J. Rey et A. Dumont (dir.), L'homme et son environnement : des lacs des montagnes et des rivières; bulles d'archéologie offertes à André Marguet, Dijon, RAE (Supplément à la Revue archéologique de l'Est, 40), p. 303382.

Rodot M.-A., Martineau R. (2007) - Les matériaux céramiques, du Néolithique moyen au Néolithique final, du lac de Constance (Suisse) à la vallée de la Saône (France) : marqueurs technoculturels de l'évolution des sociétés, in M. Besse (dir.), Sociétés néolithiques, des faits archéologiques aux fonctionnements socio-économiques, actes du $27^{\mathrm{e}}$ Colloque interrégional sur le Néolithique (Neuchâtel, 1 -2 octobre 2005), Lausanne, CAR (Cahiers d'archéologie romande, 108), p. 227-248.

Rodot M.-A., Martieau R., Bonvalot J., Galletti J. (2006) - Nature et provenance des matériaux céramiques Horgen (3179-3118 av. J.-C.) de Montilier - Platzbünden, Cahiers d'archéologie fribourgeoise, 7, p. 90-113.

Schwab H. (1999) - Archéologie de la $2^{e}$ correction des eaux du Jura, 2. Les premiers paysans sur la Broye et la Thielle, Fribourg, Éditions universitaires (Archéologie fribourgeoise, 14), $318 \mathrm{p}$.

Thirault É. (2004) - Échanges néolithiques : les haches alpines, Montagnac, Monique Mergoil (Préhistoires, 10), $468 \mathrm{p}$.

Timsit D., Escallon G. (2003) - La culture matérielle du site des Vautes. La céramique, in J. Guilaine et G. Escallon (dir.), Les Vautes (Saint-Gély-du-Fesc, Hérault) et la fin $d u$ Néolithique en Languedoc oriental, Toulouse, Archives d'écologie préhistorique, EHESS, Centre d'anthropologie et INRAP (Recherches en archéologie préventive, 2), p. $77-126$.

ViTAL J. (2006) - Les fouilles 1981-1987 dans la grotte de la Chauve-Souris à Donzère (Drôme) : visées initiales, problématiques actuelles, premières caractérisations chronoculturelles, implications pour le Sud-Est de la France et le domaine circum-alpin, in P. Fouéré, C. Chevillot, P. Courtaud, O. Ferullo et C. Leroyer (dir.), Paysages et peuplement : aspects culturels et chronologiques en France méridionale, actes des $\mathrm{VI}^{\mathrm{e}}$ Rencontres méridionales de Préhistoire récente (Périgueux, 14-16 octobre 2004), Périgueux, ADRAHP (Supplément à Préhistoire du Sud-Ouest, 11), p. 257-292.

Vital J. (2011) - Articulations chrono-culturelles et connexions transalpines de la séquence céramique Néolithique final dans le Sud-Est de la France : questions et hypothèses, in Atti della XLIII Riunione Scientifica, L'età del rame in Italia; dedicata a Gianni Bailo Modesti (Bologne, 26-29 novembre 2008), Florence, Istituto Italiano di Preistoria e Protostoria, p. 145-150.

Vital J., Benamour P., dir. (2012) - Économies, sociétés et espaces en Alpe : La grotte des Balmes à Sollières-Sardières (Savoie), du Néolithique moyen 2 à l'âge du Fer, Lyon, ALPARA et Maison de l'Orient et de la Méditerranée, université Lumière-Lyon 2 (Documents d'archéologie en Rhône-Alpes et en Auvergne, 36), 388 p.

Vital J., Bintz P. et collab. (1991) - Les occupations protohistoriques et historiques des sites du cirque de Choranche (Isère), Gallia Préhistoire, 33, p. 207-267.

Vital J., Convertini F., Lemercier O. (2012) - Composantes culturelles et premières productions céramiques du Bronze ancien dans le Sud-Est de la France, Oxford, Archaeopress, (British Archaeological Reports, International series 2446), $412 \mathrm{p}$.

Voruz J.-L., Perrin T., Sordoillet D., et collab. (2004) - La séquence néolithique de la grotte du Gardon (Ain), Bulletin de la Société préhistorique française, 101, 4, p. 827-866.

Wolf C. (1993) - Le site littoral d'Yverdon, Avenue des Sports (canton de Vaud). Une étude du développement culturel et chronologique de la fin du Néolithique de Suisse occidentale et des régions voisines, Lausanne, CAR (Cahiers d'archéologie romande, 59) et Freiburg-im-Breisgau, Institut für Ur- und Frühgeschichte der Universität Freiburg im Breisgau (Freiburger Archäologische Studien, 1), 449 p.

Pierre-Jérôme REY UMR 5204, « EDYTEM (Environnements, dynamiques et territoires de la montagne) », CNRS et université de Savoie Pôle montagne, Campus scientifique, F-73376 Le Bourget-du-Lac cedex pierre-jerome.rey@univ-smb.fr

André Marguet

Département des recherches archéologiques subaquatiques et sous-marines (jusqu'en mai 2013) UMR 6249, « Chrono-environnement » CNRS et université de Franche-Comté, 7, rue du Manoir, F-74960 Cran-Gevrier marguet.andre@wanadoo.fr 